Aus dem Institut für Tierphysiologie und Tierernährung der Georg-August-Universität zu Göttingen

\title{
Untersuchungen zum Stoffwechselweg des Phosphatidylcholins beim Geflügel
}

\author{
Dissertation \\ zur Erlangung des Doktorgrades \\ des Fachbereiches Agrarwissenschaften \\ der Georg-August-Universität zu Göttingen
}

\author{
vorgelegt von \\ Petra Melisch \\ geboren in Einbeck
}

Göttingen 1999 
D7

Referent: $\quad$ Prof. Dr. S. Molnar

Korreferent: Prof. Dr. G. Flachowsky

Tag der mündlichen Prüfung: 20.05.1999 


\section{INHALTSVERZEICHNIS}

Charakterisierung der Phospholipide. 3

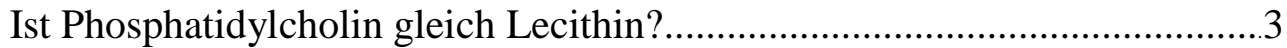
Einordnung der Phospholipide unter den Gesamtlipiden............................. 3

2.1.3 Nomenklatur/Chemischer Aufbau von Phospholipiden................................4

2.1.4 Klasseneinteilung der Phospholipide........................................................6

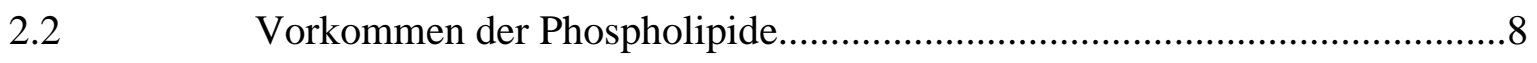

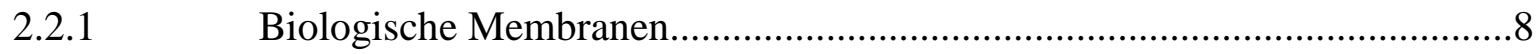

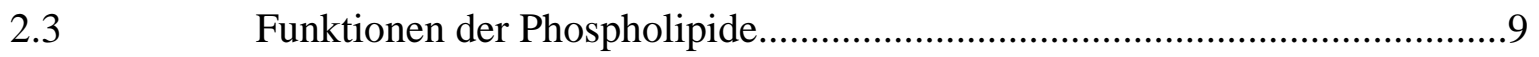

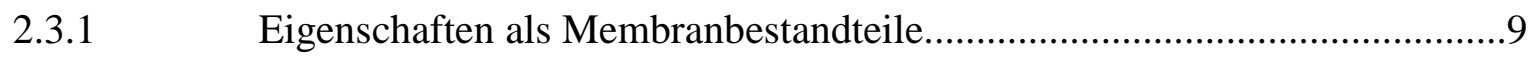

2.3.2 Lieferant von Fettsäuren und Cholin.......................................................... 11

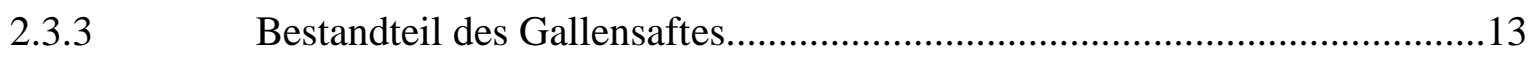

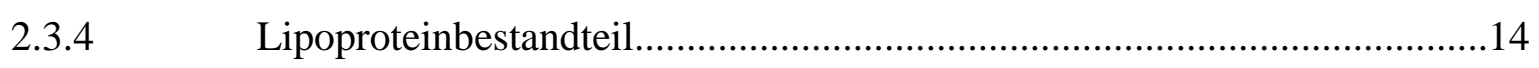

2.4 Stoffwechsel von exogen zugeführtem Phosphatidylcholin.........................15

2.4.1 Funktionen der Phospholipasen...............................................................15

2.4.2 Von der Aufnahme bis in die Mucosazellen...............................................18

2.4.3 Von den Mucosazellen bis zu den Geweben...............................................21

Biosynthese von Phosphatidylcholin.......................................................25

2.5.1 De novo Synthese von Phosphatidylcholin...............................................26

2.5.2 Schrittweise N-Methylierung von Phosphatidylethanolamin......................28

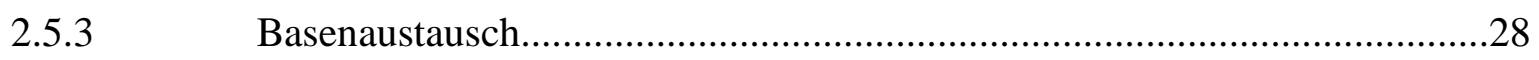

2.5.4 Acylierung von Lysophosphatidylcholin............................................28

2.5.5 Transacylierung von Lysophosphatidylcholin.......................................29

2.6 Einsatz von Phospholipiden in der Tierernährung.......................................30 
3.1.2.1 Versuchsanlage zur Messung der quantitativen ${ }^{14} \mathrm{C}$-Aktivitätsausscheidung mit der Atemluft..... .34

3.1.3.5 Herstellung der Lipidextrakte und ${ }^{14} \mathrm{C}$-Aktivitätsbestimmungen in den

Nichtlipidphasen und den Lipidextrakten.

3.1.4.1 Vorbereitungen für dünnschichtchromatograpische Trennungen................44

3.1.4.2 Angewandte Methoden zur Trennung der Lipidextrakte...............................46

3.1.4.3 Erstellung der Standardplatten......................................................... 48

3.1.4.4 Ermittlung der ${ }^{14} \mathrm{C}$-Aktivität nach dünnschichtchromatographischer Auftrennung. 
4.3.2 PC-Linolsäure- ${ }^{14} \mathrm{C}$ Tiere. .58

4.4 Verteilung der verabreichten ${ }^{14} \mathrm{C}$-Aktivität auf die einzelnen Fraktionen....59

Ergebnisse der Trennung der Lipidextrakte mittels Dünnschicht-

chromatographie.

Gemessene ${ }^{14} \mathrm{C}$-Aktivität in den getrennten Lipidfraktionen.

${ }^{14} \mathrm{C}$-Aktivitätsverteilung in den Fraktionen mit den höchsten

${ }^{14} \mathrm{C}$-Anteilen.

5.3.1 ${ }^{14}$ C-Aktivität pro Gramm der Fraktionen mit den höchsten Aktivitäten......87

5.7 Vergleichende Diskussion der Ergebnisse der PC-Cholin- ${ }^{14} \mathrm{C}$ Tiere und PC-Linolsäure- ${ }^{14} \mathrm{C}$ Tiere. 
5.7.1 ${ }^{14} \mathrm{C}$-Gesamtaktivitätsverteilung der wichtigsten Fraktionen unter Einbezug der ${ }^{14} \mathrm{C}$-Aktivitätsgehalte pro Gramm Fraktion und der ${ }^{14} \mathrm{C}$-Aktivitätsverteilung in den Lipidextrakten. 96

5.7.2 $\quad{ }^{14}$ C-Aktivitätsverteilung auf die Lipid- und Phospholipidfraktionen nach dünnschichtchromatographischer Trennung der Lipidextrakte. .98

6 


\section{ABKÜRZUNGSVERZEICHNIS}

\begin{tabular}{|c|c|}
\hline$\%$ & Prozent \\
\hline${ }^{\circ} \mathrm{C}$ & Grad Celsius \\
\hline$\mu l$ & Microliter \\
\hline$\mu \mathrm{mol}$ & Micromol \\
\hline${ }^{14} \mathrm{C}$ & radioaktiv markierter Kohlenstoff \\
\hline ADP & Adenosindiphosphat \\
\hline ATP & Adenosintriphosphat \\
\hline$\alpha$ & alpha \\
\hline aqua dest. & destilliertes Wasser \\
\hline ATPase & Adenosintriphosphatase \\
\hline BHT & 2,6-Di-tert-butyl-4-methyl-phenol \\
\hline $\mathrm{Bq}$ & Bequerel \\
\hline $\mathrm{Ca}$ & Calcium \\
\hline CDP & Cytosindiphosphat \\
\hline Chol & Cholesterinester \\
\hline $\mathrm{CL}$ & Cardiolipin \\
\hline CMP & Cytosinmonophosphat \\
\hline $\mathrm{CO}_{2}$ & Kohlendioxid \\
\hline $\mathrm{CoA}$ & CoenzymA \\
\hline СТP & Cytosintriphosphat \\
\hline d & Tag \\
\hline $\mathrm{DC}$ & Dünnschichtchromatographie \\
\hline DPG & Diphosphatidylglycerin \\
\hline dpm & desintegrations per minute \\
\hline EW & Einwaage \\
\hline $\mathrm{fFS}$ & freie Fettsäuren \\
\hline $\mathrm{h}$ & Stunde \\
\hline HDL & Lipoproteine hoher Dichte \\
\hline $\mathrm{H}_{2} \mathrm{SO}_{4}$ & Schwefelsäure \\
\hline
\end{tabular}




\begin{tabular}{|c|c|}
\hline IDL & Lipoproteine intermediärer Dichte \\
\hline $\mathrm{K}$ & Kalium \\
\hline $\mathrm{kBq}$ & Kilobequerel \\
\hline Konz. & Konzentrat \\
\hline LCAT & Lecithin-Cholesterin-Acyltransferase \\
\hline LDL & Lipoproteine niedriger Dichte \\
\hline LPC & Lysophosphatidylcholin \\
\hline LPE & Lysophosphatidylethanolamin \\
\hline LPS & Lysophosphatidylserin \\
\hline Lyso-PC & Lysophosphatidylcholin \\
\hline Lyso-PE & Lysophosphatidylethanolamin \\
\hline ME & Metabolizable energy \\
\hline $\mathrm{Mg}$ & Magnesium \\
\hline $\min$ & Minute \\
\hline MJ & Megajoule \\
\hline $\mathrm{n}$ & Normalität \\
\hline $\mathrm{N}$ & Stickstoff \\
\hline $\mathrm{Na}$ & Natrium \\
\hline $\mathrm{NaCL}$ & Natriumchlorid \\
\hline $\mathrm{NaOH}$ & Natronlauge \\
\hline NfE & N-freie-Extraktstoffe \\
\hline org. & organisch \\
\hline PA & Phosphatidsäure \\
\hline PC & Phosphatidylcholin \\
\hline PC-Cholin- $-{ }^{14} \mathrm{C}$ & Phosphatidylcholin-L- $\alpha$-dipalmitoyl, [cholin-methyl- ${ }^{14} \mathrm{C}$ ] \\
\hline PC-Linolsäure- ${ }^{14} \mathrm{C}$ & Phosphatidylcholin-L- $\alpha$-1-palmitoyl-2-linoleoyl, [linoleoyl-1- $\left.{ }^{14} \mathrm{C}\right]$ \\
\hline $\mathrm{PE}$ & Phosphatidylethanolamin \\
\hline PG & Phosphatidylglycerin \\
\hline PGL & Phytoglykolipid \\
\hline PI & Phosphatidylinosit \\
\hline PL & Phospholipide \\
\hline PM & Polymere \\
\hline
\end{tabular}




$\begin{array}{ll}\text { PS } & \text { Phosphatidylserin } \\ \mathrm{R}_{1-3} & \text { Rest 1-3 } \\ \text { raff. } & \text { raffiniert } \\ \mathrm{S} & \text { Schwefel } \\ \mathrm{SM} & \text { Sphingomyelin } \\ \mathrm{T} & \text { Trockensubstanz } \\ \text { TG } & \text { Triacylglyceride } \\ \text { VLDL } & \text { Lipoproteine sehr niedriger Dichte } \\ \text { XL } & \text { Rohfett } \\ \text { XP } & \text { Rohprotein } \\ \text { XS } & \text { Rohstärke } \\ \text { XZ } & \text { Rohzucker }\end{array}$




\section{ABBILDUNGSVERZEICHNIS}

Abbildung 1: Allgemeine Formel für Glycerinphospholipide

Abbildung 2: Angriffspunkte der Phospholipasen am Molekül des Phosphatidylcholins..16

Abbildung 3: Stoffwechselwege von oral appliziertem Phosphatidylcholin bei Ratten.....20

Abbildung 4: CDP-Cholin Pathway.....

Abbildung 5: Schematische Darstellung der Versuchsanlage. 35

Abbildung 6: Analysenschritte der Körperfraktionenen und der Exkremente .39

Abbildung 7: Analysenschritte der Lipidextrakte. .40

Abbildung 8: Einteilung der Dünnschichtchromatographie-Platten .46

Abbildung 9: Standardplatte zur Bestimmung von Phospholipiden (1), Polymeren (2), freie Fettsäuren (3), Triacylglyceriden (4) und Cholesterinestern (5). .48

Abbildung 10: Standardplatte zur Bestimmung von Lysophosphatidylcholin (1), Lysophosphatidylethanolamin (2), Phosphatidylcholin (3), Phosphatidylethanolamin (4), Phosphatidylinosit (5), Phosphatidylserin (6), Cardiolipin (7) und Triacylglyceriden (8).

Abbildung 11: Verlauf der ${ }^{14} \mathrm{C}$-Aktivitätsausscheidung in der Atemluft der Versuchstiere eins und zwei (PC-Cholin- ${ }^{14} \mathrm{C}$ ) in den ersten 24 Stunden nach der Markierung 
Abbildung 12: Verlauf der ${ }^{14} \mathrm{C}$-Aktivitätsausscheidung in der Atemluft der Versuchstiere drei und vier (PC-Linolsäure- $\left.{ }^{14} \mathrm{C}\right)$ in den ersten 24 Stunden nach der Markierung.

Abbildung 13:Vergleich der jeweils zehn Fraktionen mit den höchsten Aktivitätsanteilen (\%) der vier Versuchstiere. 


\section{TABELLENVERZEICHNIS}

Tabelle 1: Einteilungsschema der Gesamtlipide 4

Tabelle 2: Zusammensetzung verschiedener Glycerinphospholipide .6

Tabelle 3: Klasseneinteilung der wichtigsten Phospholipide. .7

Tabelle 4: Meist vorkommende Fettsäuren des Phosphatidylcholins in verschiedenen Geweben von Ratten (in \% der gesamten Fettsäuren). 11

Tabelle 5: Dichte, Größe, chemische Zusammensetzung und Apoproteinanteile der verschiedenen Lipoproteine. .14

Tabelle 6: Absoluter Phospholipidgehalt einiger Rattengewebe, sowie der relative Anteil einiger Phospholipidfraktionen.

Tabelle 7: Gewichte und Alter der Versuchstiere am Tag der Applikation. .31

Tabelle 8: Nährstoff- und Energiegehalte des eingesetzten Alleinfuttermittels für Masthühnerküken

Tabelle 9: Radiochemikalien, Versuchstiere und Tag der Markierung..... .33

Tabelle 10: Vergleich von Laufmittel, Laufzeit und getrennten Lipidfraktionen zweier dünnschichtchromatographischer Trennmethoden.

Tabelle 11: Absolute Gewichte (g) einzelner Fraktionen und ihr relativer Anteil (\%) an der Summe aller Fraktionen der PC-Cholin- ${ }^{14} \mathrm{C}$ Tiere .52 
Tabelle 12: Absolute Gewichte (g) einzelner Fraktionen und ihr relativer Anteil (\%) an der Summe aller Fraktionen der PC-Linolsäure- ${ }^{14} \mathrm{C}$ Tiere....53

Tabelle 13: Relative Verteilung der ${ }^{14} \mathrm{C}$-Aktivität auf den jeweiligen Lipidextrakt und Nichtlipidanteil von den Fraktionen mit den höchsten ${ }^{14} \mathrm{C}$-Anteilen der PC-Cholin- $-{ }^{14} \mathrm{C}$ Tiere. .57

Tabelle 14: Relative Verteilung der ${ }^{14} \mathrm{C}$-Aktivität auf den jeweiligen Lipidextrakt und Nichtlipidanteil von den Fraktionen mit den höchsten ${ }^{14} \mathrm{C}$-Anteilen der PC-Linolsäure- ${ }^{14} \mathrm{C}$ Tiere. 58

Tabelle 15: Absolute (kBq) und relative (\%) Verteilung der ${ }^{14} \mathrm{C}$-Aktivität von den Fraktionen mit den höchsten ${ }^{14} \mathrm{C}$-Anteilen der PC-Cholin- ${ }^{14} \mathrm{C}$ Tiere. .60

Tabelle 16: Absolute (kBq) und relative (\%) Verteilung der ${ }^{14} \mathrm{C}$-Aktivität von 21 weiteren Fraktionen der PC-Cholin- ${ }^{14} \mathrm{C}$ Tiere .61

Tabelle 17: Absolute (kBq) und relative (\%) Verteilung der ${ }^{14} \mathrm{C}$-Aktivität von den Fraktionen mit den höchsten ${ }^{14} \mathrm{C}$-Anteilen der PC-Linolsäure- ${ }^{14} \mathrm{C}$ Tiere.....62

Tabelle 18: Absolute (kBq) und relative (\%) Verteilung der ${ }^{14} \mathrm{C}$-Aktivität von 21 weiteren Fraktionen der PC-Linolsäure- ${ }^{14} \mathrm{C}$ Tiere .63

Tabelle 19: $\quad{ }^{14}$ C-Aktivität pro Gramm Fraktion $(\mathrm{Bq} / \mathrm{g})$ der Fraktionen mit den höchsten ${ }^{14} \mathrm{C}$-Gehalten der PC-Cholin- ${ }^{14} \mathrm{C}$ Tiere.

Tabelle 20: $\quad{ }^{14} \mathrm{C}$-Aktivität pro Gramm Fraktion $(\mathrm{Bq} / \mathrm{g})$ von 19 weiteren Fraktionen der PC-Cholin- ${ }^{14} \mathrm{C}$ Tiere .65

Tabelle 21: $\quad{ }^{14} \mathrm{C}$-Aktivität pro Gramm $(\mathrm{Bq} / \mathrm{g})$ Fraktion aller Fraktionen der PC-Linolsäure- ${ }^{14} \mathrm{C}$ Tiere. .67 
Tabelle 22: Absolute (kBq) und relative (\%) Verteilung der ${ }^{14} \mathrm{C}$-Aktivität von den Lipidextrakten aller Fraktionen der PC-Cholin- ${ }^{14} \mathrm{C}$ Tiere

Tabelle 23: Absolute (kBq) und relative (\%) Verteilung der ${ }^{14} \mathrm{C}$-Aktivität von den Lipidextrakten aller Fraktionen der PC-Linolsäure- ${ }^{14} \mathrm{C}$ Tiere.

Tabelle 24: Relative Verteilung der ${ }^{14} \mathrm{C}$-Aktivität der Lipidextrakte von fünf Körperfraktionen und der Exkremente der PC-Linolsäure- ${ }^{14} \mathrm{C}$ Tiere auf die Lipidfraktionen.

Tabelle 25: Relative Verteilung der ${ }^{14} \mathrm{C}$-Aktivität von Lipidextrakten der Körperfraktionen verschiedener Organe und der Blutbestandteile der PC-Linolsäure- ${ }^{14} \mathrm{C}$ Tiere auf die Lipidfraktionen. .73

Tabelle 26: Relative Verteilung der ${ }^{14} \mathrm{C}$-Aktivität von Lipidextrakten der Körperfraktionen des Gastrointestinaltraktes und der Luftröhre der PC-Linolsäure- ${ }^{14} \mathrm{C}$ Tiere auf die Lipidfraktionen. .74

Tabelle 27: Relative Verteilung der ${ }^{14} \mathrm{C}$-Aktivität der Lipidextrakte von fünf Körperfraktionen und der Exkremente der PC-Cholin- ${ }^{14} \mathrm{C}$ Tiere auf die Lipidfraktionen. .76

Tabelle 28: Relative Verteilung der ${ }^{14} \mathrm{C}$-Aktivität von Lipidextrakten verschiedener Organe und der Blutbestandteile der PC-Cholin- $-{ }^{14} \mathrm{C}$ Tiere auf die Lipidfraktionen .77

Tabelle 29: Relative Verteilung der ${ }^{14} \mathrm{C}$-Aktivität von Lipidextrakten der Körperfraktionen des Gastrointestinaltraktes und der Luftröhre der PC-Cholin- ${ }^{14} \mathrm{C}$ Tiere auf die Lipidfraktionen. .78 
Tabelle 30: $\quad$ Relative Verteilung der ${ }^{14} \mathrm{C}$-Aktivität der Lipidextrakte von fünf Körperfraktionen und der Exkremente der PC-Linolsäure- ${ }^{14} \mathrm{C}$ Tiere auf die Lipidfraktionen

Tabelle 31: Relative Verteilung der ${ }^{14} \mathrm{C}$-Aktivität von Lipidextrakten verschiedener Organe und der Blutbestandteile der PC-Linolsäure- ${ }^{14} \mathrm{C}$ Tiere auf die Lipidfraktionen .80

Tabelle 32: $\quad$ Relative Verteilung der ${ }^{14} \mathrm{C}$-Aktivität von Lipidextrakten der Körperfraktionen des Gastrointestinaltraktes und der Luftröhre der PC-Linolsäure- ${ }^{14} \mathrm{C}$ Tiere auf die Lipidfraktionen .81

Tabelle 33: ${ }^{14} \mathrm{C}$-Aktivität pro Gramm (Bq/g) Fraktion der Fraktionen mit den höchsten ${ }^{14} \mathrm{C}$-Gehalten der PC-Cholin- ${ }^{14} \mathrm{C}$ Tiere. .88 
Das Phosphatidylcholin kommt als Hauptbestandteil der Phospholipide ubiquitär in pflanzlichen und tierischen Zellen vor und zählt somit zu einer der am weitesten verbreiteten komplexen Gruppen in der Natur. Im Organismus üben die Phospholipide wichtige Funktionen aus. Im Zellinnern steuern sie zahlreiche physiologisch-biochemische Prozesse und in den Zellmembranen garantieren sie den allgemeinen Stoffaustausch für viele Stoffwechselwege.

Für die tierische Erzeugung sind die physiologischen Effekte der Phospholipide sowohl bei der Verdauung als auch im intermediären Stoffwechsel von besonderer Bedeutung. Sie erhöhen die Verdaulichkeit des Futterfettes und somit die Nährstoffverwertung für die Tiere, was sich positiv auf die Gesundheit, Lebendmassezunahme und Leistung auswirkt (POLIN, 1980; CLIFFORD, 1994; GÜNTHER 1994a,b). Aus diesem Grund haben die Phospholipide als Bestandteile des Lecithins seit 30 - 35 Jahren einen festen Platz in der Tierernährung. Bei der Fütterung wird Lecithin in erster Linie als Emulgator eingesetzt (VOGT und HARNISCH, 1977). Als weitere Komponente von Geflügelfutter findet es Verwendung als Pigment- bzw. Energieträger (LIPSTEIN et al., 1967; 1970; 1977) und als Lieferant essentieller Nährstoffe, wie der Linolsäure (NIEUHUYZWEN, 1985).

In der Literatur wird gezeigt, daß sowohl die intrazellulären Funktionen der Phospholipide als auch ihre Wirkungen als Komponenten im Futtermittel weitgehend untersucht sind. Im Gegensatz dazu sind die physiologischen Hintergründe, d.h. die Stoffwechselwege von exogen zugeführten Phospholipiden beim Geflügel erst wenig erforscht. Hierzu sollten in der vorliegenden Dissertation Grundlagen geschaffen werden, auf die in weiterführenden Untersuchungen aufgebaut werden kann.

Ziel der Arbeit war es, den Verbleib der radioaktiv markierten Gruppen Cholin (PCCholin- ${ }^{14} \mathrm{C}$ ) und Linolsäure (PC-Linolsäure- ${ }^{14} \mathrm{C}$ ) des Phosphatidylcholins 24 Stunden nach oraler Applikation in einzelnen Körperfraktionen, den Exkrementen und der Atemluft von Broilern zu ermitteln und daraus die möglichen Stoffwechselwege abzuleiten.

Untersucht wurde, wie sich bei jeweils zwei 22 bis 25 Tage alten Broilern, nach Verabreichung von Phosphatidylcholin-L- $\alpha$-dipalmitoyl, [cholin-methyl- ${ }^{14} \mathrm{C}$ ] bzw.

Phosphatidylcholin-L- $\alpha-1$-palmitoyl-2-linoleoyl, [linoleoyl-1- $\left.{ }^{14} \mathrm{C}\right]$, 
die ${ }^{14} \mathrm{C}$-Aktivität innerhalb von 24 Stunden im Organismus verteilte.

Vom Zeitpunkt der Markierung bis zur Tötung der Tiere erfolgte die Erfassung der ${ }^{14} \mathrm{C}$ Aktivität in der Atemluft und den Exkrementen. Nach 24 Stunden wurde das jeweilige Tier getötet und die ${ }^{14} \mathrm{C}$-Aktivität in den Exkrementen und einzelnen Körperfraktionen gemessen.

Bei der Untersuchung des Stoffwechsels der exogen zugeführten ${ }^{14} \mathrm{C}$-markierten Phosphatidylcholine stellten sich folgende Fragen:

- Welche Fraktionen beinhalten die wiedergefundene ${ }^{14} \mathrm{C}$-Aktivität, wie ist diese verteilt?

- Wie hoch ist die ${ }^{14} \mathrm{C}$-Aktivität pro Gramm in den einzelnen Fraktionen?

- Wie hoch sind die ${ }^{14} \mathrm{C}$-Aktivitätsanteile in den Lipidextrakten und den Nichtlipidanteilen der einzelnen Fraktionen?

- In welchen Lipidfraktionen (Phospholipide, Polymere, freie Fettsäuren, Triacylglyceride und Cholesterinester) ist die ${ }^{14} \mathrm{C}$-Aktivität der Lipidextrakte verteilt?

- In welchen Phospholipidfraktionen (Lysophosphatidylcholin, -ethanolamin, Phosphatidylcholin, -ethanolamin, -inosit, -serin, Cardiolipin, Triacylglyceride/freie Fettsäuren) ist die ${ }^{14} \mathrm{C}$-Aktivität der Lipidextrakte verteilt?

Bei allen Fragen war zusätzlich zu klären, ob es Unterschiede bei der Verteilung des PCCholins- ${ }^{14} \mathrm{C}$ und der PC-Linolsäure- ${ }^{14} \mathrm{C}$ gab. 


\section{LITERATURÜBERSICHT}

Charakterisierung der Phospholipide

\subsubsection{Ist Phosphatidylcholin gleich Lecithin?}

Das Phosphatidylcholin wird in der wissenschaftlichen Sprachweise mit dem Trivialnamen Lecithin belegt (IUPAC-IUB, 1978; THIELE, 1979). Auch das im Handel vorkommende Phosphatidylcholin trägt diese Bezeichnung (FIEBIG und BONEKAMP, 1997).

In der älteren Literatur werden neben dem Phosphatidylcholin alle in Alkohol löslichen Phospholipide unter dem Begriff Lecithin zusammengefaßt, wobei das Phosphatidylcholin den Hauptanteil ausmacht (FIEBIG und BONEKAMP, 1997). Nach PARDUN (1988) werden Pflanzenlecithine als Gemische aus ca. 50 \% Phospholipiden, ca. 10 \% Kohlenhydraten und Glykolipiden, ca. 40 \% Triacylglyceriden, freie Fettsäuren, Sterinen und anderen Nebenbestandteilen der Pflanzenöle definiert, wobei das Phosphatidylcholin nur ein Teil der Phospholipide darstellt.

Der Begriff Lecithin findet somit keine einheitliche Verwendung. Man versteht darunter sowohl Phospholipidgemische, die durch Extraktion von Zellgeweben mit selektiven Lösungsmitteln erhalten werden, als auch die Klasse der Diacylphosphatidylcholine (PARDUN, 1989).

\subsubsection{Einordnung der Phospholipide unter den Gesamtlipiden}

Das Phosphatidylcholin zählt zu der Gruppe der Phospholipide, die in Glycerinphospholipide und Sphingosinphospholipide unterteilt sind. Die Phospholipide sind ein Teil der Gesamtlipide, deren Stellung in folgender Übersicht (Tabelle 1) gezeigt wird. 
Tabelle 1: $\quad$ Einteilungsschema der Gesamtlipide (modifiziert nach THIELE, 1979)

\begin{tabular}{|c|c|c|c|c|}
\hline \multicolumn{2}{|l|}{ Lipid-Klasse } & Polarität & Löslichkeit & Lipidform \\
\hline \multicolumn{2}{|l|}{ Freie Fettsäuren } & Neutral- & Aceton- & einfache \\
\hline \multicolumn{2}{|l|}{ Wachse } & Lipide & löslich & Lipide \\
\hline \multicolumn{5}{|l|}{ Glyceride } \\
\hline \multirow[t]{2}{*}{ Phospholipide } & Glycerinphospholipide & \multirow{5}{*}{$\begin{array}{l}\text { Polare } \\
\text { Lipide }\end{array}$} & \multirow{5}{*}{$\begin{array}{l}\text { Aceton- } \\
\text { unlöslich }\end{array}$} & \multirow{5}{*}{$\begin{array}{l}\text { komplexe } \\
\text { Lipide }\end{array}$} \\
\hline & Sphingosinphospholipide & & & \\
\hline \multirow[t]{2}{*}{ Glykolipide } & Sphingosinglykolipide & & & \\
\hline & Glyceringlykolipide & & & \\
\hline \multicolumn{2}{|l|}{ Aminolipide } & & & \\
\hline \multirow[t]{2}{*}{ Isoprenoide } & Terpene & Neutral- & Aceton- & \\
\hline & Steroide & Lipide* & löslich & \\
\hline
\end{tabular}

*Terpen- und Steroid-Glykoside sowie konjugierte Gallensäuren sind polar

Die Phospholipide zählen zu den polaren, acetonunlöslichen, komplexen Lipiden. Die komplexen Lipide werden auch als Lipoide bezeichnet (KARLSON et al., 1994).

\subsection{3}

Nomenklatur/Chemischer Aufbau von Phospholipiden

Nach der IUPAC-IUB- Nomenklatur (IUPAC-IUB, 1978) sind Phospholipide diejenigen Lipide, die Phosphorsäure als Mono- bzw. Diester enthalten. Die alkoholische Komponente ist ein Polyalkohol, wie Glycerin oder Sphingosin, der an den noch freien Hydroxylgruppen mit Fettsäuren verestert ist (FIEBIG und BONEKAMP, 1997). Eine detailliertere Bezeichnung des Phospholipidmoleküls erfolgt über die stereospezifische Numerierung, die durch das Präfix sn gekennzeichnet ist. Diese Nomenklatur wurde erstmalig für die Kennzeichnung der Stereochemie von STJERNHOLM und WOOD (1960) verwendet und später von der IUPAC-IUB Kommission (1968) anerkannt. So trägt das Phosphatidylcholin z.B. die Bezeichnung 1,2-Diacyl-sn-Glycerin-3-Phosphatidylcholin.

Die Glycerinphospholipide (Abbildung 1), zu denen das Phosphatidylcholin zählt, bestehen aus dem Alkohol Glycerin, an dessen erste Hydroxylgruppe vorwiegend eine gesättigte Fettsäure $\left(\mathrm{R}_{1}\right)$ verestert ist. Die zweite Hydroxylgruppe ist überwiegend mit einer ungesättigten Fettsäure $\left(\mathrm{R}_{2}\right)$ verestert. Als gesättigte Fettsäuren sind meistens Palmitinsäure oder 
Stearinsäure und als ungesättigte Fettsäuren Linolsäure, Ölsäure oder Arachidonsäure verestert. Abhängig von der Diät variieren die Fettsäuren in der Kettenlänge und dem Grad der Sättigung (BERDANIER, 1988). Die dritte Hydroxylgruppe ist mit Phosphorsäure verestert, welche wiederum mit einer alkoholischen Gruppe $\left(\mathrm{R}_{3}\right)$ verestert ist, die variieren kann (VOGT und HARNISCH, 1977).

Mögliche alkoholische Gruppen sind:

- Aminoalkohole (Cholin, Ethanolamin)

- mehrwertige Alkohole (Glycerin, Inosit)

- oder Hydroxyaminosäuren (Serin) (ANSELL und HAWTHORNE, 1964).

Der chemische Aufbau der Glycerinphospholipide wird in Abbildung 1 skizziert:

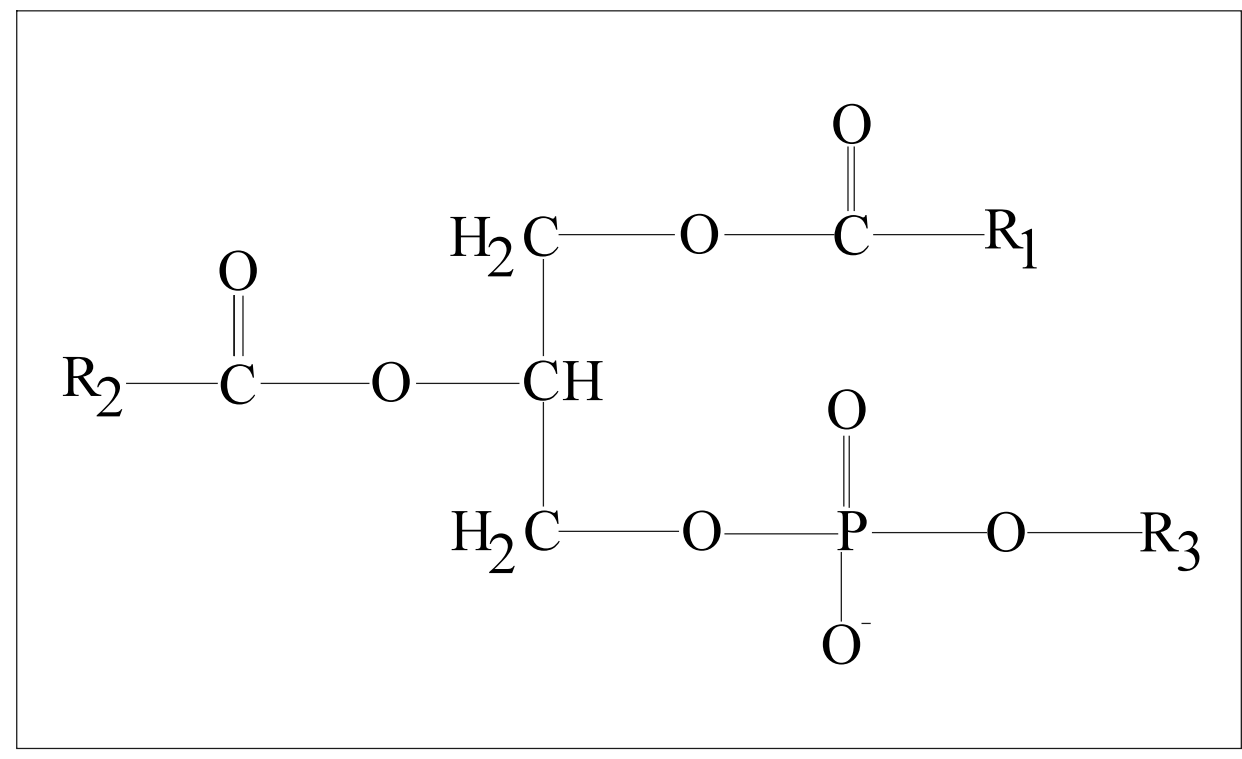

Abbildung 1: Allgemeine Formel für Glycerinphospholipide

Chemisch betrachtet sind Phospholipide amphiphile Moleküle, deren hydrophober Anteil aus den veresterten Fettsäuren besteht, während die alkoholische Gruppe den hydrophilen Anteil des entsprechenden Phospholipids bildet. Das befähigt die Phospholipide im wässrigen Medium mizelläre bzw. liposomale Strukturen zu bilden (HILLS, 1988).

Die Zusammensetzung verschiedener Glycerinphospholipide wird in Tabelle 2 aufgeführt. $\mathrm{R}_{1-3}$ beziehen sich auf die in Abbildung 1 benannten Reste. 
Tabelle 2: Zusammensetzung verschiedener Glycerinphospholipide (modifiziert nach FIEBIG und BONEKAMP, 1997)

\begin{tabular}{|c|c|c|c|c|}
\hline $\mathbf{R}_{\mathbf{1}}$ & $\mathbf{R}_{\mathbf{2}}$ & $\mathbf{R}_{\mathbf{3}}$ & Bezeichnung & Kürzel \\
\hline Acyl & Acyl & $\mathrm{H}$ & Phosphatidsäure & PA \\
\hline Acyl & Acyl & $\mathrm{CH}_{2}-\mathrm{CH}_{2}-\mathrm{N}^{+}\left(\mathrm{CH}_{3}\right)_{3}$ & Phosphatidylcholin & $\mathrm{PC}$ \\
\hline Acyl & Acyl & $\mathrm{CH}_{2}-\mathrm{CH}_{2}-\mathrm{NH}_{3}$ & Phosphatidylethanolamin & $\mathrm{PE}$ \\
\hline Acyl & Acyl & $\mathrm{CH}_{2} \mathrm{CH}\left(\mathrm{NH}_{3}\right)-\mathrm{COO}^{-}$ & Phosphatidylserin & PS \\
\hline Acyl & Acyl & $\mathrm{CH}_{2}-\mathrm{CH}_{2} \mathrm{OH}-\mathrm{CH}_{2} \mathrm{OH}$ & Phosphatidylglycerin & PG \\
\hline Acyl & Acyl & OH & Phosphatidylinosit & PI \\
\hline Acyl & $\mathrm{H}$ & siehe PA bis PI & Lysophospholipide & z.B. LPC \\
\hline
\end{tabular}

Die Abkürzungen für die Lysophospholipide variieren in unterschiedlichen Veröffentlichungen. So werden sie, am Beispiel des Lysophosphatidylcholins gezeigt, einerseits als Lyso-PC und andererseits als LPC abgekürzt. Die Lysophospholipide unterscheiden sich von den jeweiligen Phospholipiden dadurch, daß nicht beide Hydroxylgruppen $\left(\mathrm{R}_{1}\right.$ und $\mathrm{R}_{2}$ ), sondern nur eine der beiden Hydroxylgruppen $\left(\mathrm{R}_{1}\right.$ oder $\left.\mathrm{R}_{2}\right)$ mit einer Fettsäure verestert ist.

\subsubsection{Klasseneinteilung der Phospholipide}

Die Klasseneinteilung der wichtigsten Phospholipide wird in Tabelle 3 beschrieben (PARDUN, 1988). Die Esterphospholipide umfassen den größten Teil der Phospholipide. Eines der wichtigsten Glycerinphospholipide ist das Phosphatidylcholin, welches neben dem Trivialnamen Lecithin unter anderem auch als Cholinlecithin bezeichnet wird. 
Tabelle 3: $\quad$ Klasseneinteilung der wichtigsten Phospholipide (PARDUN, 1988)

\begin{tabular}{|c|c|c|}
\hline Klasse, Bezeichnung & Trivialname & Kürzel \\
\hline \multicolumn{3}{|l|}{ 1. Glycerinphospholipide } \\
\hline \multicolumn{3}{|l|}{ 1. Esterphospholipide } \\
\hline Phosphatidylcholin & Cholinlecithin, Lecithin & $\mathrm{PC}$ \\
\hline Lysophosphatidylcholin & & LPC \\
\hline Phosphatidylethanolamin & Colaminlecithin, Kephalin & $\mathrm{PE}$ \\
\hline Lysophosphatidylethanolamin & & LPE \\
\hline Phosphatidylserin & Serinkephalin & PS \\
\hline Lysophosphatidylserin & & LPS \\
\hline Phosphatidylinosit & Lipositol & PI \\
\hline Lysophosphatidylinosit & & LPI \\
\hline Phosphatidylglycerin & & $\mathrm{PG}$ \\
\hline Diphosphatidylglycerin & Cardiolipin & DPG \\
\hline Phosphatidsäure & & PA \\
\hline \multicolumn{3}{|l|}{ 2. Etherphospholipide } \\
\hline Cholinplasmalogen & Plasmalogen & \\
\hline Ethanolaminplasmalogen & & \\
\hline \multicolumn{3}{|l|}{ 11. Sphingosinphospholipide } \\
\hline Ceramidphosphorylcholin & Sphingomyelin & SM \\
\hline Phytoglykolipid & & PGL \\
\hline
\end{tabular}

Im Rahmen dieser Dissertation sind für weitere Betrachtungen die Glycerinphospholipide, besonders das Phosphatidylcholin, von Bedeutung, während die Etherphospholipide und Sphingosinphospholipide weitestgehend außer acht gelassen werden. 
Die biologischen Membranen der Eukaryonten bestehen aus Lipid- und Proteinmolekülen, die durch nicht-kovalente Bindungen zusammen gehalten werden. Die Lipid-Doppelschicht der Membranen bildet das Grundgerüst der Zellmembranen, in der die Proteinmoleküle gelöst sind. Das „Fluid-Mosaic-Modell“ von SINGER und NICOLSON (1972) zeigt diese Verteilung. Die Lipide machen $30 \%$ - $40 \%$ der biologischen Membranen aus (HAUSCHILDT, 1980). Sie setzen sich aus den Phospholipiden, Glykolipiden und Cholesterin zusammen (BERDANIER, 1988). Die Phospholipide sind aufgrund ihrer amphoteren Eigenschaften besonders an biologischen Grenzflächen zu finden (DEENEN, 1972). Sie bilden mit $50 \%$ - $90 \%$ den Hauptteil der Lipide (HAUSCHILDT, 1980). Die Phospholipidkopfgruppen und veresterten Fettsäuren können variieren (SEEWALD und EICHINGER, 1989). Mengenmäßig sind Phosphatidylcholin, -ethanolamin, -serin sowie das Sphingomyelin die wichtigsten Phospholipide in der biologischen Membran (BRETSCHER, 1973). Die Phospholipide sind in der Zellmembran asymmetrisch verteilt (BELL et al., 1981). Während die cholinhaltigen Phospholipide (Phosphatidylcholin und Sphingomyelin) vorwiegend an der Außenseite der Membran lokalisiert sind, werden Phosphatidylethanolamin, -serin und -inosit vorwiegend an der Innenseite gefunden (BERGELSON und BARSUKOV, 1977; GENNIS, 1989). In den Prokaryontenmembranen wurden als häufigste Phospholipide Phosphatidylethanolamin, Phosphatidylglycerin und Cardiolipin festgestellt (CULLIS et al., 1996).

Von ANSELL und SPANNER (1982) durchgeführte Untersuchungen an Ratten ergaben, daß die Körperfraktionen Gehirn, Nieren, Leber und Pankreas die höchsten Phospholipidgehalte enthalten. Dabei dominierte der Phosphatidylcholingehalt vor dem von Phosphatidylethanolamin, Phosphatidylserin und Lysophosphatidylcholin. WEIDNER et al. (1993) berichteten von hohen Phospholipidgehalten im Eigelb. Als Hauptträger pflanzlicher Phospholipide wurden die Ölsaaten, insbesondere die Sojabohne und Raps ermittelt (WEIDNER et al., 1993, PARDUN, 1988; GÜNTHER, 1995). 
Die Eigenschaften der Phospholipide für die Membranfluidität, Permeabilität und die Oberflächenspannung konnte an künstlichen Membransystemen nachgewiesen werden (SPECTOR und YOREK,1985; HAUSCHILDT, 1980).

Membranfluidität

Ausschlaggebend für den Grad der Membranfluidität sind die Phospholipidkopfgruppen und die veresterten Fettsäuren der jeweiligen Phospholipide (BERDANIER, 1988; ROBBLEE und CLANDININ, 1984). Diese bestimmen die sogenannte „Transition temperatur“ (Phasenübergangstemperatur). Sie definiert den Temperaturbereich in dem künstliche, nur aus einer Phospholipidklasse aufgebaute, Lipid-Doppelschichten von einem flüssig-kristallinen zu einem festen, gelartigen Zustand bei Absenkung der Temperatur übergehen (ALBERTS et al., 1986). Kurzkettige und ungesättigte Fettsäuren vermindern die Phasenübergangstemperatur und langkettige und gesättigte Fettsäuren erhöhen Sie (MERRIL und NICHOLS, 1985). Die Membranfluidität hat Bedeutung für Formveränderungen der Zelle, Fusionen von Membranen/Membranproteinen und Diffusionen von Membrankomponenten innerhalb der Membran (JUNGERMANN und MÖHLER, 1984). Besonders wichtig sind diese Eigenschaften für die Erythrozyten. Schon eine geringfügige Erhöhung des Anteils an Phospholipiden mit gesättigten Fettsäuren kann eine Hämolyse hervorrufen (LANGE et al., 1980).

Ebenso wie für den physikalischen Zustand der Membran haben die Phospholipide Funktionen für wichtige biologische Prozesse.

\section{Bestandteile von Enzymsystemen}

Die Aufrechterhaltung intakter Phospholipidsysteme führt zur Sicherstellung der Aktivitäten der am Stoffwechsel beteiligten Enzymsysteme und somit zur Funktionalität der Atmumgskette und zur Beweglichkeit der Membranen (SCHÄFER und WYWIOL, 1986). Die Beeinflussung der Enzymaktivitäten der Phospholipide wird durch Konformationsän- 
derungen von Enzymen, Änderungen der Membranfluidität sowie anderen enzymspezifischen Prozessen beschrieben (ZAKIM und VESSEY, 1980). In den Arbeiten von CERLETTI et al. (1967), REICH und WAINIO (1961), CARAFOLI und ZURINI (1982), ATTWOOD et al. (1971) und ZAKIM (1970) wurde der Einfluß von Membranphospholipiden auf die Aktivität membranständiger Enzyme belegt. Wie KIMELBERG und PAPAHADJOPOULOS (1972) zeigten, sind für die Aktivierung bzw. Inhibierung von Enzymen die alkoholischen Gruppen der Phospholipide von Bedeutung. Ihnen gelang es mit Phosphatidylserin und-glycerin inaktivierte $\mathrm{Na}^{+}-\mathrm{K}^{+}$-ATPase zu reaktivieren, wohingegen die anderen Phospholipide keine Reaktivierung ermöglichten. POON et al. (1981) zeigten die Wichtigkeit veresterter Fettsäuren der Phospholipide für die Aktivierung bzw. Inaktivierung bestimmter Enzyme. Sie hemmten durch Zusatz gesättigter Fettsäuren die $\mathrm{Na}^{+}-\mathrm{K}^{+}$-ATPase und aktivierten sie durch Zusatz von ungesättigten Fettsäuren.

Wie neuere Untersuchungen bestätigen, haben die Phospholipide auch bei membranbezogenen Vorgängen wie der Signaltransduktion wichtige Funktionen (CANTY und ZEISEL, 1994).

Membranpermeabilität

Die Membrane sind nicht nur passive Grenzen zwischen den Zellen, sondern kontrollieren als aktive Filter den Wechsel von Substanzen aus und in die Zellen (BONACKER, 1988). Die Zusammensetzung der veresterten Fettsäuren der Phospholipide kann die Permeabilität und somit die Funktionen der Membranen beeinflussen (ROBBLEE und CLANDININ, 1984). Phospholipide mit einem hohen Gehalt an ungesättigen Fettsäuren ermöglichen eine bessere Membranpermeabilität als Phospholipide mit langkettigen und gesättigten Fettsäuren. So zeigten z.B. ZAKIM und VESSEY (1980), daß Phospholipide mit einem hohen Gehalt an ungesättigten Fettsäuren eine erhöhte Permeabilität für Glucose und einwertige Kationen haben. 


\section{Lieferant von Fettsäuren und Cholin}

Fettsäuren

In vielen wissenschaftlichen Arbeiten (BOSCH und DEENEN, 1965; POSSMAYER et al., 1969; KANOH, 1969; AKESSON, 1970; GOLDE et al., 1971; VEREYKEN et al., 1972; TREWHELLA und COLLINS, 1973; BAISTED et al., 1988; SKREDE et al., 1997) wird gezeigt, daß die Fettsäuren Palmitin-, Stearin-, Linol- und Arachidonsäure einen großen Anteil an den Gesamtfettsäuren der Phosphatidylcholine ausmachen, wobei das Verhältnis der Fettsäuren zueinander in den verschiedenen Geweben variiert. Tabelle 4 stellt die Fettsäurenzusammensetzung von Phosphatidylcholin in verschiedenen Geweben von Ratten, modifiziert nach ANSELL und SPANNER (1982), dar. Angegeben sind jeweils die Fettsäuren, die am ersten und zweiten C-Atom der Phosphatidylcholine gebunden sind.

Tabelle 4: Meist vorkommende Fettsäuren des Phosphatidylcholins in verschiedenen Geweben von Ratten (in \% der gesamten Fettsäuren)

\begin{tabular}{|l|c|c|c|c|c|c|}
\hline Fettsäuren & Gehirn & Leber & Lunge & Nieren & Darm & Galle \\
\hline $16: 0 / 18: 1$ & 30 & 4 & $10-17$ & - & 7 & - \\
\hline $16: 0 / 18: 2$ & - & $16-20$ & $6-10$ & 8 & 19 & 25 \\
\hline $18: 0 / 18: 2$ & - & $9-10$ & 6 & 10 & 16 & 10 \\
\hline $18: 1 / 16: 0$ & 10 & - & 12 & 7 & - & - \\
\hline $16: 0 / 20: 4$ & 8 & $19-22$ & 15 & 22 & 14 & 15 \\
\hline $18: 0 / 20: 4$ & 10 & $21-25$ & - & 25 & 9 & - \\
\hline
\end{tabular}

Im Sojaöl enthaltene Phospholipide liefern unter anderem die essentielle Linolsäure (JAKOBSEN, 1990). Im Organismus kann aus der Linolsäure weiter Linolen- und Arachidonsäure gebildet werden (ENSER, 1984). Sie dienen als wichtige Bausteine der Membranstrukturen und als Vorstufen der Prostaglandine, Thromboxane, Leukotriene und anderer Derivate (KUNZE, 1993; CHRISTENSEN-JAKOBSEN, 1985). Bei Mangel an Linolsäure sinkt die Linolen- und Arachidonsäurebildung (ROBBLEE und CLANDININ, 1984; MALAU-ADULI et al., 1998) und somit der Gehalt an mitochondrialen Phospholipiden. Die Aktivität membranständiger Enzyme und somit der Transportvorgänge in der Zelle und die Membranfluidität werden negativ beeinflußt (KUNZE, 1993). 
Cholin

Funktionen als Neurotransmitterbestandteil

Das Phosphatidylcholin hat als Lieferant des Aminoalkolhols Cholin wichtige Funktionen im Organismus. Zuerst erkannte STRECKER 1862 die Funktion von Cholin im Säugetiergewebe als eine Komponente anderer Moleküle, wie dem Neurotransmitter Acetylcholin (CANTY und ZEISEL, 1994). In Rattenversuchen stellten COHEN und WURTMANN (1976) fest, daß exogen zugeführtes Cholin als Phosphatidylcholin oder in freier Form die Blut-Hirn-Schranke durchbrechen kann und somit als Cholinquelle für die Acetylcholinbildung fungiert, welches wichtig für die Funktionsfähigkeit des Gehirns ist. Membranphospholipide stellen ein Reservoir für freies Cholin dar. Das kann für die Acetylcholinsynthese genutzt werden. Neuere Arbeiten von ULUS et al. (1988) belegen, daß Acetylcholin an den Nervenenden für die Reizweiterleitung zum Erfolgsorgan verantwortlich ist. BLUSZTAJN und WURTMAN (1983) beschrieben, daß das Phospholipid Phosphatidylcholin in den cholinergischen Nervenfasern zum Aufbau von Membranen und zur Bereitstellung von Cholin für die Synthese von Acetylcholin dient.

ULUS et al. (1988) stellten nach Untersuchungen an Rattenhirnen fest, daß bei einem Mangel an freiem Cholin, der Abbau von Phosphatidylcholin in den Membranen und Nervenfasern zur Synthese von Acetylcholin erfolgt. CHUNG et al. (1995) verabreichten gesunden Mäusen und Mäusen die an Gehirnstörungen litten Phosphatidylcholin. Nach 45 Tagen war bei den Mäusen mit Gehirnstörungen ein verbesserter Zustand der Tiere sowie eine Erhöhung der Cholin- und Acetylcholinkonzentration meßbar. Bei den gesunden Tieren waren dagegen keine Veränderungen zu verzeichnen.

Positive Effekte nach Einsatz von Phospholipiden im Tierbereich führten dazu, daß auch im Humanbereich Versuche unternommen wurden, Krankheiten, die auf einem gestörten Gehirnstoffwechsel beruhen, mit Cholinderivaten zu behandeln. Wie PARDUN (1989) an Beispielen aufzeigt, wurden bei einigen Versuchen Erfolge verzeichnet.

\section{Funktionen im Methylgruppen-Metabolismus}

Oxidationsprodukt des Cholins ist das Betain. Die Betain-Homocystein-Methylase ist fähig Methylgruppen von Betain auf Homocystein zu übertragen, so daß daraus Methionin entsteht. Cholin ist somit eine Quelle für labile Methylgruppen (CANTY und ZEISEL, 1997). Unter Einfluß der Methionin-Adenosyltransferase wird aus Methionin + ATP die aktive 
Form, S-Adenosylmethionin, gebildet. Diese ist wiederum in der Lage, bei Cholinbedarf im Organismus, Colamin zu methylieren, so daß Cholin und S-Adenosylhomocystein entstehen. Colamin kann unter anderem durch Decarboxylierung von Serin gebildet werden (SCHENK und KOLB, 1990). Nach dem gleichen Prinzip stellt die Methylierung des Phosphatidylethanolamins durch S-Adenosylmethionin unter Bildung von Phosphatidylcholin und S-Adenosylhomocystein einen möglichen Syntheseweg des Phosphatidylcholins dar (BLUZTAJN und WURTMAN, 1983; CANTY und ZEISEL, 1997).

Ein Mangel an Methionin und/oder Cholin kann demnach zu einer Störung der Phospholipidsynthese führen (GEBHARDT, 1981). Als Phosphatidylcholinbautstein hat Cholin Einfluß auf den Lipidstoffwechsel, besonders der Leber sowie der Zellmembranen (PÜSCHNER und SIMON, 1988). Ein Cholinmangel kann sich bei stärkereicher und proteinarmer Ernährung entwickeln, wenn die Nahrung wenig Cholin, Methionin und Serin enthält. Eine Anreicherung von Triacylglyceriden in der Leber, die Hemmung der Lipoprotein- sowie Membran- und Acetylcholinsynthese sind die Folge (SCHENK und KOLB, 1990). Untersuchungen an Hühnern ergaben, daß ein Mangel an Cholin, d.h. bei Aufnahmen von unter $800 \mathrm{mg} / \mathrm{Tag}$, Störungen im Fettstoffwechsel in der Leber, Perosis und eine Abnahme in der Eierproduktion verursachen kann (DAGHIR et al., 1960; FEATHERSTONE und STEPHENSON, 1960; FRITZ et al., 1967).

\subsubsection{Bestandteil des Gallensaftes}

Neben Wasser, gallensauren Salzen, Cholesterin, Proteine und Bilirubin sind 0,5 \% - 7 \% Lecithin (je nach Tierart) in der Galle enthalten. Geflügel bildet 0,6 ml Galle/g Leber/Tag. Die Gallenausschüttung erfolgt, indem der Parasympathicus auf die Kontraktion der Gallenblasenmuskulatur wirkt und Cholecystokinin die Entleerung der Gallenblase anregt (KOLB, 1962). Die Funktion der Galle besteht darin, im Darmlumen auf die Lipolyseprodukte einzuwirken und sie aufzunehmen (STAFFORD und CAREY, 1981; CAREY, 1983). Aus den zuvor reinen Gallensäurenmicellen werden gemischte Micellen gebildet (MANSBACH et al., 1975; THIELE et al., 1979). 


\subsection{4}

Lipoproteinbestandteil

Bei der Verdauung werden die Lipide im Duodenum zum Teil hydrolysiert und in die intestinale Mucosa absorbiert. In der Mucosa werden die Hydrolyseprodukte wieder zu Triacylglyceride, Cholesterinester und Phospholipide resynthetisiert (KARLSON et al., 1994). Da Lipide im Wasser unlöslich sind, ist ihr Transport im Blut nur in Form von Komplexen mit Proteinen, den sogenannten Lipoproteinen, möglich. Deren funktionelle Aufgabe besteht darin, Lipide aufzunehmen, zu transportieren und wieder abzugeben und die Proteine (=Apoproteine) auszutauschen (BEIL und GRUNDY, 1980; KARLSON et al., 1994). Das befähigt die Lipoproteine Phospholipide, Triacylglyceride, Cholesterin und Cholesterinester im wässrigen Millieu des Blutes zu transportieren (ELLSWORTH et al., 1986).

Die Lipoproteine werden in vier unterschiedliche Klassen eingeteilt: Chylomikronen, Lipoproteine sehr niedriger Dichte (VLDL), niedriger Dichte (LDL) und hoher Dichte (HDL). Ihre Eigenschaften und Zusammensetzungen sind in Tabelle 5 aufgeführt.

Tabelle 5: Dichte, Größe, chemische Zusammensetzung und Apoproteinanteile der verschiedenen Lipoproteine (KARLSON et al., 1994)

\begin{tabular}{|c|c|c|c|c|}
\hline \multicolumn{5}{|c|}{ Physikalische Eigenschaften } \\
\hline Lipoproteine & Chylomikronen & VLDL & LDL & HDL \\
\hline Dichte $(\mathrm{g} / \mathrm{ml})$ & \multicolumn{2}{|c|}{$0,9-1,006$} & $1,006-1,063$ & $1,063-1,21$ \\
\hline Größe (nm) & $100-1000$ & $30-70$ & $15-25$ & $7,5-10$ \\
\hline $\begin{array}{l}\text { Zusammensetzung (\%): } \\
\text { Protein } \\
\text { Phospholipid } \\
\text { Cholesterin } \\
\text { Triacylglycerid }\end{array}$ & $\begin{array}{c}1 \\
4 \\
6 \\
85-90 \\
\end{array}$ & $\begin{array}{c}8-10 \\
18 \\
13 \\
60 \\
\end{array}$ & $\begin{array}{l}20 \\
23 \\
45 \\
10 \\
\end{array}$ & $\begin{array}{c}50 \\
30 \\
18 \\
2-5 \\
\end{array}$ \\
\hline $\begin{array}{l}\text { Apoproteine: } \\
\text { A (Al, All) } \\
\text { B (B48, B100) } \\
\text { C (Cl, Cll, Clll) } \\
\text { D } \\
\text { E }\end{array}$ & $\begin{array}{c}\text { A } \\
\text { B48 } \\
\text { C } \\
- \\
\text { E }\end{array}$ & $\begin{array}{c}\text { A } \\
\text { B100 } \\
\text { C } \\
\text { D } \\
\text { E }\end{array}$ & $\begin{array}{l}- \\
\text { B100 } \\
\text { C } \\
\text { D } \\
\text { E }\end{array}$ & $\begin{array}{l}\mathrm{A} \\
- \\
\mathrm{C} \\
- \\
\mathrm{E}\end{array}$ \\
\hline
\end{tabular}


Nicht in Tabelle 5 aufgeführt ist das Stoffwechselzwischenprodukt von VLDL und LDL. Der Abbau der VLDL läuft über Lipoproteine intermediärer Dichte (IDL), die direkt weiter zu LDL abgebaut werden. Die Chylomikronen und VLDL sind die größten Lipoproteine mit der geringsten Dichte, die hauptsächlich Triacylglyceride transportieren. Die HDL sind die kleinsten Lipoproteine mit der größten Dichte. Sie transportieren zum größten Anteil Proteine und Phospholipide. Die etwas größeren LDL sind besonders für den Cholesterintransport im Organismus verantwortlich. Die hydrophoben Triacylglyceride und Cholesterinester (=Neutrallipide) bilden den Kern der Lipoproteine und die Hülle besteht aus den hydrophilen Phospholipiden, Cholesterin und Apoproteinen (THIELE et al., 1979).

Die Funktionen der Lipoproteine im Metabolismus des Phosphatidylcholins sind im Kapitel 2.4 .3 beschrieben.

\subsection{Stoffwechsel von exogen zugeführtem Phosphatidylcholin}

\subsubsection{Funktionen der Phospholipasen}

Wie in Abbildung 2 aufgeführt, sind die fünf verschiedenen Phospholipasen $A_{1}, A_{2}, B, C$ und D für die Hydrolyse von Phosphatidylcholin und anderen Phospholipiden verantwortlich (BOSCH, 1982). 


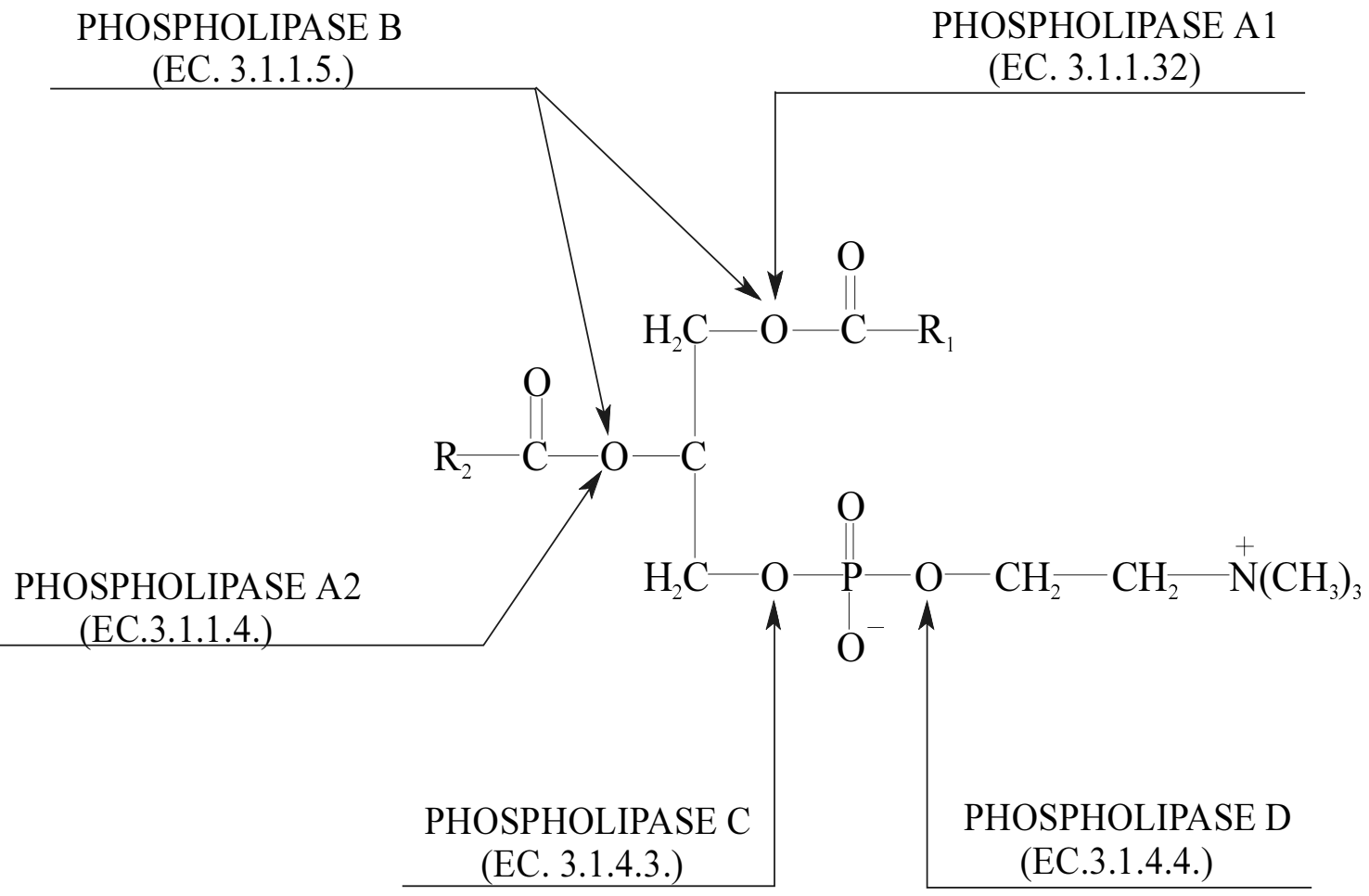

Abbildung 2: Angriffspunkte der Phospholipasen am Molekül des Phosphatidylcholins (BOSCH, 1982)

Phospholipase $\mathrm{A}_{1}$

Die Phospholipase $A_{1}$ hydrolysiert die Acylesterbindung am ersten Kohlenstoffatom (C-1) des Phosphatidylcholins, so daß 2-Acyl-Lysophosphatidylcholin entsteht (WAITE und DEENEN, 1967). Die Phospholipase $A_{1}$ kommt in der Leber, aber auch in anderen Geweben vor (GATT et al., 1966; WINKLER et al., 1967; BOSCH et al., 1974). Lokalisiert ist sie in der Plasmamembran (NACHBAUR et al.,1972; COLEBEAU et al., 1974), in der microsomalen Fraktion (SCHERKOPF et al., 1966; WAITE und DEENEN, 1967), im Golgi-Apparat (GOLDE et al., 1971) und in den Lysosomen (FRANSON et al., 1971).

Extrazellulär liegt die Phospholipase $A_{1}$ zusammen mit $A_{2}$ im Pankreassaft als inaktives Zymogen vor (NILSSON und BORGSTRÖM, 1967). Durch eine trypsinvermittelte Hydrolyse werden die aktiven Phospholipasen gebildet (HAAS, 1972). Ihre Wirkung ist intraluminal an die Anwesenheit von Gallensäuren und $\mathrm{Ca}^{++}$gekoppelt (CAREY, 1983). 
Phospholipase $\mathrm{A}_{2}$

Die Phospholipase $\mathrm{A}_{2}$ hydrolysiert die Acylesterbindung am zweiten Kohlenstoffatom (C-2) des Phosphatidylcholins und anderer Phospholipide (WAITE und DEENEN, 1967; ONO et al., 1984). Ebenso wie die Phospholipase $A_{1}$ kommt $A_{2}$ in der Leber und in anderen Geweben von Säugetieren vor (HAAS et al., 1968; OHTA et al., 1972; CINGOLANI et al., 1972). Die Lokalisation ist z.T. pH-Wert abhängig. In den Rattenlysosomen wurde sie bei einem pH-Wert von 4,0 - 4,5 nachgewiesen (WINKLER et al., 1967; RAHMANN et al., 1970; FRANSON et al., 1971) und in den Mitochondrien (WAITE und DEENEN, 1967) sowie in der Plasmamembran bei einem basischen pH-Wert (NACHBAUR et al., 1972; NEWKIRK und WAITE, 1973). Geringe Aktivität der Phospholipase $A_{2}$ konnte noch im Golgi-Apparat (GOLDE et al., 1971) und in der microsomalen Fraktion nachgewiesen werden (NEWKIEK und WAITE, 1973).

\section{Phospholipase B (Lysophospholipase)}

Die Phospholipase B hydrolysiert 1- bzw. 2-Lysophosphatidylcholin zu Glycerin-3Phosphat und freie Fettsäuren (DAWSON, 1956; BOSCH et al., 1968). Sie kommt in der Leber und in anderen Organen vor (LEIBOVITZ et al., 1972; BOSCH et al., 1973; FERBER und RESCH, 1973). Lokalisiert ist sie im Cytosol, in der microsomalen Fraktion und den Mitochondrien (BJØRNSTAD und BREMER, 1966; BOSCH et al., 1968; BOSCH, 1982).

\section{Phospholipase C}

Die Phospholipase C spaltet Phosphatidylcholin in 1,2-Diacylglycerin und Phosphorylcholin (BOSCH und DEENEN, 1965, WUTHIER, 1973). Ihr Vorkommen wurde in Leber und Gehirn von Ratten beobachtet (KANFER et al., 1966; ANSELL, 1972). Lokalisiert ist sie in den Lysosomen (BOSCH, 1982).

\section{Phospholipase D}

Die Phospholipase D spaltet Phosphatidylcholin in Phosphatidsäure und Cholin (KANFER, 1980; BOSCH, 1982). Sie kommt im Gehirn und anderen Geweben vor. Lokalisiert ist sie in den Membranen und im Cytosol der Zellen (WAITE, 1996). 
Die Verdauung der Phospholipide erfolgt im Intestinum tenue. Im Duodenum treffen die mit der Nahrung aufgenommenen Phospholipide und endogen synthetisierte Phospholipide zusammen (ANSELL und SPANNER, 1982). Es erfolgt eine Vermischung der NahrungsPhospholipide mit Pankreassaft und Gallensekret, welches aus gallensauren Salzen, Cholesterin und endogen gebildeten Phospholipiden besteht (PARDUN, 1988). Das Phosphatidylcholin wird micellar gelöst (SENIOR, 1964; NILSSON und BORGSTRÖM, 1967) und mit Hilfe der im Pankreassaft enthaltenen Phospholipase A hydrolysiert (SCOW et al., 1967). Hierbei entstehen vorangig 1-Acyl-Lysophosphatidylcholine und freie Fettsäuren (BOUCROT, 1972; PARTHASARATHY et al., 1974; LEKIM und BETZING, 1976), da die Phospholipase $\mathrm{A}_{1}$ im Darmlumen deutlich geringere Aktivitäten aufweist als die Phospholipase $A_{2}$ (PARTHASARATHY et al., 1974). Ein weiterer Abbau der Lysophosphatidylcholine zu Glycerophosphorylcholin scheint im Darmlumen sehr gering zu sein (BEIL und GRUNDY, 1980; ANSELL und SPANNER, 1982).

Die Phospholipidabsorption findet hauptsächlich in den proximalen Dünndarmabschnitten statt (MANSBACH, 1973), kann sich aber bei hoher Phospholipidaufnahme bis in den distalen Bereich ausdehnen. Das verhindert eine Überladung des proximalen Dünndarmabschnittes mit Phosphatidylcholin und gewährleistet eine optimale Resorptionsquote (SABESIN et al., 1975; BEIL und GRUNDY, 1980). Micellar gelöst penetrieren Lysophosphatidylcholin und andere Lipolyseprodukte aus dem Darmlumen in die Enterozyten (Mucosazellen) (NILSSON und BORGSTRÖM, 1967; GLICKMAN, 1980). Untersuchungen von LEKIM und BETZING (1976) mit dreifach markiertem Phosphatidylcholin an Ratten zeigen, daß in den ersten sechs bis acht Stunden die Resorption besonders rasch erfolgt und nach 24 Stunden über 90 \% der Aktivität aus dem Gastrointestinaltrakt in den Organismus übergeht.

Forschungen an Ratten von ARTOM und SWANSON (1948); BLOOM et al. (1954) und BLOMSTRAND (1955) ergaben, daß nach oraler Gabe eines einfach markierten Phospholipidgemisches bis zu 20 \% intakte Phospholipide absorbiert wurden. HÖLZL und WAGNER (1971) bestätigten diese Ergebnisse nach Applikation von doppelt markiertem Phosphatidylcholin an Ratten. Die Untersuchungen anderer Wissenschaftler (SCOW et al., 1967; NILSSON, 1968; PARTHASARATHY et al., 1974; LEKIM und BETZING, 1976; 
ZIERENBERG und GRUNDY, 1982) zeigen dagegen, daß nach der Applikation von mehrfach markiertem Phosphatidylcholin mit anschließender Untersuchung der Lymphlipide, nur ein sehr geringer Teil des Phosphatidylcholins intakt, der größte Anteil aber als Lysophosphatidylcholin absorbiert wird.

In den Enterocyten kann das Lysophosphatidylcholin hauptsächlich über zwei verschiedene Stoffwechselwege um- bzw. abgebaut werden. Nach Angaben von LEKIM und BETZING (1976) laufen beide Wege zu etwa gleichen Anteilen (50:50) ab. Die dafür notwendigen Enzyme kommen im Darmlumen und in der Mucosa vor (GANGULY et al., 1972; BOSCH et al., 1974).

\section{Stoffwechselweg des Lysophosphatidylcholins in den Enterocyten:}

Ein Teil der 1-Acyl-Lysophosphatidylcholine wird von Lysophospholipasen im Verdauungstrakt komplett zu freien Fettsäuren, Glycerophosphocholin und dessen Hydrolyseprodukten hydrolysiert (LEKIM und BETZING, 1976; LEKIM und GRAF, 1976; PARTHASARATHY et al., 1974; BEIL und GRUNDY, 1980; ZIERENBERG und GRUNDY, 1982). Aus den Fettsäuren und Glycerinphosphat können über den KennedyPathway wieder Triacylglyceride (BAXTER, 1966; OCKNER et al., 1969; PARTHASARATHY et al., 1974) und Phospholipide aufgebaut werden (LEKIM und GRAF, 1976). Glycerophosphocholin wird entweder zu Glycerin und Phosphocholin oder durch Phosphodiesterasen zu Glycerophosphat und Cholin hydrolysiert. Als wasserlösliche Bruchstücke gelangen sie nach der Resorption via der Vena portae zur Leber (LEKIM und GRAF, 1976).

\section{Stoffwechselweg des Lysophosphatidylcholins in den Enterocyten:}

An die C-2 Position des 1-Acyl-Lysophosphatidylcholins wird durch die LysolecithinAcyltransferase vorwiegend eine ungesättigte Fettsäure reacyliert, so daß wieder Phosphatidylcholin entsteht (SCOW et al., 1967; NILSSON und BORGSTRÖM, 1967; NILSSON; 1968; PARTHASARATHY et al., 1974; LEKIM und BETZING, 1976; LEKIM und GRAF, 1976; BEIL und GRUNDY, 1980; ZIERENBERG und GRUNDY, 1982). Das Phosphatidylcholin wird zusammen mit weiteren Resyntheseprodukten, wie den Triacylglyceriden oder Cholesterinestern, mit Apoproteinen kombiniert und somit zu 
Chylomikronen (oder VLDL) geformt und via Ductus thoracicus in die Lymphbahn sekretiert (OCKNER et al., 1969; TYTGAT et al., 1971; BEIL und GRUNDY,1980). Abbildung 3 zeigt die beschriebenen Stoffwechselwege.

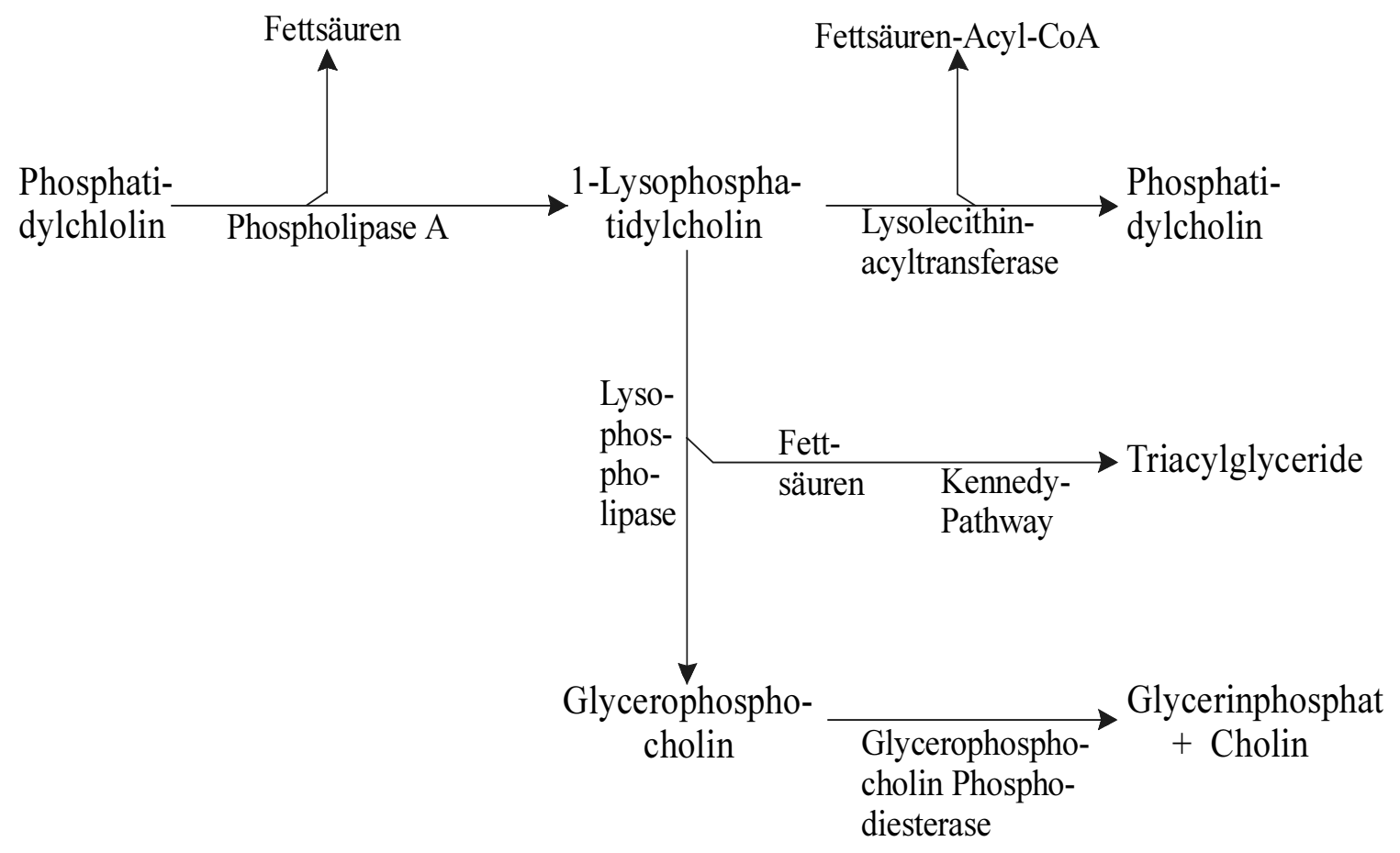

Abbildung 3: Stoffwechselwege von oral appliziertem Phosphatidylcholin bei Ratten (LEKIM und BETZING, 1976)

Bei fettreicher Fütterung machen die Triacylglyceride den Hauptteil der ChylomikronenTriacylglyceride aus. Der Umfang der Chylomikronen vergrößert sich bei gleichzeitiger Abnahme des Phospholipid : Triacylglycerid Verhältnisses (YOKOHAMA und ZILVERSMIT, 1965; FRAZER et al., 1970).

SCOW et al. (1967) stellten fest, daß ein hoher Phospholipidgehalt im Futter nicht den Phospholipidgehalt in den Chylomikronen erhöht, sondern das der Hauptteil der Phospholipidfettsäuren in den Triacylglyceriden des Plasmas wiederzufinden ist. Nach ihren Untersuchungen stammen nur $40 \%$ der Phospholipide in den Chylomikronen aus der Nahrung und $60 \%$ sind endogenen Ursprungs. Als endogene Phospholipidquellen stehen neben der Galle (PHILLIPS, 1960) Lysophosphatidylcholin und Phosphatidylcholin des Blutes (STEIN und STEIN, 1966; NELSON und FREEMAN, 1960) und im Intestimun de novo 
synthetisiertes Phosphatidylcholins zur Verfügung (MANSBACH, 1973). LEKIM und GRAF (1976) sowie LEKIM und BETZING (1976) berichteten, daß 75 \% der Fettsäuren der Phospholipide als Chylomikronen-Triacylglyceride (oder Lipoprotein-Triacylglyceride) vorliegen und nur $25 \%$ als Chylomikronen-Phospholipide. Auch NILSSON (1968) und PARTHASARATHY et al. (1974) stellten fest, daß der größte Anteil der markierten C-2 Fettsäuren des Phosphatidylcholins in reacylierten Triacylglyceriden in den Mucoazellen wieder zu finden ist. Insgesamt wurden 90 \% der gesamten Fettsäuren der Phospholipide in Chylomikronen nachgewiesen und $50 \%$ des Cholins. Die übrigen $50 \%$ des Cholins wurden in der Leber wiedergefunden (s. 1. Stoffwechselweg; LEKIM und BETZING, 1976).

Phosphatidylcholin kann de novo in der Mucosa synthetisiert werden (NOMA, 1964). Während der CDP-Cholin Pathway im Intestinum aktiv ist (GURR et al., 1965), ist es der PE-N-Methyltransferase Pathway nicht (BREMER und GREENBERG, 1961). Exogen aufgenommenes Phosphatidylcholin inhibiert die intestinale Phosphatidylcholinbildung über den CDP-Cholin Pathway (MANSBACH, 1977; ZIERENBERG und GRUNDY, 1982). Nur wenn im Darmlumen ein Unterangebot an Phosphatidylcholin vorliegt, erfolgt die Synthese (GREEN und GLICKMAN, 1981).

Ein dritter, jedoch nicht signifikant meßbarer Weg (LEKIM und BETZING, 1976), ist der Transport von Lysolecithin aus den Enterocyten über das portale Blut direkt in die Leber (ANSELL und SPANNER, 1982; ZIERENBERG und GRUNDY, 1982). Nach Untersuchungen von BOUCROT (1972) gelangt das resynthetisierte Lecithin vorangig in den enterohepatischen Kreislauf.

\subsubsection{Von den Mucosazellen bis zu den Geweben}

\section{Transport über Lipoproteine}

\section{Chylomikronen}

In den Mukosazellen werden aus den resynthetisierten Lipiden, Phospholipiden und verschiedenen Apoproteinen Chylomikronen gebildet. Die Chylomikronen gelangen über 
endogene Pinozytose in die Lymphe und via Ductus thoracicus in die Blutbahn (EISENBERG und LEVY, 1975). Dort nehmen sie von der HDL-Fraktion das Lipoproteinlipase-aktivierende Apoprotein C 11 und das Apoprotein E auf (GREEN und GLICKMAN, 1981; GREGG et al., 1984). In den Kapillarbereichen des extrahepatischen Gewebes beginnt der Abbau der Chylomikronen durch die Enzyme Lipoproteinlipase und Triacylglyceridhydrolase. Aufgrund ihrer Phospholipaseaktivität können die Enzyme die im Inneren der Chylomikronen befindlichen Triacylglyceride angreifen (GROSSER et al., 1981). Die durch die Triacylglyceridhydrolyse entstehenden Spaltprodukte werden über Lateraldiffusion ins Gewebe aufgenommen oder im Plasma hydrolysiert. Albumin bindet einen Teil der Fettsäuren und transportiert sie ab (GREEN und GLICKMAN, 1981). Durch die fortlaufende Hydrolyse werden Phospholipide auf HDL übertragen und die Chylomikronen-Remnants über bestimmte Rezeptoren an die Makrophagen und Parenchymzellen der Leber gebunden und abgebaut (KOLB, 1980).

\section{Lipoproteine sehr niedriger Dichte (VLDL)}

Die Synthese der VLDL erfolgt zum Teil in den Mukosazellen des Jejunums aber hauptsächlich in der Leber (ELLSWORTH et al., 1986; KOSTNER, 1976). Die Hauptfunktion besteht im Transport von endogen gebildeten Triacylglyceriden und zum geringen Teil im Abtransport exogener Triacylglyceride von den Mucosazellen über den Ductus thoracicus in den Blutstrom (THIELE et al., 1979). Der Abbau der VLDL erfolgt wie bei den Chylomikronen durch die Lipoproteinlipase an den Kapillarendotheloberflächen, die durch das Apoprotein C 11 aktiviert wird und durch die Triacylglyceridlipase der Hepatozyten (EISENBERG und SCHUR, 1976).

\section{Lipoproteine intermediärer Dichte (IDL)}

Durch die Aktivität der Lipoproteinlipase verliert das VLDL den größten Inhalt an Triacylglyceriden. Es formen sich Lipoproteine mit intermediärer Dichte (ELLSWORTH et al., 1986). Sie enthalten noch etwa $20 \%$ der ursprünglichen Triacylglyceridmenge, $30 \%$ - 40 \% der Phospholipide und des Cholesterins, $10 \%$ des Apoproteins C 11 und $50 \%$ des Apoproteins E (EISENBERG und LEVY, 1975). Etwa 50 \% der IDL werden über einen Rezeptormechanismus in die Hepatozyten aufgenommen und der Rest wird durch Lipoproteinlipasen bei einem Verlust von Apoprotein E zu LDL umgebaut (KATAN, 1987). 


\section{Lipoproteine niedriger Dichte (LDL)}

Die Lipoproteine mit niedriger Dichte haben eine wichtige Rolle beim intravasalen Cholesterintransport und für die Bereitstellung von Cholesterin für die peripheren Zellen. Bei normalen Serumlipidwerten liegen in den LDL-Partikel circa 60 \% des Serumcholesterins, das zu $80 \%$ als Ester gebunden ist und das Apoprotein B, vor (KOLB, 1980). Ein membrangebundener Rezeptor bindet über das Apoprotein B die LDL. Der Rezeptorkomplex wird ins Zellinnere geschleust und von Lysosomen abgebaut (GOLDSTEIN und BROWN, 1977). Dadurch kann das freigesetzte Cholesterin zur Versorgung der Zellen dienen. Gleichzeitig wirkt das freie Cholesterin als Repressor für die Synthese des Schlüsselenzyms der Cholesterin-Biosynthese, der 3-Hydroxy-3-Methyl-Glutaryl-CoA-Reduktase. Dieser Mechanismus unterdrückt die Cholesterin-Biosynthese in den peripheren Zellen (KARLSON, 1994) und soll die Zellen vor Cholesterinüberladung schützen.

\section{Lipoproteine hoher Dichte (HDL)}

Im endoplasmatischen Retikulum von Leber und Dünndarm werden discoidale HDLPartikel produziert (TALL et al., 1982). Diese nehmen im Blut aus den VLDL und den Chylomikronen die Apoproteine $\mathrm{C}$ und E, Phospholipide und Cholesterin auf (EISENBERG, 1984). HDL ist ein bevorzugtes Substrat für das Lecithin-CholesterinAcyltransferase (LCAT) Enzym, welches die C-2 Fettsäure von Phospholipiden auf freies Cholesterin transferiert, wobei Cholesterinester und Lysophospholipide entstehen. Die Lysophospholipide werden an Albumin gebunden in die Leber transportiert (THIELE et al., 1979; EISENBERG, 1984) und die Cholesterinester gelangen in den HDL-Kern, so daß das discoidale HDL eine runde Form annimmt (KATAN, 1987). Mit der LCAT-Reaktion wird überschüssiges Cholesterin aus der Körperperipherie herausgelöst und zur Leber transportiert. Dort erfolgt der Abbau zu Cholesterin und der Einbau in Gallensäuren mit der es ausgeschieden wird (KARLSON, 1994; KATAN, 1987). Desweiteren ist HDL das größte Reservoir für die Lipoproteinlipase im Plasma von Geflügel (GRIFFIN et al., 1982). Im Säugetiergewebe aktiviert das Apoprotein C 1l, welches von HDL sekretiert wird, die Lipoproteinlipase. 
Besonderheiten beim Geflügel

Das Lymphsystem von Vögeln ist wenig ausgebildet. Deshalb werden Lipoproteine, die die Bezeichnung Portomikronen tragen, direkt über das portale Blut zur Leber sekretiert (BENSADOUN und ROTHFIELD, 1972). Die Portomikronen haben fast die gleiche Zusammensetzung wie die Chylomikronen, nur ihr Durchmesser ist mit durchschnittlich $150 \mathrm{~nm}$ geringer (GRIFFIN et al., 1982). VLDL und HDL sind die zwei Hauptklassen der Lipoproteine, die in der Leber synthetisiert und sekretiert werden. Die ebenfalls in der Leber synthetisierten Apoproteine B 100 (SIUTA-MANGANO et al., 1982) und A 1 (BANARJEE und REDMAN, 1984) sind die am meisten vorkommenden Apoproteine der Geflügel-VLDL und -HDL. Triacylglyceride werden bevorzugt mit dem Apoprotein B und Phospholipide und Cholesterin mit dem Apoprotein A verbunden. Nach Übergang der Triacylglyceride von VLDL (und Portomikronen) ins Fettgewebe werden sie durch die Lipoproteinlipase zu Glycerin und Fettsäuren abgebaut. Die Fettsäuren treten ins Gewebe ein, werden reverestert und als Triacylglyceride gespeichert (HERMIER, 1997).

Phospholipidgehalt in den Geweben

Über Lipoproteine transportiert und endogen gebildet, liegen die Phospholipide in den verschiedenen Geweben vor. Tabelle 6 zeigt den Phospholipidgehalt einiger Gewebe und die Phospholipidfraktionen mit den höchsten prozentualen Phospholipidanteilen.

Tabelle 6: Absoluter Phospholipidgehalt einiger Rattengewebe, sowie der relative Anteil einiger Phospholipidfraktionen (ANSELL und SPANNER, 1982)

\begin{tabular}{|l|c|c|c|c|c|}
\hline Gewebe & $\begin{array}{c}\text { gesamte } \\
\text { Phospholipide }\end{array}$ & $\begin{array}{c}\text { Phosphatidyl- } \\
\text { cholin }\end{array}$ & $\begin{array}{c}\text { Phosphatidyl- } \\
\text { ethanolamin }\end{array}$ & $\begin{array}{c}\text { Phosphatidyl- } \\
\text { serin }\end{array}$ & $\begin{array}{c}\text { Lysophospha- } \\
\text { tidylcholin }\end{array}$ \\
\hline & $(\mu \mathrm{mol} / \mathrm{g})$ & \multicolumn{4}{|c|}{ (\% der gesamten Phospholipide) } \\
\hline Gehirn & 60 & 25 & 12 & 8 & - \\
\hline Nieren & 37 & 34 & 27 & 7 & 1 \\
\hline Lunge & - & 54 & 20 & 6 & - \\
\hline Milz & 18 & 42 & 24 & 8 & 1 \\
\hline Muskel & 11 & 51 & 22 & 4 & 3 \\
\hline Herz & 15 & 36 & 30 & 3 & 1 \\
\hline Galle & 4 & 90 & 4 & 1 & $<1$ \\
\hline
\end{tabular}


Tabelle 6 verdeutlicht, daß die Fraktionen Gehirn, Nieren, Lunge, Milz, Muskel und Herz hohe Phospholipidgehalte aufweisen. Der relative Anteil der Fraktion Phosphatidylcholin dominiert in allen Geweben, gefolgt vom Phosphatidylethanolamin, Phosphatidylserin und den Lysophosphatidylcholinen. GETZ et al. (1968) untersuchten den Phospholipidgehalt in verschiedenen Körperfraktionen von Schafen und stellten die höchsten Gehalte ( $\mu \mathrm{mol} / \mathrm{g} T$ Fraktion) in den Körperfraktionen: Gehirn 190, Leber 150, Herz 146, Niere 136 und Milz fest.

Übereinstimmend mit den Ergebnissen von ANSELL und SPANNER (1982) fanden MARINETTI et al. (1958) und GETZ et al. (1968) die höchsten Phospholipidgehalte in den Phospholipidfraktionen Phosphatidylcholin und -ethanolamin. Auch BLANK et al. (1992), die die Phospholipidzusammensetzung von Muskelfleisch beim Geflügel untersuchten, konnten höchste Gehalte im Phosphatidylcholin und Phosphatidylethanolamin feststellen. PARTHASARATHY und GANGULY (1973) gaben Ratten mit ${ }^{14} \mathrm{C}$ markiertes Glycerin und fanden davon $12 \%$ in Diacylglyceriden, $58 \%$ in Triacylglyceriden und $23 \%$ in Phospholipiden wieder, wovon 12 \% Phosphatidylcholin, 2 \% Phosphatidylethanolamin und $1 \%$ Lysophosphatidylcholin waren.

\subsection{Biosynthese von Phosphatidylcholin}

Phospholipide können vom Organismus im erforderlichen Ausmaß gebildet werden und sind daher nicht essentiell (PARDUN, 1988).

Für die Biosynthese von Phosphatidylcholin in den Säugetierzellen sind fünf verschiedene Reaktionswege bekannt (ANSELL und SPANNER, 1982). Ein Reaktionsweg ist die de novo Synthese (PELECH et al., 1984; WILKISON und BELL, 1997), die es als einzige Reaktion ermöglicht, den Phosphatidylcholingehalt in den Zellen $\mathrm{zu}$ erhöhen (WURTHIER, 1973). Die anderen vier Reaktionswege stellen Konversionsreaktionen dar, die in der Lage sind vorhandenes Phosphatidylcholin $\mathrm{zu}$ modifizieren (ANSELL und SPANNER, 1982).

Die Leber ist das zentrale Organ für den Phospholipidstoffwechsel, aber auch in anderen Organen findet eine Metabolisierung statt (SCOW et al., 1967; KARLSON et al., 1994). Bei der Biosynthese von Phosphatidylcholin und anderer Phospholipide haben die Enzyme 
an der Cytoplasmaoberfläche des endoplasmatischen Retikulums (PARTHASARATHY und BAUMANN, 1979; BALLAS und BELL, 1980; VALTERSSON und DALLNER, 1982) sowie der Mitochondrien und Microsomen (WILGRAM und KENNEDY, 1963; BRINDLEY und HÜBSCHER, 1965; GETZ et al., 1968; WIRTZ und ZILVERSMIT, 1968; EIBL et al., 1969) wichtige Funktionen.

\subsubsection{De novo Synthese von Phosphatidylcholin}

Die de novo Synthese des Phosphatidylcholins erfolgt über den Cytidin-Pathway (ANSELL und SPANNER, 1982) auch CDP-Cholin Pathway (MAN et al., 1994) oder Kennedy-Pathway (PELECH und VANCE, 1984) genannt. Über diesen Weg wird der größte Teil des Phosphatidylcholins synthetisiert (SKØRVE, et al., 1993; MAN et al., 1994; HATCH et al., 1997), da freies Cholin vorrangig für die Phosphatidylcholinsynthese via CDP-Cholin Pathway genutzt wird (PELECH und VANCE, 1984). Wie Abbildung 4 zeigt, wird mit Hilfe der Cholinkinase Cholin mit ATP zu Phosphocholin phosphorylisiert. Durch das Enzym Cytosintriphosphat(CTP)-Phosphocholin-Cytidyltransferase wird das Phosphocholin mit CTP zu CDP-Cholin umgewandelt. Das CDP-Cholin kondensiert unter Einwirkung des Enzyms CDP-Cholin-Diacylglycerin-Cholinphosphotransferase mit Diacylglycerin zum Phosphatidylcholin (MAN et al., 1994). Dieser Schritt ist reversibel (KANOH und OHNO, 1973). Das Diacylglycerin wird zuvor über mehrere Schritte aus dem Glycerin-3-Phosphat umgewandelt (BELL et al., 1981; WILKISON und BELL, 1997). Dieses entsteht wiederum entweder aus Dihydroxyacetonphosphat, welches aus dem Kohlenhydratstoffwechsel zur Verfügung gestellt wird oder aus Glycerin, welches aus dem Fettstoffwechsel stammt (HAUSCHILDT, 1980). Über den CDP-Cholin Pathway wird in der Leber die erste Hydroxylgruppe des Phosphatidylcholins bevorzugt mit Palmitin- oder Stearinsäure und die zweite Hydroxylgruppe mit Linolsäure verestert (KANOH, 1969; AKESSON, 1970; GOLDE et al., 1971; VEREYKEN et al., 1972; TREWHELLA und COLLINS, 1973). 


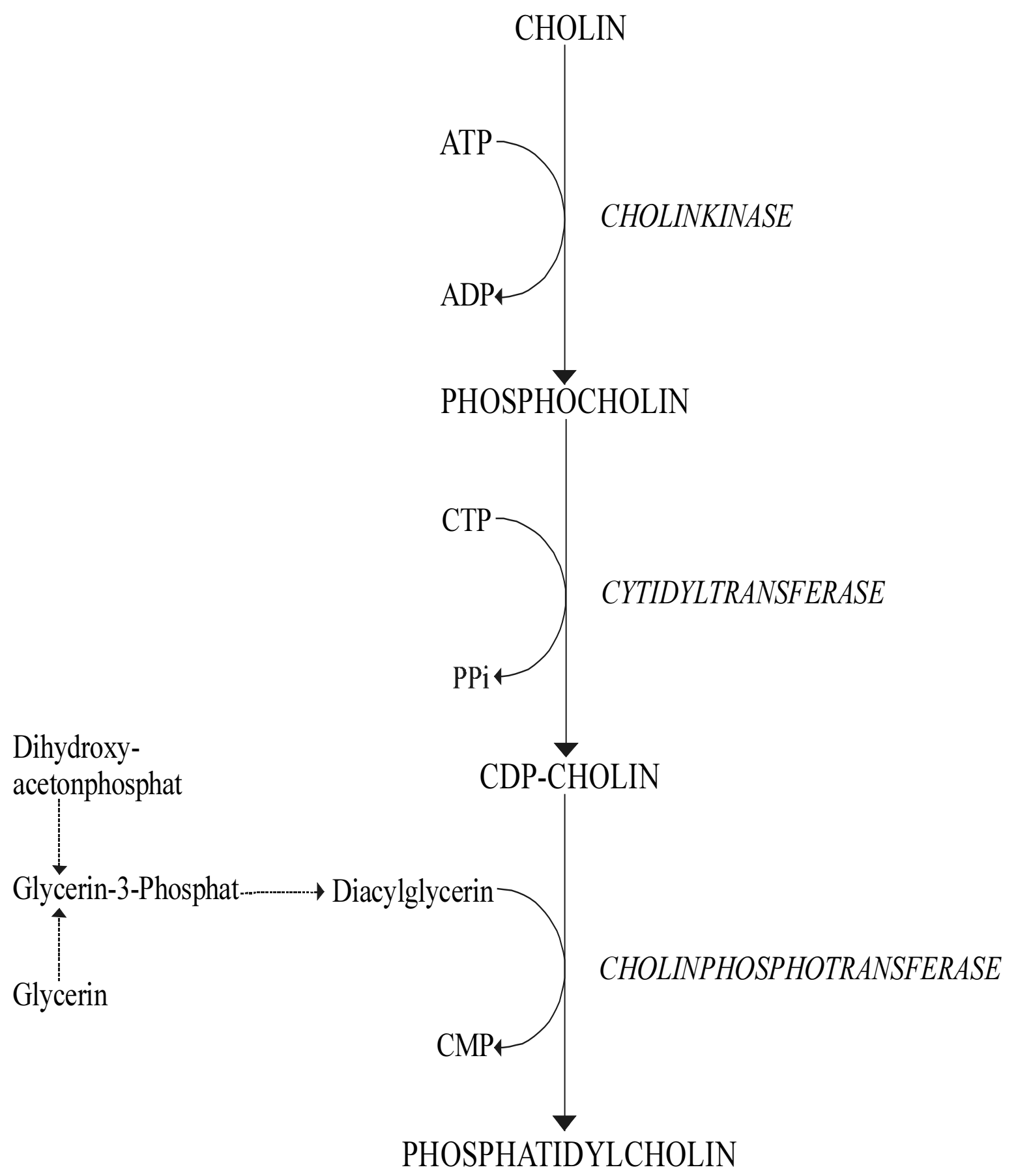

Abbildung 4: CDP-Cholin Pathway (modifiziert nach PELECH und VANCE, 1984)

Regulierend für den CDP-Cholin Pathway wirkt das Enzym Cytidyltransferase, welches die Aktivität anderer Enzyme limitieren bzw. erhöhen kann (PELECH et al., 1984; SKØRVE et al., 1993; MAN et al., 1994). Die Steroide Diethylstilbestrol und Glucocorticoide wirken stimulierend auf die Phosphatidylcholinsynthese. Norepinephrin und Vasopressin wirken inhibierend (MAN et al., 1994). 
Die Umwandlung von Phosphatidylethanolamin zu Phosphatidylcholin wurde 1941 zuerst von STETTEN beschrieben (PELECH und VANCE, 1984). Erst 1960/61 entdeckten BREMER und GREENBERG $(1960 ; 1961)$ sowie GIBSON et al. (1961), daß das Phosphatidylethanolamin über Methyltransferasen durch Dreifachmethylierung zu Phosphatidylcholin umgewandelt werden kann, wobei das S-Adenosylmethionin als Methylgruppendonator dient. Die Methyltransferasen sind mit der microsomalen Fraktion der Gewebe, vor allem der Leber, verbunden (SKØRVE et al., 1993). Die erste Methylgruppe wird von einer $\mathrm{Mg}^{+}$-abhängigen Methyltransferase (EC 2.1.1.17) übertragen und die zweite und dritte Methylgruppe von einer $\mathrm{Mg}^{+}$-unabhängigen Methyltransferase (EC 2.1.1.71) (HOFMANN, 1993). Von Bedeutung ist die N-Methylierung hauptsächlich in der Leber (BJØRNSTAD und BREMER, 1966; PELECH und VANCE, 1984), da sie dort $20 \%$ $40 \%$ der Phosphatidylcholinbildung ausmacht (SUNDLER und AKESSON, 1975).

\subsection{3}

\section{Basenaustausch}

Zuerst wurde in der Leber und nachfolgend in anderen Geweben (Gehirn, Lunge, etc.) ein weiterer Syntheseweg für Phosphatidylcholin nachgewiesen. Bei diesem Pathway wird Cholin mit einer Kopfgruppe eines anderen Phospholipids ausgetauscht, so daß Phosphatidylcholin entsteht (BJERVE, 1973; KANFER, 1980; GREGG et al., 1984). Die energieunabhängige Reaktion benötigt $\mathrm{Ca}^{++}$(FILLER und WEINHOLD, 1980). Der Syntheseweg hat insgesamt eine relativ geringe Bedeutung, da er nur 1/20 der de novo Phosphatidylcholinsynthese über den CDP-Cholin Pathway ausmacht (SUNDLER et al., 1972).

\subsubsection{Acylierung von Lysophosphatidylcholin}

LANDS (1960) beschrieb die Acylierung von Lysophosphatidylcholin zu Phosphatidylcholin, was von weiteren Autoren (BOSCH und DEENEN, 1965; STEIN und STEIN, 1965; NILSSON und BORGSTRÖM, 1967) bestätigt wurde. Für die Acylierungen sind 
zwei Enzyme verantwortlich. Zum einen die Lysolecithin-Acyltransferase (EC 2.3.1.23), die in der Lage ist, die Hydroxylgruppe am zweiten C-Atom von 1-Lysophosphatidylcholinen zu verestern und zum anderen die 2-Acylglycerinphosphocholin-Acyltransferase (EC 2.3.1.62), die fähig ist, die Hydroxylgruppe des ersten C-Atoms von 2-Lysophosphatidylcholinen mit Fettsäuren zu verestern (SPANNER und ANSELL, 1982). Die Acylierungen laufen vorwiegend am endoplasmatischen Retikulum und an der Mitochondrienmembran ab (DAAE, 1973). Der Typ der zu acylierenden Fettsäure wird von der Position der freien Hydroxylgruppe bestimmt. Gesättigte Fettsäuren werden eher mit der ersten Hydroxylgruppe und ungesättige Fettsäuren mit der zweiten Hydroxylgruppe der jeweiligen Lysophosphatidylcholine verestert (MERKL und LANDS, 1963). Das Fettsäuremuster wird intracellular weiter de- und reacyliert, ohne das das Grundgerüst zerstört wird (LANDS, 1960). 1-Palmitin-, 2-Arachidonsäure- und 1-Stearin-, 2-ArachidonsäurePhosphatidylcholine werden durch Acylierung von Lysophosphatidylcholinen gebildet (HOLUB et al., 1971; AKESSON, 1970), wobei letzteres sogar durch einen zweifachen Deacylierungs-Acylierungs-Prozeß synthetisiert wird (TREWHELLA und COLLINS, 1973).

\subsubsection{Transacylierung von Lysophosphatidylcholin}

Die Transacylierung von Lysophosphatidylcholin wird durch die 1-Acyl-Lysophosphatidylcholin-Acyltransferase katalysiert. Mit Hilfe dieses Enzyms, welches auch als „Marinetti-Enzym“ bezeichnet wird, erfolgt die Reaktion von zwei Molekülen 1-Acyl-Lysophosphatidylcholin zu Phosphatidylcholin und Glycerin-3-Phosphocholin (MARINETTI et al., 1958). Die Reaktion läuft überwiegend im Cytoplasma ab (ERBLAND und MARINETTI, 1965a; ERBLAND und MARINETTI, 1965b) und ist erst bei erhöhten Lysophosphatidylcholin-Konzentrationen nachweisbar (ELSBACH, 1966; MULDER et al., 1965). Unter physiologischen Bedingungen ist sie relativ unbedeutend (STEIN und STEIN, 1966; EISENBERG et al., 1967; STEIN und STEIN, 1967). 


\subsection{Einsatz von Phospholipiden in der Tierernährung}

Da die Phospholipide aufgrund ihrer amphiphilen Eigenschaften emulgierend wirken, werden sie in der Tierernährung als Emulgator von Kälbermilchaustauschern eingesetzt. Das verbessert die Qualität der Milchaustauscher, die Fettverdaulichkeit und ist eine Quelle für essentielle Nährstoffe (NIEUWENHUYZEN, 1985). Wie im Milchaustauscher für Kälber, finden die Phospholipide auch Einsatz im Sauenmilchersatz für Ferkel und für die Verabreichung flüssiger Versuchstierfutter (ZIEGELITZ, 1994). Der Einsatz von Lecithinen, besonders von Reinlecithin als Futterzusatzstoff, verbessert die Verdaulichkeit der organischen Substanzen und die Körpergewichtszunahmen von Ferkeln (GÜNTHER, 1994a, 1994b). Außerdem hat Lecithin einen positiven Effekt auf Parameter der Infektionsabwehr von Ferkeln (RÖTTGERMANN und MOLNAR, 1994; GÜNTHER, 1995). Auch im Geflügelsektor werden Phospholipide als Emulgatoren verwendet (VOGT und HARNISCH, 1977). Desweiteren beschreiben LIPSTEIN et al. $(1967 ; 1970 ; 1977)$ die Nutzung von Phospholipiden als Pigmentträger im Broiler- und Legehennenfutter und als Cholinträger für Kükenfutter. CLIFFORD (1994) berichtet vom Einsatz des Lysophosphatidylcholins bei Ferkeln und Broilern, zur Erhöhung der Futterverwertung und POLIN (1980) zeigt, daß Lecithin die scheinbare Verdaulichkeit von gesättigten Fettsäuren in der Geflügelernährung steigert. 


\section{Radiorespiratorische Untersuchungen bei Broilern}

\subsubsection{Vorbereitungen für radiorespiratorische Versuche}

\subsubsection{Versuchstiere}

Als Versuchstiere dienten insgesamt nur vier männliche Lohmann Meat Broiler (Geflügelmästerei Dryzymola, Steinheuterode), da es sich um Screening-Versuche handelte, die grundlegende Erkenntnisse über den Phospholipidstoffwechsel beim Geflügel liefern sollten. Die Tiere wurden im Alter von 20 Tagen von der Mästerei bezogen. Pro Durchgang konnte jeweils nur ein Tier radioaktiv markiert werden, da ein hoher analytischer Arbeitsaufwand für die Aufbereitung der geschlachteten Tiere bestand.

\subsubsection{Haltung und Fütterung}

Bis zum Versuchsbeginn wurden die Broiler zur Gewöhnung in einem offenen Respirationskäfig unter Infrarotwärmelampen im Tierstall des Zentralen Isotopenlabors für Medizinische und Biologische Forschung der Universität Göttingen eingestallt. Gewichte und Alter der Versuchstiere am Tag der Applikation sind in Tabelle 7 aufgeführt.

Tabelle 7: Gewichte und Alter der Versuchstiere am Tag der Applikation

\begin{tabular}{|c|c|c|}
\hline Versuchstiere & Alter der Tiere (d) & Gewicht (g) \\
\hline 1 & 21 & 681,3 \\
\hline 2 & 21 & 667,1 \\
\hline 3 & 22 & 785,3 \\
\hline 4 & 25 & 737,3 \\
\hline
\end{tabular}

Aus Tabelle 7 ist ersichtlich, daß das Alter der ersten zwei Versuchstiere zum Zeitpunkt der Applikation 21 Tage betrug. Aus organisatorischen Gründen konnte die Aktivität beim 
dritten Versuchstier erst am 22. Lebenstag verabreicht werden. Das vierte Versuchstier wuchs langsamer als das vorherige Tier. Mit Rücksicht auf das geringere Gewicht, erfolgte die Markierung erst am 25. Lebenstag.

Die Temperatur in den Käfigen betrug durchschnittlich $25,0^{\circ} \mathrm{C}\left( \pm 2,1^{\circ} \mathrm{C}\right)$, die relative Luftfeuchte schwankte zwischen $65 \%$ und $80 \%$. Pelletiertes Futter und Wasser standen den Tieren bis zum Versuchsende ad libitum zur Verfügung.

\section{Futterzusammensetzung:}

Als Futter diente ein handelsübliches Alleinfuttermittel für Masthühnerküken (Firma Mega, Rechterfeld), daß aus den Komponenten Weizen, Sojaextraktionsschrot geschält und getrocknet, Mais, Rapsextraktionsschrot, Triticale, Maisfuttermittel, Tierfett, Pflanzenfett raffiniert und Erbsen bestand. Die Nährstoff- und Energiegehalte gehen aus Tabelle 8 hervor.

Tabelle 8: Nährstoff- und Energiegehalte des eingesetzten Alleinfuttermittels für Masthühnerküken

\begin{tabular}{|lrlr|}
\hline Rohnährstoffe & \multicolumn{3}{c|}{ Aminosäuren (g/kg Futtermittel) } \\
T (\%) & 90,9 & Methionin & 4,9 \\
Org. Substanz (in \% T) & 94,4 & Threonin & 6,1 \\
Rohasche & 5,6 & Lysin & 11,2 \\
Rohprotein & 23,3 & Arginin & 12,5 \\
Rohfett & 10,0 & \\
Rohfaser & 3,7 & Fettsäuren (in \% der Gesamtfettsäuren) \\
NfE & 57,4 & $12: 0=2$ & $14: 0=2$ \\
Stärke & 41,1 & $16: 0=23$ & $16: 1=3$ \\
Zucker & 5,5 & $18: 0=11$ & $18: 1=32$ \\
Org. Rest & 10,8 & $18: 2=21$ & restliche Fettsäuren $<1$ \\
& \\
MJ (ME)/kg T & \\
\multicolumn{4}{|}{} \\
Zugesetzte Stoffe (je kg Mischfutter) \\
12000 I.E. Vitamin A, 4000 I.E. Vitamin D3, 40 mg Vitamin E, \\
15 mg Kupfer, 110 mg Monensin-Natrium \\
\end{tabular}

\footnotetext{
${ }^{1}$ N-korrigiert nach WPSA (1984) für Geflügelmischfutter: $\mathrm{sME}(\mathrm{MJ} / \mathrm{kg})=(15,51 \mathrm{XP}+34,31 \mathrm{XL}+16,69 \mathrm{XS}+13,01 \mathrm{XZ}) \times 10^{-3}$

(Rohnährstoffe in $\mathrm{g} / \mathrm{kg}$ )
} 


\subsubsection{Vorbereitung und Applikation der Radiochemikalien}

$\underline{\text { Radiochemikalien }}$

- Phosphatidylcholin, L- $\alpha$-dipalmitoyl [cholin-methyl- ${ }^{14} \mathrm{C}$ ] (Biotrend, Nr. ARC-376)

- Phosphatidylcholin, L- $\alpha$-1-palmitoyl-2-linoleoyl-[linoleoyl-1- $\left.{ }^{14} \mathrm{C}\right]$ (Biotrend, Nr. ARC-853)

Die in Ethanol : Toluol (1:1) gelöste ${ }^{14} \mathrm{C}$ markierte Verbindung wurde einen Tag vor der Applikation mit einer Pipette aus der Transportkapsel in eine Gelatinekapsel überführt. Das Ethanol : Toluol wurde mit Stickstoff abgedampft, so daß lediglich das aktive Phosphatidylcholin in der Gelatinekapsel blieb. In die Transportkapsel wurden $100 \mu \mathrm{l}$ Ethanol gefüllt, 20 Minuten gewartet, dann das Ethanol in die Gelatinekapsel überführt und abgedampft. Der Vorgang mußte dreimal wiederholt werden um sicherzustellen, daß die gesamte ${ }^{14} \mathrm{C}$-Aktivität in die Gelatinekapsel überführt war.

Am Versuchstag wurde aus einer Gruppe von drei Broilern ein Tier ausgewählt, gewogen und mit der in der Gelatinekapsel eingewogenen ${ }^{14} \mathrm{C}$-markierten Verbindung per oral markiert, indem die Gelatinekapsel unter Zuhilfenahme einer Pinzette auf den hinteren Zungenteil gelegt und mit Wasser herunter gespült wurde. Tabelle 9 zeigt, wie die Versuche angeordnet waren.

Tabelle 9: $\quad$ Radiochemikalien, Versuchstiere und Tag der Markierung

\begin{tabular}{|l|c|c|}
\hline \multicolumn{1}{|c|}{ Radiochemikalien } & \multicolumn{1}{|c|}{$\begin{array}{c}\text { Versuchs- } \\
\text { tiere }\end{array}$} & $\begin{array}{c}\text { Datum der } \\
\text { Markierung }\end{array}$ \\
\hline $\begin{array}{l}\text { Phosphatidylcholin, L- } \alpha \text {-dipalmitoyl- } \\
{\left[\text { cholin-methyl- }{ }^{14} \mathrm{C}\right]}\end{array}$ & 1 & 07.02 .1998 \\
\hline $\begin{array}{l}\text { Phosphatidylcholin,L- } \alpha-1-\text { palmitoyl-2- } \\
\left.\text { linoleoyl-[linoleoyl-1- }{ }^{14} \mathrm{C}\right]\end{array}$ & 2 & 24.03 .1998 \\
\cline { 2 - 3 } & 4 & 26.03 .1998 \\
\hline
\end{tabular}

Den Versuchstieren eins und zwei wurde Phosphatidylcholin, L- $\alpha$-dipalmitoyl-[cholinmethyl- ${ }^{14} \mathrm{C}$ ] und den Versuchstieren drei und vier Phosphatidylcholin, L- $\alpha-1$-palmitoyl-2- 
linoleoyl-[linoleoyl-1- ${ }^{14} \mathrm{C}$ ] appliziert. Im direkten Anschluß an die Applikation wurde das jeweilige Versuchstier für 24 Stunden in den Respirationskäfig gesetzt (s. Abbildung 5).

\subsubsection{Radiorespirometrie}

Verwendete Chemikalien und Verbrauchsmaterialien:

- Chloroform (Merck, Nr. 2444)

- Methanol (Merck, Nr. 6012)

- NaCL (Merck, Nr. 6404)

- $\mathrm{NaOH}$ (Merck, Nr. 6498)

- 2,6-Di-tert-butyl-4-methyl-phenol - BHT (Merck, Nr. 822021)

- Gewebeauflöser - TS-1 (Fa. Zinsser)

- Szintillator - Lumasafe ${ }^{\mathrm{m}}$ Plus (Lumac * LSC B.V .Nr. 3097)

- Szintillationsfläschchen (Fa. Zinsser)

- Rundfilter (Schleicher \& Schüll, Nr. 604)

- Knf Laboport-Pumpe (Neuberger, Typ N840.3 FT.18)

\subsubsection{Versuchsanlage zur Messung der quantitativen ${ }^{14} \mathrm{C}$-Aktivitätsausschei- dung mit der Atemluft}

Zur Erfassung der quantitativen ${ }^{14} \mathrm{CO}_{2}$-Ausscheidung mit der Atemluft wurde die von EYO (1975) beschriebene, von LINGENS (1987) modifizierte, Versuchsanlage in modifizierter Weise aufgebaut. 


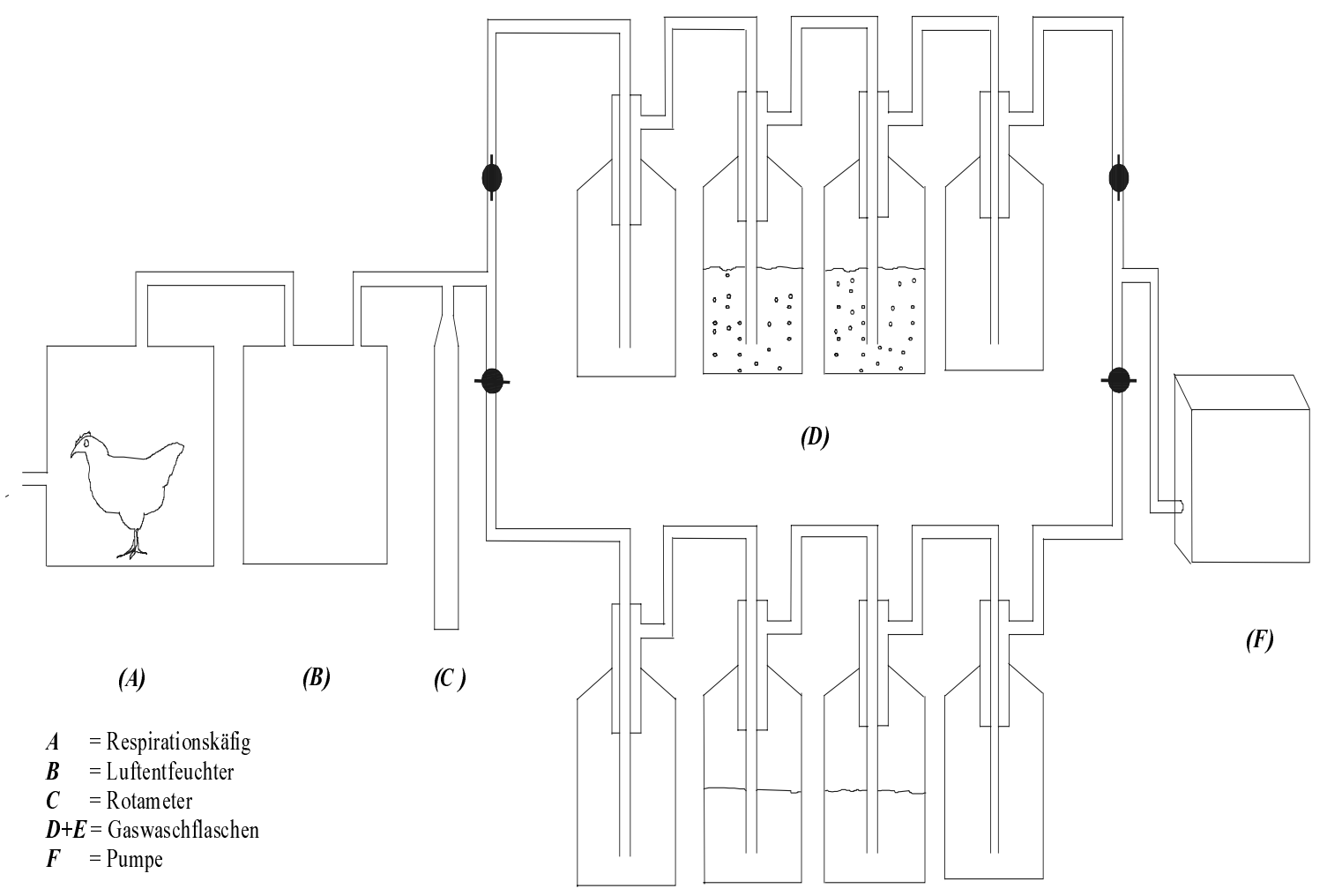

Abbildung 5: Schematische Darstellung der Versuchsanlage 
Als Respirationskäfig diente ein luftdicht verschließbarer Hartplastikkäfig. Die Kammerinnentemperatur betrug während des Versuchszeitraumes durchschnittlich $25,0^{\circ} \mathrm{C}\left( \pm 2,1^{\circ} \mathrm{C}\right)$. Eine Knf Laboport-Pumpe $(F)$ gewährleistete während der 24-stündigen Versuchszeit einen kontinuierlichen Luftstrom durch die Versuchsanlage.

Die aus dem Respirationskäfig $(A)$ gesogene Atemluft wurde durch einen Luftentfeuchter $(B)$ geleitet. Die entfeuchtete Luft durchströmte den Rotameter $(C)$, mit einer Geschwindigkeit des Luftstroms von 50 1/h. Die vom Rotameter kommende Luft wurde durch zwei mit $2 \mathrm{n} \mathrm{NaOH}$ gefüllte Gaswaschflaschen (Füllmenge je $200 \mathrm{ml}$ ) (D) geleitet und so das ${ }^{14} \mathrm{CO}_{2}$ gebunden. Das gewährleistete die quantitative Erfassung der ausgeatmeten ${ }^{14} \mathrm{C}$ Aktivität. Vor und hinter den mit 2n NaOH gefüllten Gaswaschflaschen war jeweils eine leere Sicherheits-Gaswaschflasche geschaltet, die überlaufendes $\mathrm{NaOH}$ auffangen sollte.

Um eine zeitliche Trennung der anfallenden ${ }^{14} \mathrm{CO}_{2}$-Ausscheidung zu ermöglichen, wurden die Gaswaschflaschen alle zwei Stunden ausgewechselt. Zur Erleichterung des Flaschenwechels wurden zwei Flaschen (E) parallel geschaltet, so daß beim Austausch der Luftstrom nur umgeleitet werden mußte.

Während des 24-stündigen radiorespiratorischen Versuches zur Erfassung der quantitativen

${ }^{14} \mathrm{C}$-Ausscheidung in der Atemluft nahmen die Broiler durchschnittlich $180 \pm 20 \mathrm{ml}$ Wasser und $63 \pm 10 \mathrm{~g}$ Futter auf.

\subsubsection{Aufarbeitung der Versuchstiere}

\section{Sammlung der Exkremente}

Nach Versuchsende erfolgte eine quantitative Sammlung der Exkremente aus dem Respirationskäfig. Die Exkremente wurden gewogen, durchmengt und bis zur anschließenden Analyse in geschlossenen Plastikbechern im Kühlraum $\left(+2^{\circ} \mathrm{C}\right)$ aufbewahrt.

\section{Töten und Zerlegen der Tiere}

Im direkten Anschluß an den radiorespiratorischen Versuch wurde das jeweilige Tier betäubt und durch Dekapitation getötet. Das Auffangen und Wiegen der Gesamtblutmenge erfolgte in einem Becherglas. Aus dem Glas wurde mit einer $10 \mathrm{ml}$ heparinisierten Spritze 
Blut entnommen, zentrifugiert (279,5 g für 10 Minuten) und somit in die Blutbestandteile getrennt.

Nach dem Ausbluten wurde das Tier mit einer Geflügelschere aufgeschnitten und mit Hilfe von Skapell und Pinzette in folgende Körperfraktionen (+ Exkremente) zerlegt:

-1 Muskelfleisch

-2 Abdominalfett

-3 Speiseröhre und Kropf

-4 Speiseröhren- und Kropfinhalt

-5 Drüsenmagen mit Inhalt

-6 Muskelmagen

-7 Muskelmageninhalt

-8 Dünndarm

-9 Dünndarminhalt

-10 Zwölffingerdarm mit Inhalt und Pankreas

-11 Blinddarm

-12 Dickdarm, Kloake mit Inhalt

-13 Leber

-14 Lunge
-15 Herz

-16 Nieren

-17 Gehirn

-18 Luftröhre

-19 Exkremente

-20 Haut und Federn

-21 Knochen

-22 Füße und Kopf

-23 Blinddarminhalt

-24 Milz

-25 Galle

-26 Serum

-27 feste Blutbestandteile

-28 Gesamtblut

Die einzelnen Körperfraktionen und Exkremente wurden gewogen und bis zur ${ }^{14} \mathrm{C}$-Analyse in Plastikbechern bei $+2^{\circ} \mathrm{C}$ gekühlt.

\section{Aufbereitung der Körperfraktionen und Exkremente:}

\section{Körperfraktionen (1-18) und Exkremente (19):}

Die Fraktionen wurden in Reagenzgläser überführt, nochmals gewogen und mit jeweils $1 / 3$ ihres Gewichtes aqua dest. versetzt. Um eine homogene Masse herzustellen, wurden die Proben mit einem Ultra Turrax (Ika Werk) homogenisiert. Die Kühlung der Reagenzgläser während des Homogenisierens minimierte die Gefahr eines Abbaus von Phospholipiden durch Hitze. Die Weiterverarbeitung der Homogenisate erfolgte, indem ein Teil der jewei- 
ligen Körperfraktion zur Aktivitätsbestimmung (3.1.3.4) und ein Teil zur Herstellung eines Lipidextraktes (3.1.3.5) genutzt wurde.

\section{Körperfraktionen (20-22)}

Die Körperfraktionen 20 (Haut und Federn), 21 (Knochen) und 22 (Füße und Kopf) wurden gewogen, in $500 \mathrm{ml}$ Einmachgläser, in die zuvor $50 \mathrm{ml}$ aqua dest. pipettiert wurde, überführt, mit Alufolie bedeckt und autoklaviert $\left(120^{\circ} \mathrm{C} / 1 \mathrm{~h}\right)$. Nach halbstündiger Abkühlzeit konnten die Körperfraktionen, wie bei den Fraktionen 1-19 beschrieben, zerkleinert und homogenisiert werden.

\section{Körperfraktionen (23-28)}

Aufgrund ihrer geringen Gewichtsanteile wurden die Körperfraktionen 23-25 ohne aqua dest.-Zusatz homogenisiert und direkt zur Aktivitätsbestimmung eingewogen.

Aus den festen Blutbestandteilen und dem Gesamtblut konnten nach der vorgenommenen Methode keine Lipidextrakte hergestellt werden, da sie bei der Extrkation klumpten. Lediglich das Serum stand zur Lipidextraktherstellung zur Verfügung.

\subsubsection{Weitere Analysenschritte der Körperfraktionen und Exkremente}

\subsubsection{Analysenschritte im Überblick}

$\underline{\text { Schema der weiteren Analysen }}$

Nach dem Aufarbeiten der Körperfraktionen und der Exkremente erfolgten die in der Abbildung 6 dargestellten Analysenschritte: 


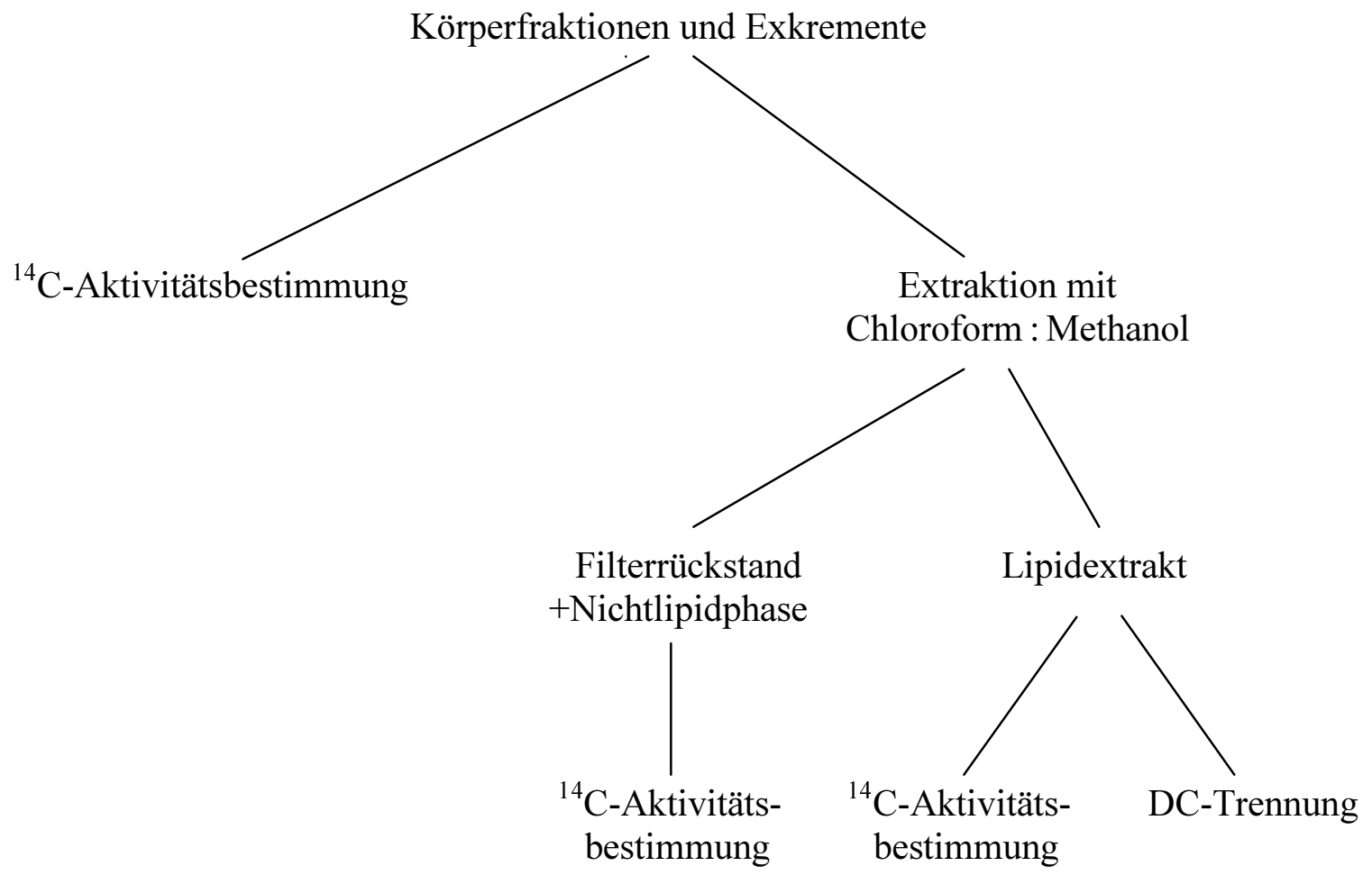

Abbildung 6: Analysenschritte der Körperfraktionen und der Exkremente

Ein Teil der jeweils aufgearbeiteten Fraktionen diente zur ${ }^{14} \mathrm{C}$-Aktivitätsbestimmung in der gesamten Fraktion (s. Kapitel 3.1.3.4).

Durch die

- Bestimmung der ${ }^{14} \mathrm{C}$-Aktivität in der Atemluft in den 24 Stunden nach der Markierung

- Bestimmung der ${ }^{14} \mathrm{C}$-Aktivität in den gesamten Körperfraktionen und die

- Bestimmung der ${ }^{14} \mathrm{C}$-Aktivität in den Exkrementen

war das Ermitteln der wiedergefundenen ${ }^{14} \mathrm{C}$-Aktivität möglich, auf die sich im weiteren bezogen wurde.

Ein weiterer Teil der aufgearbeiteten Fraktionen wurde für die Extraktion genutzt. In den bei der Extraktion entstandenen Nichtlipidphasen erfolgte die Messung ${ }^{14} \mathrm{C}$-Aktivität (s. Kapitel 3.1.3.5). Auch in den Lipidextrakten wurde die ${ }^{14} \mathrm{C}$-Aktivität bestimmt. Der ${ }^{14} \mathrm{C}$ Aktivitätsanteil in den Filterrückständen konnte rechnerisch ermittelt werden: 
Formel:

$$
\mathrm{F}=\mathrm{G}-(\mathrm{N}+\mathrm{L})
$$

wobei:

$$
\begin{aligned}
& \mathrm{F}={ }^{14} \mathrm{C} \text {-Aktivität im Filterrückstand/g EW } \\
& \mathrm{G}={ }^{14} \mathrm{C} \text {-Aktivität in der Fraktion/g EW } \\
& \mathrm{N}={ }^{14} \mathrm{C} \text {-Aktivität in der Nichtlipidphase/g EW } \\
& \mathrm{L}={ }^{14} \mathrm{C} \text {-Aktivität im Lipidextrakt/g EW }
\end{aligned}
$$

Die Lipidextrakte wurden dünnschichtchromatographisch getrennt (Abbildung 7):

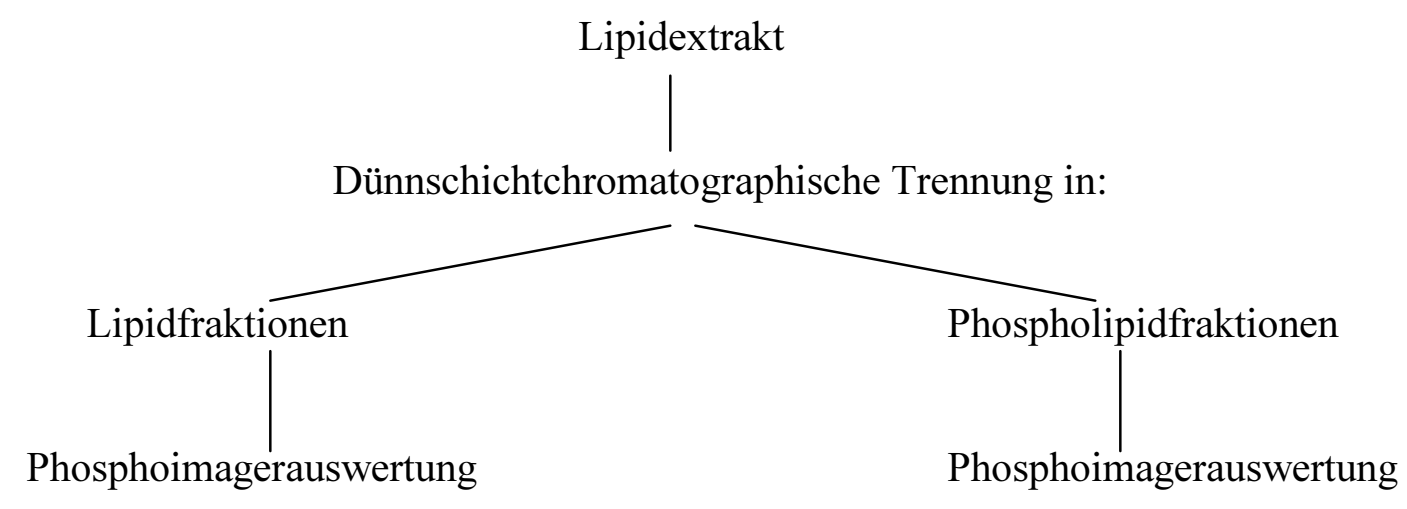

Abbildung 7: Analysenschritte der Lipidextrakte

$500 \mu \mathrm{l}-800 \mu \mathrm{l}$ der jeweiligen Lipidextrakte wurden dünnschichtchromatographisch in die Lipidfraktionen (FOLCH et al. 1957) getrennt und aus weiteren $500 \mu \mathrm{l}-800 \mu$ l erfolgte die Trennung in die Phospholipidfraktionen (GILFILLAN et al., 1983) (s. Kapitel 3.1.4.2). Die anschließende Phosphoimagerauswertung ermöglichte die Feststellung der Höhe an ${ }^{14} \mathrm{C}$-Aktivität in den getrennten Lipid- bzw. Phospholipidfraktionen.

\subsubsection{Allgemeines zu Aktivitätsmessungen}

Nach entsprechender Aufbereitung der Proben erfolgten die ${ }^{14} \mathrm{C}$-Aktivitätsbestimmungen in einem Flüssigkeitszintillationszähler (Packard Tri-Carb 2200 CA). Unter Berücksichtigung einer spezifischen automatischen Quenchkorrektur wurden die Werte in Verbindung 
mit dem jeweiligen Wirkungsgrad als Zerfälle pro Minute $=$ desintegrations per minute (dpm) ausgedruckt und in Bequerel (Bq) umgerechnet.

Berechnung der ${ }^{14} \mathrm{C}$-Aktivität

Nach Abzug des Nullwertes erfolgte die Berechnung der ${ }^{14} \mathrm{C}$-Aktivität auf Grund des aus den Doppelmessungen gewonnenen Mittelwertes unter Berücksichtigung von Einwaage und Verdünnung.

Formel:

${ }^{14} \mathrm{C}$-Aktivität $(\mathrm{Bq}) / \mathrm{Organ}=\frac{\mathrm{A}-\mathrm{NW}}{\mathrm{EW}} \times \mathrm{OA} \times \mathrm{OG}$

wobei:

$$
\begin{aligned}
\mathrm{A} & ={ }^{14} \mathrm{C} \text {-Aktivität }(\mathrm{Bq}) / \text { Probe } \\
\mathrm{NW} & ={ }^{14} \mathrm{C} \text {-Aktivität }(\mathrm{Bq}) / \text { Nullwert } \\
\mathrm{EW} & =\text { Einwaage }(\mathrm{g}) / \text { Probe } \\
\mathrm{OA} & =\text { Organanteil }(\%) / 100 \% \\
\mathrm{OG} & =\text { Organgewicht }(\mathrm{g})
\end{aligned}
$$

\subsubsection{Bestimmung der ${ }^{14} \mathrm{C}$-Aktivitätsausscheidung in der Atemluft}

Zur Ermittlung des im Versuchszeitraumes von 24 Stunden ausgeatmeten Gesamt- ${ }^{14} \mathrm{CO}_{2}$ wurden nach jeweils zwei Versuchsstunden die 2 x $200 \mathrm{ml} 2 \mathrm{n} \mathrm{NaOH}$ aus den Gaswaschflaschen mit aqua dest. in einen $500 \mathrm{ml}$ Meßkolben überführt, bis zur Eichmarke aufgefüllt und gut durchmischt. Von den jeweiligen $500 \mathrm{ml}$ wurden zwei Parallelproben à $1 \mathrm{ml}$ entnommen, in ein Szintillationsfläschchen gegeben, mit je $10 \mathrm{ml}$ Szintillator aufgefüllt und die ${ }^{14} \mathrm{C}$-Aktivität im Flüssigkeitszintillationszähler bestimmt. 
Vorversuche

Von allen Fraktionen (1-28) erfolgte die Bestimmung der Gesamtaktivität. In Vorversuchen wurden zwei Möglichkeiten zur Aktivitätsbestimmung ausgetestet. Das Lösen der Proben mit Gewebeauflöser und die Verbrennung im Oxymaten. Im Vorversuch erbrachte die Methode mit dem Gewebeauflöser eine höhere Zählausbeute als die Verbrennung im Oxymaten, so daß für die ${ }^{14} \mathrm{C}$-Aktivitätsmessungen bei den Körperfraktionen des ersten Versuchtieres mit Gewebeauflöser gearbeitet wurde. Da im Vorversuch der Gewebeauflöser nur an leicht löslichen Körperfraktionen wie Leber und Muskel getestet wurde, traten Probleme, die bei schwer löslichen Körperfraktionen (z.B. Luftröhre) entstanden, erst bei der Aufarbeitung der Körperfraktionen des ersten Versuchtieres auf. Daher wurden zusätzlich Messungen im Oxymaten vorgenommen, die insgesamt genauere Ergebnisse lieferten. Aus diesem Grund wurde bei der Aufarbeitung des zweiten, dritten und vierten Versuchstieres zur Aktivitätsbestimmung die Verbrennung im Oxymaten gewählt.

Verwendung von Gewebeauflöser

Von allen Körperfraktionen des ersten Versuchtieres wurden ca. $150 \mathrm{mg}-180 \mathrm{mg}$ zur ${ }^{14} \mathrm{C}$ Aktivitätsbestimmung mit je zwei Parallelen in Szintillationsfläschchen eingewogen, mit $0,1 \mathrm{ml}$ aqua dest. angefeuchet und $1 \mathrm{ml}$ Gewebeauflöser zugegeben. Die Gewebeauflösung dauerte im Wasserbad bei $50^{\circ} \mathrm{C}-60^{\circ} \mathrm{C}$, je nach Körperfraktion, 60 Minuten bis 12 Stunden. Nach Abkühlung auf Zimmertemperatur wurden die Proben in $10 \mathrm{ml}-20 \mathrm{ml}$ Szintillator aufgenommen und die ${ }^{14} \mathrm{C}$-Aktivität im Flüssigkeitszintillationszähler gemessen.

\section{Verbrennungen im Oxymaten}

Von allen Körperfraktionen des zweiten bis vierten Versuchstieres wurden je zwei Parallelen à ca. 250-300 mg (bei Galle und Blinddarminhalt soviel wie vorhanden war) in Verbrennungskapseln eingewogen. Diese wurden im Oxymaten (Intertechnique $1 \mathrm{~N}$ 4101) verbrannt, wobei das bei der Verbrennung freigewordene ${ }^{14} \mathrm{CO}_{2}$ in phenetylaminhaltige Szintillationsflüssigkeit absorbiert und im Flüssigkeitszintillationszähler die ${ }^{14} \mathrm{C}$-Aktivität bestimmt wurde. Zur Ermittlung der ${ }^{14} \mathrm{C}$-Aktivität/Organ mußte der durch externen Standard bei der Oxymatmessung ermittelte Wirkungsgrad berücksichtigt werden. Außerdem 
mußte der bei der Aufbereitung der Körperfraktionen (Kap. 3.1.2.2) zugesetzte aqua dest.Anteil abgezogen werden.

Formel:

${ }^{14} \mathrm{C}$-Aktivität $(\mathrm{Bq}) /$ Organ $=\frac{\frac{\mathrm{AE} \times \mathrm{P}}{\mathrm{WG}}}{\mathrm{EW}} \times \mathrm{OA} \times \mathrm{OG}$

wobei:

$$
\begin{array}{ll}
\mathrm{AE} & ={ }^{14} \mathrm{C} \text {-Aktivität }(\mathrm{Bq}) / \text { Einwaage }(\mathrm{g}) \\
\mathrm{P} & =100 \% \\
\mathrm{EW} & =\text { Einwaage }(\mathrm{g}) \\
\mathrm{WG} & =\text { Wirkungsgrad }(\%) \\
\mathrm{OA} & =\text { Organanteil }(\%) / 100 \% \\
\mathrm{OG} & =\text { Organgewicht }(\mathrm{g})
\end{array}
$$

\subsubsection{Herstellung der Lipidextrakte und ${ }^{14} \mathrm{C}$-Aktivitätsbestimmungen in den Nichtlipidphasen und den Lipidextrakten}

Nach modifizierter Methode von FOLCH et al. (1957) wurden Lipidextrakte hergestellt. Von jedem der Homogenisate und vom Serum wurde je $1 \mathrm{~g}$ in ein $20 \mathrm{ml}$ Reagenzglas mit Schliff eingewogen, 7,5 ml Chloroform : Methanol (2:1) zugegeben und das Glas verschlossen. Zum Lösen der Lipide kam das Reagenzglas dreimal für 10 Sekunden auf einen Rüttler (dazwischen jeweils eine Minute Ruhe). Die durchmischte Probe wurde mit Hilfe einer Wasserstrahlpumpe durch einen mit Filterpapier ausgelegten Keramikfilter in einen Glasmeßzylinder mit Schliff filtriert. Zusätzlich erfolgte ein dreimaliges Nachspülen des Reagenzglases mit jeweils 2,5 ml Chloroform : Methanol (2 : 1). Die im Glasmeßzylinder befindliche Filtratmenge wurde abgelesen. Um eine Phasentrennung zu bekommen mußte zur Filtratmenge $20 \%$ 0,73 \%-ige $\mathrm{NaCl}$ zugegeben werden. Die Probe wurde mit einem Glasstopfen verschlossen, leicht geschwenkt und für 15 Stunden in den Kühlraum $+2{ }^{\circ} \mathrm{C}$ gestellt. 
Nach Ablauf der 15 Stunden hatten sich zwei Phasen gebildet. Die obere Phase, in der sich das Methanol, Wasser und die nicht Chloroform löslichen Stoffe befanden und die untere Phase, die die in Chloroform gelösten Lipide enthielt.

Bevor die obere Nichtlipidphase abgesaugt werden konnte, mußte ihr Anteil am Gesamtinhalt vom Glasmeßzylinder abgelesen und zwei Proben à $1 \mathrm{ml}$ für die ${ }^{14} \mathrm{C}$-Aktivitätsbestimmung in Szintillationsfläschchen pipettiert werden. Die Fläschchen wurden mit $10 \mathrm{ml}$ Szintillator aufgefüllt und die ${ }^{14} \mathrm{C}$-Aktivität im Flüssigkeitszintillationszähler ermittelt. Die ermittelte ${ }^{14} \mathrm{C}$-Aktivität der Nichtlipidphase bildete, zusammen mit der ${ }^{14} \mathrm{C}$-Aktivität der bei der Extraktion entstandenen Filterrückstände, den Nichtlipidanteil.

Nachdem die restliche obere Phase mit einer Pasteurpipette abgesaugt war, mußte die untere Phase aus den Glasmeßzylinder in einen $25 \mathrm{ml}$ Rundkolben überführt werden. Ein zweimaliges Nachspülen des Glasmeßzylinders mit jeweils 2,5 ml Methanol überführte die restliche Chloroformphase in den Rundkolben. Die Probe im Rundkolben wurde am Rotationsverdampfer eingeengt, wieder 2,5 $\mathrm{ml}$ Methanol zugegeben und nochmals eingeengt. Nach dreimaliger Wiederholung des Vorganges wurden die im Rundkolben verbliebenen Lipide mit Choloroform : Methanol (95:5) mit 0,005 \% BHT aufgenommen und in ein $2 \mathrm{ml}$ Glasgefäß mit Glasstopfen überführt.

Von dem Lipidextrakt wurden zwei Proben à $50 \mu \mathrm{l}$ zur ${ }^{14} \mathrm{C}$-Aktivitätsbestimmung in ein Szintillationsfläschchen entnommen, mit $10 \mathrm{ml}$ Szintillator aufgefüllt und mit dem Flüssigkeitszintillationszähler bestimmt. Die Lipidextrakte wurden bis zur weiteren Aufarbeitung bei $-20^{\circ} \mathrm{C}$ gelagert.

\subsubsection{Dünnschichtchromatographie}

\subsubsection{Vorbereitungen für dünnschichtchromatographische Trennungen}

Chemikalien und Verbrauchsmaterialien

- Chloroform (Merck, Nr. 2444)

- Hexan (Merck, Nr. 822280)

- Methanol (Merck, Nr. 6012)

- Essigsäure (Merck, Nr. 63) 
- Petrolether (Baker, Nr. 8166)

- Diethylether (Baker, Nr. 8033)

- Borsäure (Merck, Nr. 165)

- Dünnschichtchromatorgraphie-Platten (Merck, Nr. 5715),

Kieselgel 60 F254

Schichtdicke: $210-270 \mu \mathrm{m}$

Größe: $20 \mathrm{~cm} \mathrm{x} 20 \mathrm{~cm}$

$\underline{\text { Standards }}$

- Lecithin (Lukas Meyer)

- Ölsäure (Sigma, Nr. 01008)

- Olivenöl (Aldi)

- Cholesterinoleat (Acros, Nr. 16584-0050)

- Lysophosphatidylcholin (Sigma, Nr. 4129)

- Lysophosphatidylethanolamin (Sigma, Nr. 1506)

- Phosphatidylcholin (Sigma, Nr. 3556)

- Phosphatidylethanolamin (Sigma, Nr. 8193)

- Phosphatidylinosit (Sigma, Nr. 8443)

- Phosphatidylserin (Sigma, Nr. 7769)

- Cardiolipin (Sigma, Nr. 5646)

Einteilung der Dünnschichtchromatographie-Platten

Auf den $20 \mathrm{~cm}$ x $20 \mathrm{~cm}$ großen Dünnschichtchromatographie-Platten wurden von der linken Plattenkante aus nach einem und $19 \mathrm{~cm}$ die Seitenränder und nach $10 \mathrm{~cm}$ eine Mittellinie gezogen. Die Startlinie lag $1 \mathrm{~cm}$ und die Laufmittelfront $17 \mathrm{~cm}$ oberhalb der unteren Plattenkante (Abbildung 8).

So ergaben sich zweigeteilte Platten mit Laufmittelfronten von $2 \mathrm{~cm} \times 9 \mathrm{~cm}$ und Laufmittellängen von $16 \mathrm{~cm}$. Auf den Dünnschichtchromatographie-Platten konnten somit jeweils zwei Proben nebeneinander aufgetragen und dünnschichtchromatographisch getrennt werden. 


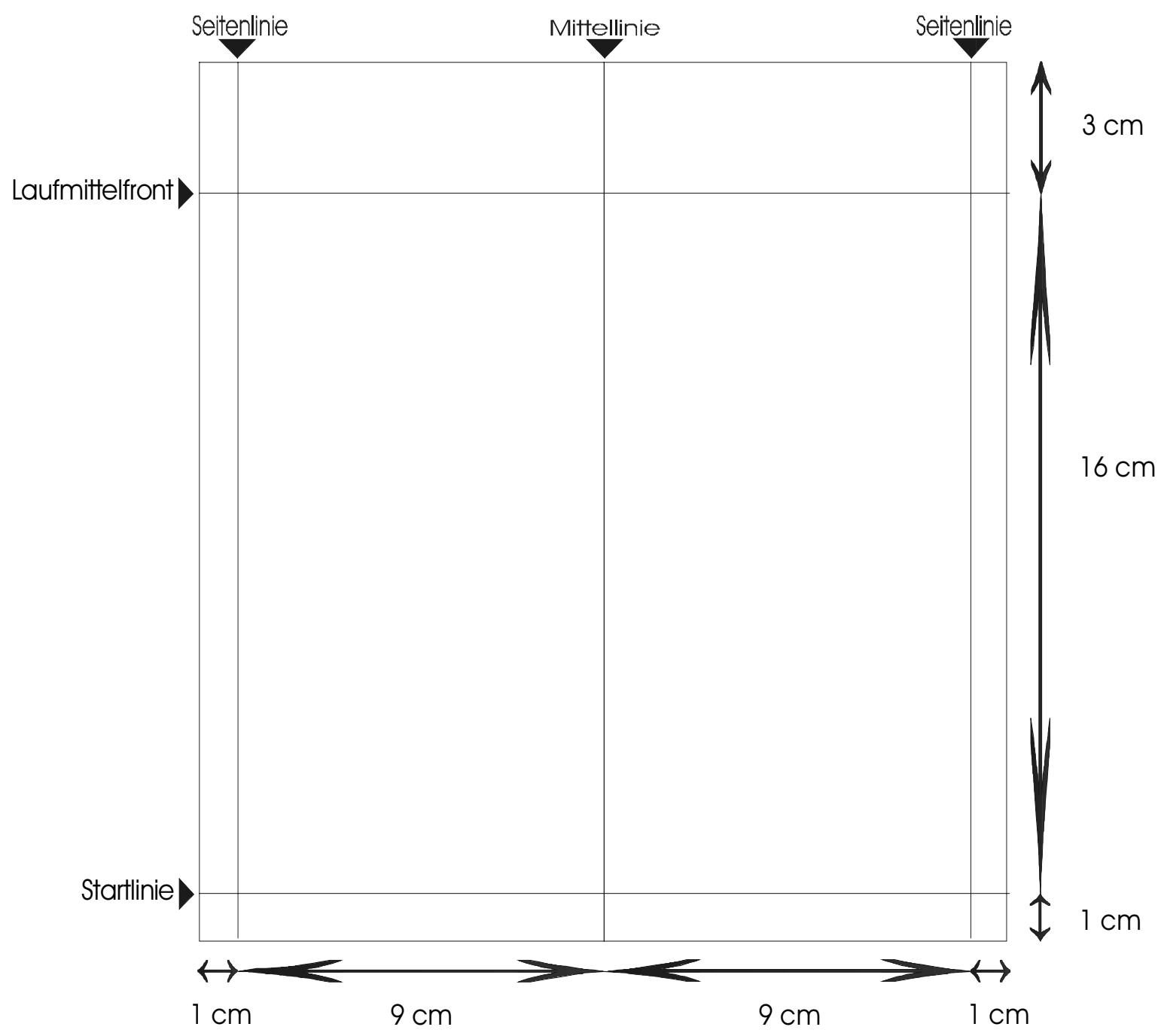

Abbildung 8: Einteilung der Dünnschichtchromatographie-Platten

\subsubsection{Angewandte Methoden zur Trennung der Lipidextrakte}

Von allen Lipidextrakten erfolgte eine dünnschichtchromatographische Trennung der Lipidfraktionen nach FOLCH et al. (1957) und eine Trennung der Phospholipidfraktionen nach GILFILLAN et al. (1983). Die zwei Methoden sind in der Tabelle 10 vergleichend dargestellt. 
Tabelle 10: Vergleich von Laufmittel, Laufzeit und getrennten Lipidfraktionen zweier dünnschichtchromatographischer Trennmethoden

\begin{tabular}{|l|l|l|}
\hline & \multicolumn{2}{|c|}{ Methoden } \\
\hline Trennung der: & Lipidfraktionen & Phospholipidfraktionen \\
\hline Laufmittel: & $\begin{array}{l}70 \text { Teile Petrolether } \\
30 \text { Teile Diethylether } \\
1 \text { Teil Essigsäure }\end{array}$ & $\begin{array}{l}\text { 40 Teile Chloroform } \\
30 \text { Teile Hexan } \\
\text { 20 Teile Methanol } \\
10 \text { Teile Essigsäure } \\
1,8 \text { Teile Borsäure }\end{array}$ \\
\hline Trennung in Lipidfraktionen: & $\begin{array}{l}\text { Phospholipide } \\
\text { Polymere } \\
\text { freie Fettsäuren } \\
\text { Triacylglyceride } \\
\text { Cholesterinester }\end{array}$ & $\begin{array}{l}\text { Lysophosphatidylcholin } \\
\text { Lysophosphatidylethanolamin } \\
\text { Phosphatidylcholin } \\
\text { Phosphatidylethanolamin } \\
\text { Phosphatidylinosit } \\
\text { Phosphatidylserin } \\
\text { Cardiolipin } \\
\text { Triacylglyceride }\end{array}$ \\
\hline Laufzeit: & \begin{tabular}{l} 
90 Minuten \\
\hline
\end{tabular} &
\end{tabular}

Vor Gebrauch wurden die Dünnschichtchromatographie-Platten bei $60^{\circ} \mathrm{C}$ aktiviert. Abhängig von der ${ }^{14} \mathrm{C}$-Aktivität der Lipidextrakte wurden 500-800 $\mu$ l mit einer Hamiltonspritze auf die Startlinie aufgetragen. Die präparierten Dünnschichtchromatographie-Platten wurden in die Dünnschichtkammern mit täglich neu angesetzten Laufmitteln gestellt und nach Beendigung der Laufzeit für vier Stunden bei $60^{\circ} \mathrm{C}$ in den Trockenschrank gelegt. Anschließend wurden die Platten mit 0,2 \% 2,7-Dichlorflurescin besprüht und somit die getrennten Banden unter UV-Licht sichtbar gemacht. 


\subsubsection{Erstellung von Standardplatten}

In Vorversuchen wurden Messungen für die Trennmethoden mit Standardsubstanzen durchgeführt, um die in den Lipidextrakten getrennten Lipidfraktionen richtig zuordnen zu können.

\section{$\underline{\text { Standardplatte 1: Trennung der Lipidfraktionen }}$}

Als Standards dienten:
1. Lecithin
Bestimmung von Phospholipiden
2. Dimere/Trimere
Bestimmung von Polymeren
3. Palmitinsäure
Bestimmung von freien Fettsäuren
4. Olivenöl
Bestimmung von Triacylglyceriden
5. Cholesterinoleat Bestimmung von Cholesterinestern

Auf die Dünnschichtchromatographie-Platten wurden die Standards in der angebenen Reihenfolge (1-5) aufgetragen (Abbildung 9).

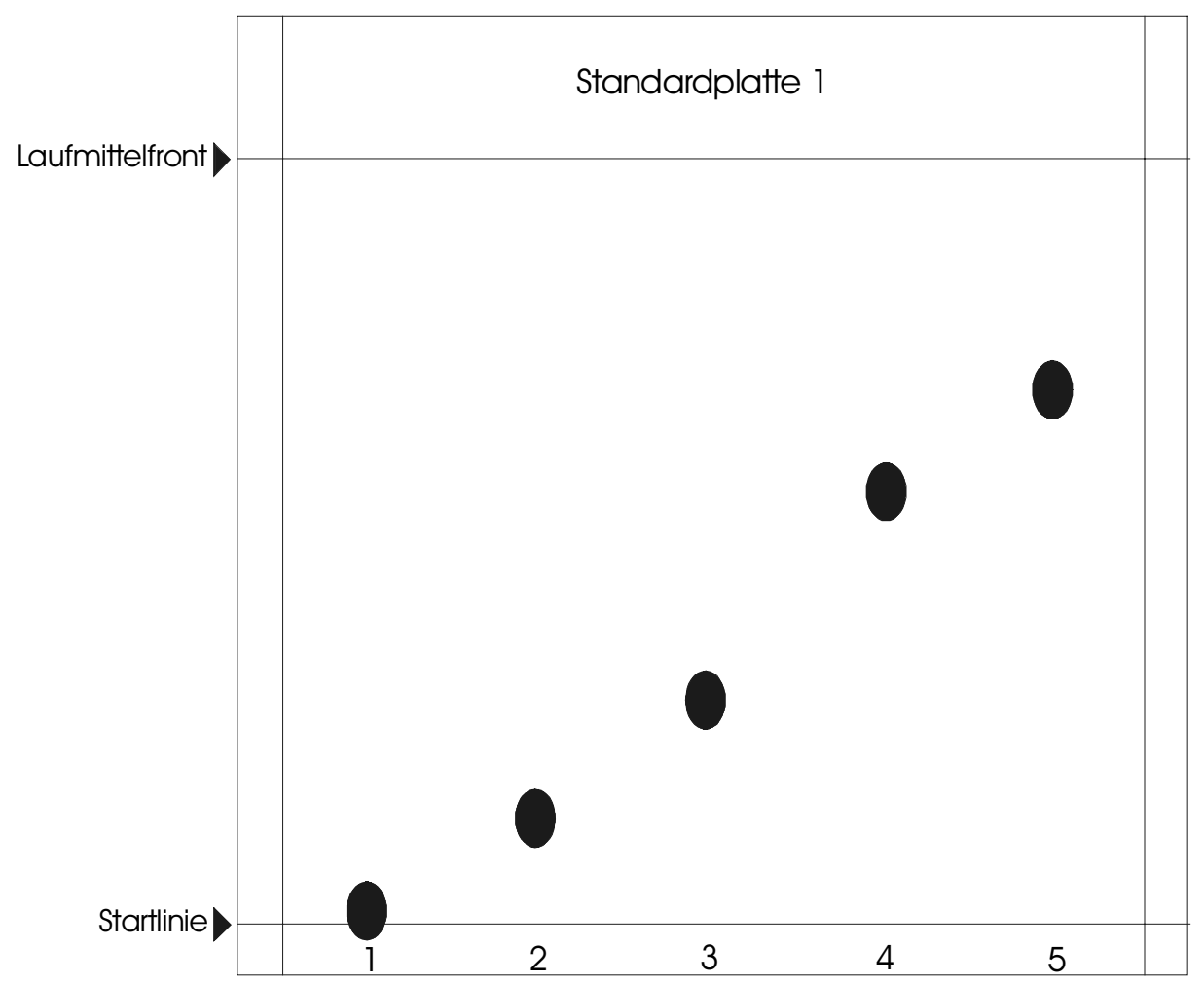

Abbildung 9: Standardplatte zur Bestimmung von Phospholipiden (1), Polymeren (2), freie Fettsäuren (3), Triacylglyceriden (4) und Cholesterinestern (5) 
$\underline{\text { Standardplatte 2: Trennung der Phospholipidfraktionen }}$

Als Standards dienten:

1. Lysophosphatidylcholin

2. Lysophosphatidylethanolamin

3. Phosphatidylcholin

4. Phosphatidylethanolamin

5. Phosphatidylinosit

6. Phosphatidylserin

7. Cardiolipin

8. Olivenöl (Triacylglyceride)

Auf der Dünnschichtchromatographie-Platten wurden die Standards in der angebenen Reihenfolge (1-8) aufgetragen (Abbildung 10).

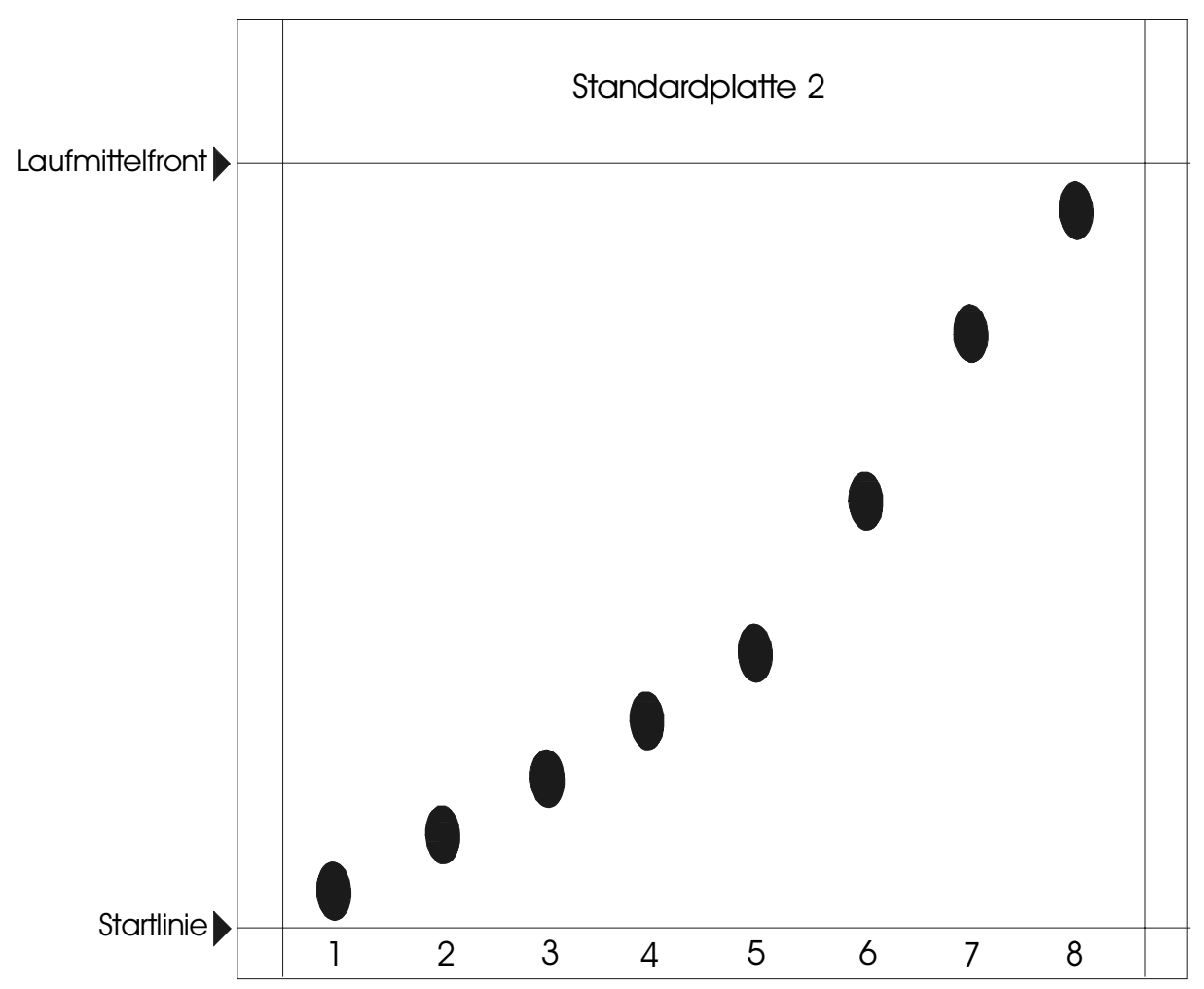

Abbildung 10: Standardplatte zur Bestimmung von Lysophosphatidylcholin (1), Lysophosphatidylethanolamin (2), Phosphatidylcholin (3), Phosphatidylethanolamin (4), Phosphatidylinosit (5), Phosphatidylserin (6), Cardiolipin (7) und Triacylglyceriden (8) 
Bei der Trennung der Lipidextrakte konnte ermittelt werden, ob bzw. wie hoch der relative ${ }^{14} \mathrm{C}$-Aktivitätsanteil in der jeweiligen Phospholipidfraktion war. Weiterführend ermöglichte die dünnschichtchromatographische Phospholipidtrennung die Ermittlung, auf welche Phospholipide sich die ${ }^{14} \mathrm{C}$-Aktivität in der Phospholipidfraktion verteilte. Da die Fraktionen Lysophosphatidylcholin und Lysophosphatidylethanolamin auf der Dünnschichtchromatographie-Platte nicht exakt trennbar waren, wurden beide Fraktionen zusammen als Lysophosphatidylfraktionen in den Ergebnissen dargestellt.

\subsubsection{Ermittlung der ${ }^{14}$ C-Aktivität nach dünnschichtchromatographischer Auftrennung}

Jeweils zwei der getrockneten Dünnschichtchromatographie-Platten wurden nebeneinander in eine handelsübliche Röntgencassette gelegt und mit einer Imager Platte (BAS-1lls 2040, Fujifilm) bedeckt. Die Cassette wurde geschlossen und, je nach Höhe der auf den Dünnschichtplatten aufgetragenen ${ }^{14} \mathrm{C}$-Aktivität, zwei bis sechs Tage in eine Bleibox gelegt. Das Lagern in der Bleibox diente dazu die Untergrundstrahlung zu unterbinden. Nach Ablauf der Expositionszeit wurde die Imager Platte im Scanner (BAS-1500-Gerät, Fujifilm) ausgelesen. Die Ergebnisse der Imager Platte wurden mit dem Tina 2.0 Programm ausgewertet. Die Lipidfraktionen die ${ }^{14} \mathrm{C}$-Aktivität enthielten, konnten unter Zuhilfenahme der Standardplatten identifiziert werden. Aus den ${ }^{14} \mathrm{C}$-Aktivitätsmessungen der Lipidextrakte war die auf die Dünnschichtchromatographie-Platten aufgetragene Aktivität bekannt. Mit Hilfe des Tina 2.0 Programmes wurde eine Kalibrierungskurve für jede aufgetragene Probe erstellt. Dazu wurde die aufgetragene Aktivität pro Platte und ein Leerwert gleich Null eingegeben. Danach ermittelte das Tina 2.0 Programm, wieviel ${ }^{14} \mathrm{C}$-Aktivität in den jeweiligen Lipid- bzw. Phospholipidfraktionen auf der Dünnschichtchromatographie-Platte festzustellen war. 
Die Versuchsergebnisse wurden folgenderweise dargestellt. Die Ergebnisse der Untersuchungen der ersten zwei Versuchstiere, deren Markierung mit Phosphatidylcholin, L- $\alpha$ dipalmitoyl [cholin-methyl- ${ }^{14} \mathrm{C}$ ] erfolgte, wurden als PC-Cholin- $-{ }^{14} \mathrm{C}$ Tiere bezeichnet. Die Ergebnisse der Untersuchungen mit den Versuchstieren drei und vier, deren Markierung mit Phosphatidylcholin, L- $\alpha$-1-palmitoyl-2-linoleoyl-[linoleoyl-1- ${ }^{14} \mathrm{C}$ ] erfolgte, wurden als PC-Linolsäure- ${ }^{14} \mathrm{C}$ Tiere bezeichnet.

\subsection{Gewichte der Fraktionen der Versuchstiere}

\subsection{1}

PC-Cholin- ${ }^{14} \mathrm{C}$ Tiere

Die direkt nach der Tötung ermittelten Gewichte einzelner Fraktionen der Versuchstiere eins und zwei und ihr relativer Anteil an der Summe aller Fraktionen werden in Tabelle 11 aufgeführt.

Die Versuchstiere eins und zwei, bei denen die Markierung mit PC-Cholin- ${ }^{14} \mathrm{C}$ erfolgte, wurden jeweils am 22. Lebenstag getötet. Sie wiesen annähernd übereinstimmende Gesamtgewichte auf. Die Abweichungen der Gewichte der jeweils gleichen Fraktionen beider Tiere waren sehr gering.

Der weitaus größte relative Anteil des gesamten Gewichtes aller Fraktionen erstreckte sich mit 30,0 \% beim ersten Broiler und 33,3 \% beim zweiten Broiler auf die Muskulatur. Ein erheblicher Teil des Gesamtgewichtes beruhte mit 16,3 \% bzw. 15,4 \% auf dem hohen Knochengewicht und dem Gewichtsanteil an Haut und Federn von über 14,3 \%. Das erste Versuchstier enthielt mit 20,2 g einen um 14,3 g höheren Abdominalfettanteil als das zweite Versuchstier. Bei der Berechnung des relativen Anteils am gesamten Gewicht aller Fraktionen wirkte sich das allerdings nur auf einen prozentualen Unterschied von 1,9\% aus. 
Tabelle 11: Absolute Gewichte (g) einzelner Fraktionen und ihr relativer Anteil (\%) an der Summe aller Fraktionen der PC-Cholin- ${ }^{14} \mathrm{C}$ Tiere

\begin{tabular}{|c|c|c|c|c|}
\hline \multirow{3}{*}{$\begin{array}{l}\text { Körperfraktionen } \\
\text { und Exkremente }\end{array}$} & \multicolumn{4}{|c|}{ PC-Cholin- ${ }^{14} \mathrm{C}$} \\
\hline & \multicolumn{2}{|c|}{ 1. Versuchstier } & \multicolumn{2}{|c|}{ 2. Versuchstier } \\
\hline & $\mathrm{g}$ & $\%$ & $\mathrm{~g}$ & $\%$ \\
\hline Muskel & 221,4 & 30,0 & 246,2 & 33,3 \\
\hline Abdominalfett & 20,2 & 2,7 & 5,9 & 0,8 \\
\hline Speiseröhre und Kropf & 8,1 & 1,1 & 5,3 & 0,7 \\
\hline Speiseröhren- und Kropfinhalt & 5,6 & 0,8 & 1,6 & 0,2 \\
\hline Drüsenmagen mit Inhalt & 4,6 & 0,6 & 4,2 & 0,6 \\
\hline Muskelmagen & 17,4 & 2,4 & 17,2 & 2,3 \\
\hline Muskelmageninhalt & 7,3 & 1,0 & 5,8 & 0,8 \\
\hline Dünndarm & 20,1 & 2,7 & 20,5 & 2,8 \\
\hline Dünndarminhalt & 11,8 & 1,6 & 10,4 & 1,4 \\
\hline Zwölffingerdarm* & 10,4 & 1,4 & 10,3 & 1,4 \\
\hline Blinddarm & 2,6 & 0,3 & 3,6 & 0,5 \\
\hline Dickdarm, Kloake mit Inhalt & 9,0 & 1,2 & 6,0 & 0,8 \\
\hline Leber & 18,4 & 2,5 & 22,2 & 3,0 \\
\hline Lunge & 3,7 & 0,5 & 3,6 & 0,5 \\
\hline Herz & 4,0 & 0,5 & 5,4 & 0,7 \\
\hline Nieren & 5,5 & 0,8 & 6,5 & 0,9 \\
\hline Gehirn & 1,6 & 0,2 & 0,9 & 0,1 \\
\hline Luftröhre & 1,6 & 0,2 & 2,5 & 0,4 \\
\hline Exkremente & 59,0 & 8,0 & 71,7 & 9,7 \\
\hline Haut und Federn & 107,5 & 14,6 & 105,8 & 14,3 \\
\hline Knochen & 120,1 & 16,3 & 114,0 & 15,4 \\
\hline Füße und Kopf & 56,5 & 7,7 & 56,1 & 7,6 \\
\hline Blinddarminhalt & 1,6 & 0,2 & 1,2 & 0,2 \\
\hline Milz & 0,3 & 0,0 & 0,9 & 0,1 \\
\hline Galle & 0,4 & 0,1 & 0,1 & 0,0 \\
\hline Serum & 4,0 & 0,5 & 3,0 & 0,4 \\
\hline feste Blutbestandteile & 2,0 & 0,3 & 6,0 & 0,8 \\
\hline Blut & 13,5 & 1,8 & 1,9 & 0,3 \\
\hline Summe aller Fraktionen & 738,2 & 100,0 & 738,8 & 100,0 \\
\hline
\end{tabular}

*mit Inhalt und Pankreas

Tabelle 11 verdeutlicht weiterhin, daß die Fraktionen Exkremente, Füße und Kopf beider Tiere mit relativen Gewichtsanteilen von 7,6 \% bis 9,7\% im Gegensatz zu den übrigen Fraktionen noch bedeutende Gewichtsanteile bei den jeweiligen Broilern aufwiesen. Die übrigen Fraktionen hatten nur relative Gewichtsanteile zwischen $0,1 \%$ bis 2,7 \%. 


\subsubsection{PC-Linolsäure- ${ }^{14} \mathrm{C}$ Tiere}

Die direkt nach der Tötung ermittelten Gewichte der einzelnen Fraktionen der Versuchstiere drei und vier und ihr relativer Anteil an der Summe aller Fraktionen werden in Tabelle 12 aufgeführt.

Tabelle 12: Absolute Gewichte (g) einzelner Fraktionen und ihr relativer Anteil (\%) an der Summe aller Fraktionen der PC-Linolsäure- ${ }^{14} \mathrm{C}$ Tiere

\begin{tabular}{|c|c|c|c|c|}
\hline \multirow{3}{*}{$\begin{array}{l}\text { Körperfraktionen } \\
\text { und Exkremente }\end{array}$} & \multicolumn{4}{|c|}{ PC-Linolsäure- ${ }^{14} \mathrm{C}$} \\
\hline & \multicolumn{2}{|c|}{ 3. Versuchstier } & \multicolumn{2}{|c|}{ 4. Versuchstier } \\
\hline & g & $\%$ & $\mathrm{~g}$ & $\%$ \\
\hline Muskel & 295,7 & 33,4 & 272,7 & 33,0 \\
\hline Abdominalfett & 15,5 & 1,8 & 2,2 & 0,3 \\
\hline Speiseröhre und Kropf & 6,4 & 0,7 & 3,8 & 0,5 \\
\hline Speiseröhren- und Kropfinhalt & 0,6 & 0,1 & - & - \\
\hline Drüsenmagen mit Inhalt & 4,9 & 0,6 & 3,4 & 0,4 \\
\hline Muskelmagen & 15,8 & 1,8 & 14,6 & 1,8 \\
\hline Muskelmageninhalt & 8,5 & 1,0 & 6,8 & 0,8 \\
\hline Dünndarm & 27,0 & 3,1 & 22,7 & 2,7 \\
\hline Dünndarminhalt & 21,1 & 2,4 & 23,2 & 2,8 \\
\hline Zwölffingerdarm* & 13,4 & 1,5 & 12,6 & 1,5 \\
\hline Blinddarm & 4,8 & 0,5 & 4,1 & 0,5 \\
\hline Dickdarm, Kloake mit Inhalt & 6,8 & 0,8 & 7,0 & 0,8 \\
\hline Leber & 26,9 & 3,0 & 18,0 & 2,2 \\
\hline Lunge & 5,5 & 0,6 & 3,4 & 0,4 \\
\hline Herz & 5,6 & 0,6 & 4,0 & 0,5 \\
\hline Nieren & 6,7 & 0,8 & 1,9 & 0,2 \\
\hline Gehirn & 2,1 & 0,2 & 1,7 & 0,2 \\
\hline Luftröhre & 2,3 & 0,3 & 1,5 & 0,2 \\
\hline Exkremente & 99,6 & 11,3 & 88,4 & 10,7 \\
\hline Haut und Federn & 127,9 & 14,5 & 100,5 & 12,2 \\
\hline Knochen & 101,7 & 11,4 & 148,4 & 18,0 \\
\hline Füße und Kopf & 62,5 & 7,1 & 62,4 & 7,6 \\
\hline Blinddarminhalt & 3,7 & 0,4 & 3,4 & 0,4 \\
\hline Milz & 1,3 & 0,1 & 0,5 & 0,1 \\
\hline Galle & 0,4 & 0,0 & 0,1 & 0,0 \\
\hline Serum & 3,0 & 0,3 & 5,0 & 0,6 \\
\hline feste Blutbestandteile & 6,0 & 0,7 & 5,0 & 0,6 \\
\hline Blut & 9,2 & 1,0 & 8,4 & 1,0 \\
\hline Summe aller Fraktionen & 884,9 & 100,0 & 825,7 & 100,0 \\
\hline
\end{tabular}

*mit Inhalt und Pankreas 
Wie aus Tabelle 12 ersichtlich ist, wog das dritte Versuchstier bei der Tötung am 22. Lebenstag 59,2 g mehr als das Vierte, obwohl dieses erst am 25. Lebenstag getötet wurde. Bei dem vierten Versuchstier wurde angenommen, daß es aufgrund veränderter klimatischer Bedingungen langsamer wuchs als die Anderen. Trotzdem wurde nach der Schlachtung zusätzlich die Tiergesundheit überprüft und bestätigt.

Die Muskulatur beider Versuchstiere erwies sich mit einem relativen Anteil am Gesamtgewicht aller Fraktionen von über $30 \%$ als größte Fraktion. Wie bei den Tieren, die mit PC-Cholin- ${ }^{14} \mathrm{C}$ markiert wurden (Tabelle 11), besaßen auch die Fraktionen Haut und Federn, Knochen und Exkremente der Versuchstiere drei und vier die zweit- bis viertgrößten relativen Anteile am Gesamtgewicht aller Fraktionen. Auffallend war, daß die Fraktion Knochen des vierten Versuchstieres mit 18,0 \% einen 6,6 \% höheren Anteil erkennen ließ, als die Fraktion des dritten Tieres.

\section{Verlauf der ${ }^{14} \mathrm{C}$-Aktivität in der Atemluft}

\subsection{1}

\section{PC-Cholin- ${ }^{14} \mathrm{C}$ Tiere}

Der zeitliche Verlauf der Höhe der gemessenen ${ }^{14} \mathrm{C}$-Ausscheidung in der Atemluft wird, in Abbildung 11 für die Versuchstiere, die mit PC-Cholin- $-{ }^{14} \mathrm{C}$ markiert wurden und in Abbildung 12 für die Versuchstiere, die mit PC-Linolsäure- ${ }^{14} \mathrm{C}$ markiert wurden, dargestellt. 


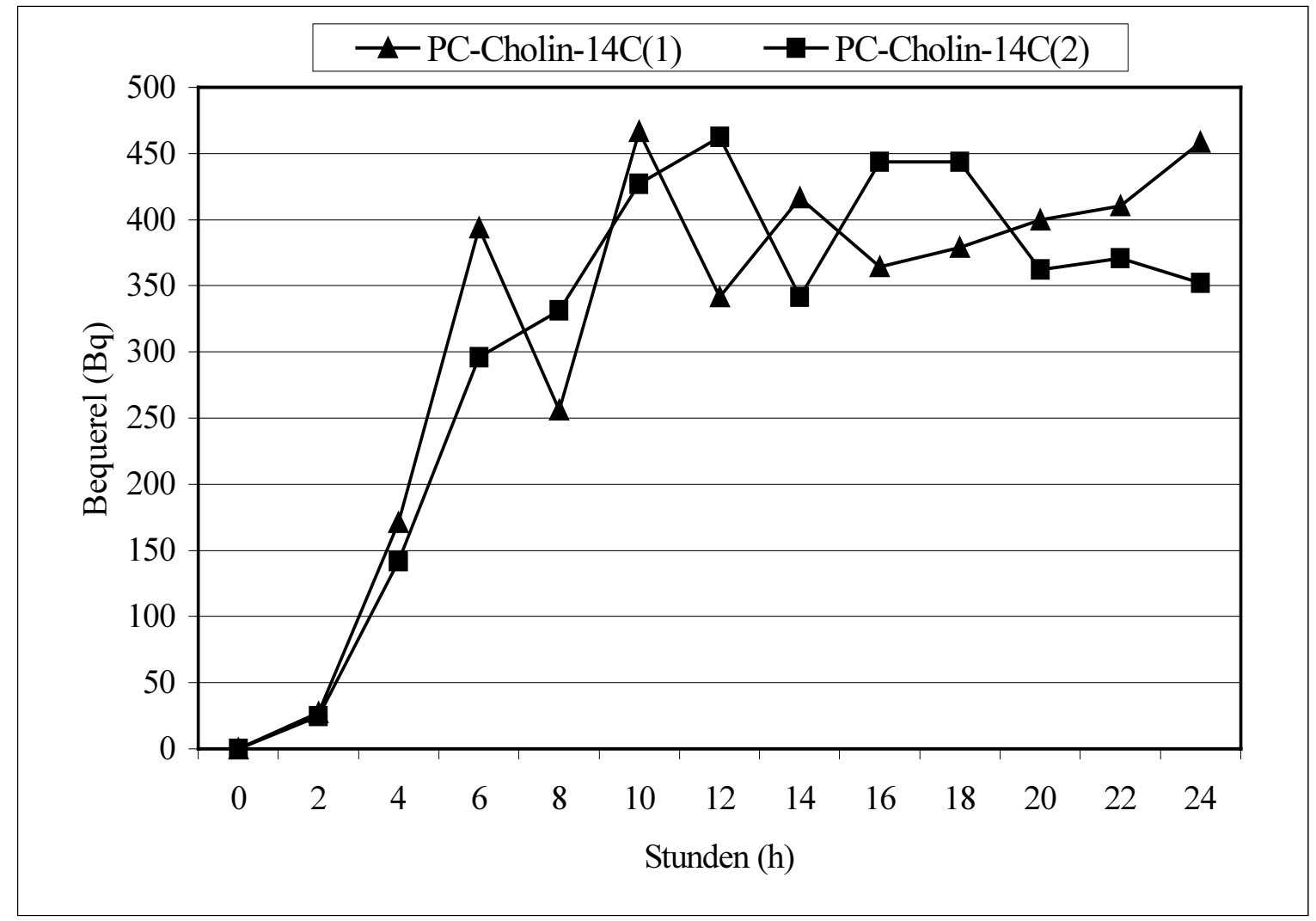

Abbildung 11: Verlauf der ${ }^{14} \mathrm{C}$-Aktivitätsausscheidung in der Atemluft der Versuchstiere eins und zwei (PC-Cholin- ${ }^{14} \mathrm{C}$ ) in den ersten 24 Stunden nach der Markierung

Wie Abbildung 11 zeigt, stieg bei beiden Versuchstieren der ${ }^{14} \mathrm{C}-$ Gehalt in der Atemluft in den ersten sechs Stunden von 0 Bq auf 300 Bq bzw. 350 Bq an. Nach acht Stunden war der ${ }^{14} \mathrm{C}$-Gehalt der Atemluft des ersten Versuchtieres auf $256 \mathrm{~Bq}$ gesunken. Er stieg in den nächsten zwei Stunden wieder an und schwankte dann, ebenso wie der ${ }^{14} \mathrm{C}$-Gehalt der Atemluft des zweiten Versuchstieres, bis zum Versuchsende zwischen 331 Bq im Minimum und $462 \mathrm{~Bq}$ im Maximum.

\subsubsection{PC-Linolsäure- ${ }^{14} \mathrm{C}$ Tiere}

Der Gehalt an ${ }^{14} \mathrm{C}$-Aktivität in der Atemluft der PC-Linolsäure- ${ }^{14} \mathrm{C}$ Tiere, während des 24-stündigen Versuches, wird in Abbildung 12 aufgeführt. 


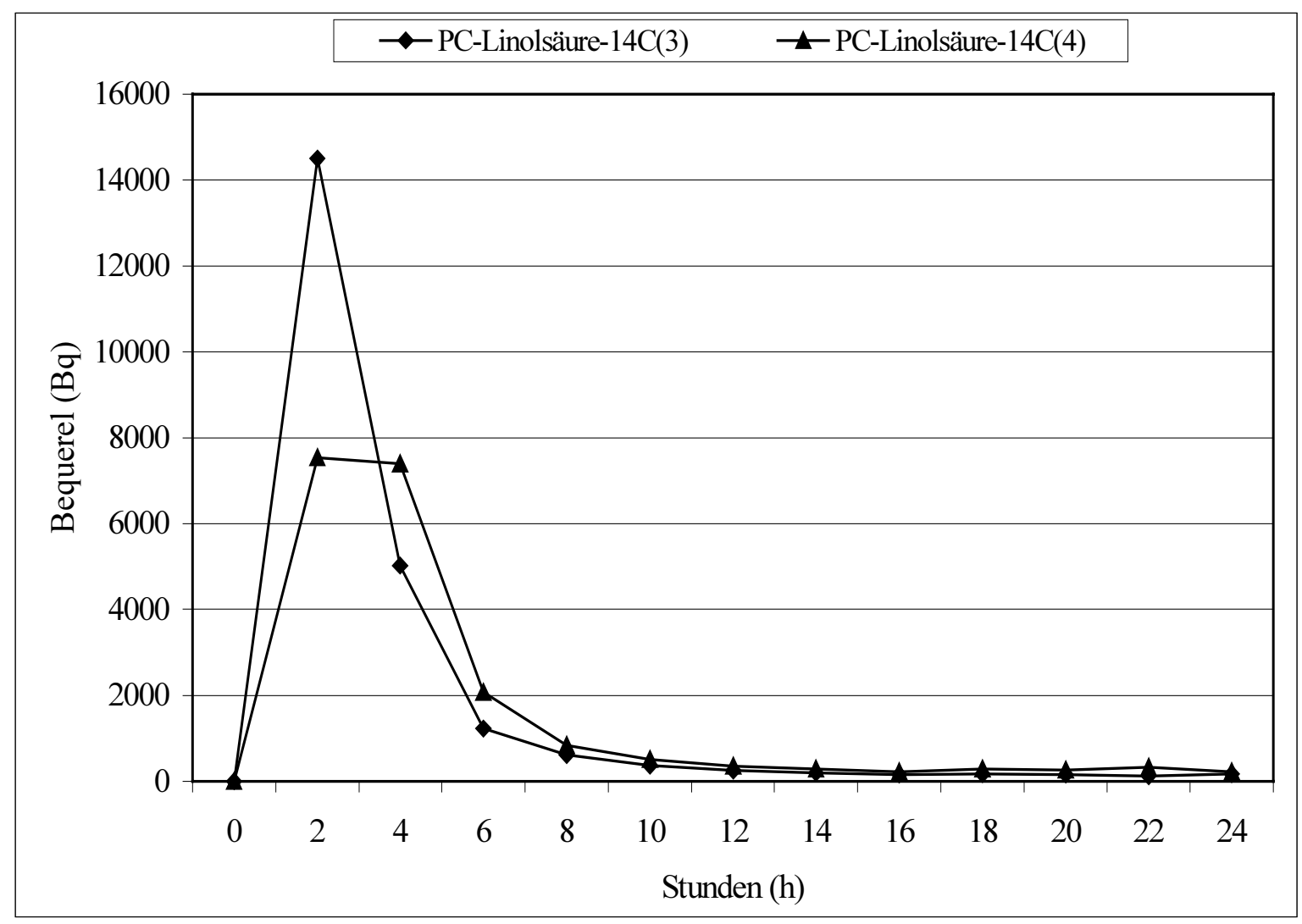

Abbildung 12: Verlauf der ${ }^{14} \mathrm{C}$-Aktivitätsausscheidung in der Atemluft der Versuchstiere drei und vier (PC-Linolsäure- ${ }^{14} \mathrm{C}$ ) in den ersten 24 Stunden nach der Markierung

Der zeitliche Verlauf der ${ }^{14} \mathrm{C}$-Ausscheidung in der Atemluft der Versuchstiere drei und vier (Abbildung 12) verlief deutlich anders, als bei den Versuchstieren eins und zwei (Abbildung 11). Nach den ersten zwei Stunden wurde beim dritten Versuchstier in der Atemluft eine ${ }^{14} \mathrm{C}$-Aktivitätsausscheidung von $14196 \mathrm{~Bq}$ und beim vierten Versuchstier von $7531 \mathrm{~Bq}$ gemessen. Nach vier Versuchsstunden konnte in der Atemluft des vierten Versuchstieres immer noch eine ${ }^{14} \mathrm{C}$-Aktivität von $7388 \mathrm{~Bq}$ gemessen werden. Die ${ }^{14} \mathrm{C}$-Aktivität der Atemluft des dritten Versuchstieres sank auf 5023 Bq. Zwei Stunden später wurden ${ }^{14} \mathrm{C}$ Aktivitäten von 1125 Bq (drittes Versuchstier) und 2073 Bq (viertes Versuchstier) festgestellt. Bis zum Versuchsende erfolgte ein kontinuierlicher Abfall der ${ }^{14} \mathrm{C}$-Aktivitätsgehalte in der Atemluft beider Versuchstiere, der sich nach 14 Stunden auf ein Niveau zwischen $288 \mathrm{~Bq}$ im Maximum und $123 \mathrm{~Bq}$ im Minimum einstellte, und dann bis zum Versuchsende nach 24 Stunden, in etwa gleich blieb. 


\subsection{1}

\section{PC-Cholin- ${ }^{14} \mathrm{C}$ Tiere}

Um zu veranschaulichen, wie sich die ${ }^{14} \mathrm{C}$-Aktivität der jeweiligen Fraktionen auf die Lipidextrakte und Nichtlipidanteile aufteilte, wurden die relativen Verteilungen ermittelt. Aufgeführt sind die neun Fraktionen, mit den größten Anteilen an ${ }^{14} \mathrm{C}$-Aktivität (Tabelle 13).

Tabelle 13: Relative Verteilung der ${ }^{14} \mathrm{C}$-Aktivität auf den jeweiligen Lipidextrakt und Nichtlipidanteil von den Fraktionen mit den höchsten ${ }^{14} \mathrm{C}$-Anteilen der PCCholin- ${ }^{14} \mathrm{C}$ Tiere

\begin{tabular}{|c|c|c|c|}
\hline \multirow{3}{*}{$\begin{array}{l}\text { Körperfraktionen } \\
\text { und Exkremente }\end{array}$} & & \multicolumn{2}{|c|}{ PC-Cholin- ${ }^{14} \mathrm{C}$} \\
\hline & & 1. Versuchstier & 2. Versuchstier \\
\hline & & \multicolumn{2}{|c|}{$\%$-Anteil an der gesamten Aktivität } \\
\hline \multirow{2}{*}{ Muskel } & Lipidextrakt & 29,3 & 25,6 \\
\hline & Nichtlipidanteil & 70,7 & 74,4 \\
\hline \multirow[t]{2}{*}{ Abdominalfett } & Lipidextrakt & 50,8 & 49,4 \\
\hline & Nichtlipidanteil & 49,2 & 50,6 \\
\hline \multirow[t]{2}{*}{ Dünndarm } & Lipidextrakt & 53,1 & 27,3 \\
\hline & Nichtlipidanteil & 46,9 & 72,7 \\
\hline \multirow{2}{*}{$\begin{array}{l}\text { Zwölffingerdarm mit } \\
\text { Inhalt und Pankreas }\end{array}$} & Lipidextrakt & 42,2 & 50,8 \\
\hline & Nichtlipidanteil & 57,8 & 49,2 \\
\hline \multirow[t]{2}{*}{ Leber } & Lipidextrakt & 30,9 & 57,3 \\
\hline & Nichtlipidanteil & 69,1 & 42,7 \\
\hline \multirow[t]{2}{*}{ Exkremente } & Lipidextrakt & 48,8 & 19,2 \\
\hline & Nichtlipidanteil & 51,2 & 80,8 \\
\hline \multirow[t]{2}{*}{ Haut und Federn } & Lipidextrakt & 28,1 & 38,5 \\
\hline & Nichtlipidanteil & 71,9 & 61,5 \\
\hline \multirow[t]{2}{*}{ Knochen } & Lipidextrakt & 34,8 & 40,4 \\
\hline & Nichtlipidanteil & 65,2 & 59,6 \\
\hline \multirow[t]{2}{*}{ Füße und Kopf } & Lipidextrakt & 51,7 & 48,6 \\
\hline & Nichtlipidanteil & 48,3 & 51,4 \\
\hline
\end{tabular}

Tabelle 13 zeigt, daß außer in den Lipidextrakten von Muskel und Knochen beider Versuchstiere, Leber, Haut und Federn des ersten Versuchtieres sowie Dünndarm und Exkremente des zweiten Versuchstieres, ein prozentualer Anteil an der ${ }^{14} \mathrm{C}$-Aktivität von $42,2 \%$ 
bis 57,3\% in den jeweiligen Lipidextrakten ermittelt wurde. Die Lipidextrakte von Leber, Haut und Federn des ersten Versuchstieres und Exkremente des zweiten Versuchstieres wiesen über $10 \%$ geringere ${ }^{14} \mathrm{C}$-Aktivitätsanteile auf, als die Lipidextrakte der jeweils gleichen Fraktionen des anderen Versuchtieres. Bei den übrigen Fraktionen stimmte der ${ }^{14} \mathrm{C}$-Aktivitätsanteil der Lipidextrakte der gleichen Fraktionen beider Versuchstiere in etwa überein.

\subsubsection{PC-Linolsäure- $-{ }^{14} \mathrm{C}$ Tiere}

Die relative Verteilung der ${ }^{14} \mathrm{C}$-Aktivität der Versuchstiere drei und vier auf die Lipidextrakte und Nichtlipidanteile der neun Fraktionen mit den höchsten ${ }^{14} \mathrm{C}$-Aktivitätsanteilen wird in Tabelle 14 gezeigt.

Tabelle 14: Relative Verteilung der ${ }^{14} \mathrm{C}$-Aktivität auf den jeweiligen Lipidextrakt und Nichtlipidanteil von den Fraktionen mit den höchsten ${ }^{14} \mathrm{C}$-Anteilen der PCLinolsäure- ${ }^{14} \mathrm{C}$ Tiere

\begin{tabular}{|ll|c|c|}
\hline \multirow{2}{*}{$\begin{array}{l}\text { Körperfraktionen } \\
\text { und Exkremente }\end{array}$} & \multicolumn{2}{|c|}{ PC-Linolsäure- ${ }^{14}$ C } \\
& & 3. Versuchstier & 4. Versuchstier \\
\cline { 2 - 4 } & \%-Anteil an der gesamten Aktivität \\
\hline Muskel & Lipidextrakt & 49,2 & 42,1 \\
& Nichtlipidanteil & 50,8 & 57,9 \\
\hline Abdominalfett & Lipidextrakt & 85,6 & 77,2 \\
& Nichtlipidanteil & 14,4 & 22,8 \\
\hline Dünndarm & Lipidextrakt & 56,4 & 35,4 \\
& Nichtlipidanteil & 43,6 & 64,6 \\
\hline Zwölffingerdarm mit & Lipidextrakt & 75,4 & 68,7 \\
Inhalt und Pankreas & Nichtlipidanteil & 24,6 & 31,3 \\
\hline Leber & Lipidextrakt & 48,5 & 45,9 \\
& Nichtlipidanteil & 51,5 & 54,1 \\
\hline Exkremente & Lipidextrakt & 27,2 & 34,5 \\
& Nichtlipidanteil & 72,8 & 65,5 \\
\hline Haut und Federn & Lipidextrakt & 76,0 & 72,2 \\
& Nichtlipidanteil & 24,0 & 27,8 \\
\hline Knochen & Lipidextrakt & 44,1 & 68,9 \\
& Nichtlipidanteil & 55,9 & 31,1 \\
\hline Füße und Kopf & Lipidextrakt & 49,2 & 61,1 \\
& Nichtlipidanteil & 50,8 & 38,9 \\
\hline
\end{tabular}


Tabelle 14 verdeutlicht, daß mit Ausnahme der Lipidextrakte der Exkremente beider Versuchstiere und des Lipidextraktes vom Dünndarm des vierten Versuchstieres alle anderen Lipidextrakte ${ }^{14} \mathrm{C}$-Aktivitätsanteile von über $42 \%$ enthielten. In den Lipidextrakten der Fraktionen Abdominalfett, Zwölffingerdarm mit Inhalt und Pankreas, Haut und Federn der PC-Linolsäure- ${ }^{14} \mathrm{C}$ Versuchstiere konnten die höchsten ${ }^{14} \mathrm{C}$-Aktivitätsanteile von $68,7 \%$ bis 85,6 \% gemessen werden. Die Lipidextrakte der Fraktionen Knochen, Füße und Kopf des dritten Versuchstieres und Dünndarm des vierten Versuchstieres wiesen über $10 \%$ geringere ${ }^{14} \mathrm{C}$-Aktivitätsanteile auf, als die Lipidextrakte der jeweils gleichen Fraktionen des anderen Versuchtieres. Bei allen anderen jeweils gleichen Fraktionen beider Versuchstiere konnten in etwa gleichhohe ${ }^{14} \mathrm{C}$-Aktivitätsanteile in den Lipidextrakten festgestellt werden.

\subsection{Verteilung der ${ }^{14} \mathrm{C}$-Aktivität auf die einzelnen Fraktionen}

Mit in die ${ }^{14} \mathrm{C}$-Aktivitätsverteilung einbezogen wurde die während des 24-stündigen radiorespiratorischen Versuches ausgeatmete ${ }^{14} \mathrm{C}$-Aktivität der Versuchstiere und die ${ }^{14} \mathrm{C}$-Aktivität in den Exkrementen, die die Tiere in den 24 Stunden zwischen Markierung und Tötung ausschieden. Als Bezugsgröße wurde die wiedergefundene ${ }^{14} \mathrm{C}$-Aktivität gewählt. Da neben der Atemluft und den Exkrementen alle Fraktionen zur ${ }^{14} \mathrm{C}$-Aktivitätsmessung exakt erfaßt wurden, kann davon ausgegangen werden, daß zwischen wiedergefundener und eingesetzter ${ }^{14} \mathrm{C}$-Aktivität keine großen Differenzen bestanden.

\subsubsection{PC-Cholin- ${ }^{14} \mathrm{C}$ Tiere}

Die ${ }^{14} \mathrm{C}$-Aktivität in den Körperfraktionen, Exkrementen und der Atemluft der Versuchstiere eins und zwei wurde gemessen und die relative Verteilung der gesamten ${ }^{14} \mathrm{C}$-Aktivität auf die einzelnen Fraktionen ermittelt. Bei dem ersten Versuchstier konnte eine gesamte ${ }^{14} \mathrm{C}$-Aktivität von $269,847 \mathrm{kBq}$ wiedergefunden werden. Die ${ }^{14} \mathrm{C}$-Aktivität aller Fraktionen des zweiten Versuchtieres betrug $327,378 \mathrm{kBq}$. Der Hauptanteil der gesamten ${ }^{14} \mathrm{C}$-Aktivität, mit einem relativen Anteil von 85,8 \% beim ersten Versuchstier und 89,7 \% beim 
zweiten Versuchstier, wird in den in Tabelle 15 aufgeführten acht Fraktionen gezeigt. In den übrigen 21 Fraktionen beider Versuchstiere (Tabelle 15) konnten insgesamt nur ${ }^{14} \mathrm{C}$ Aktivitätsanteile von unter $14,2 \%$ pro Tier gemessen werden.

Tabelle 15: Absolute (kBq) und relative (\%) Verteilung der ${ }^{14} \mathrm{C}$-Aktivität von den Fraktionen mit den höchsten ${ }^{14} \mathrm{C}$-Anteilen der PC-Cholin- ${ }^{14} \mathrm{C}$ Tiere

\begin{tabular}{|c|c|c|c|c|}
\hline \multirow{3}{*}{$\begin{array}{l}\text { Körperfraktionen } \\
\text { und Exkremente }\end{array}$} & \multicolumn{4}{|c|}{ PC-Cholin- ${ }^{14} \mathrm{C}$} \\
\hline & \multicolumn{2}{|c|}{ 1. Versuchstier } & \multicolumn{2}{|c|}{ 2. Versuchstier } \\
\hline & $\mathrm{kBq}$ & $\%$ & $\mathrm{kBq}$ & $\%$ \\
\hline Muskel & 55,277 & 20,5 & 59,206 & 18,1 \\
\hline Exkremente & 41,405 & 15,3 & 68,901 & 21,0 \\
\hline Knochen & 37,885 & 14,0 & 43,230 & 13,2 \\
\hline Leber & 31,492 & 11,7 & 44,819 & 13,7 \\
\hline Dünndarm & 21,599 & 8,0 & 20,654 & 6,3 \\
\hline Haut und Federn & 16,790 & 6,2 & 26,299 & 8,0 \\
\hline Füße und Kopf & 15,054 & 5,6 & 17,456 & 5,3 \\
\hline Zwölffingerdarm* & 12,108 & 4,5 & 13,287 & 4,1 \\
\hline${ }^{14}$ C-Aktivitätsanteil & 231,610 & 85,8 & 293,852 & 89,7 \\
\hline
\end{tabular}

*mit Inhalt und Pankreas

Tabelle 15 zeigt, daß beim ersten Versuchstier die Fraktion Muskel mit 20,5 \% den höchsten Anteil an der gesamten ${ }^{14} \mathrm{C}$-Aktivität enthielt. Das zweite Versuchstier wies dagegen den höchsten ${ }^{14} \mathrm{C}$-Anteil in der Fraktion Exkremente auf. Mit 21,0 \% war der Anteil an der gesamten ${ }^{14} \mathrm{C}$-Aktivität um 5,7 \% höher als beim ersten Versuchstier. Der ${ }^{14} \mathrm{C}$-Aktivitätsanteil des Abdominalfettes beim zweiten Versuchstier war erheblich geringer war als beim ersten Tier. Die Ursache lag darin, daß das zweite Tier einen geringeren Abdominalfettanteil aufwies als das erste Tier (Tabelle 11) und somit die ${ }^{14} \mathrm{C}$-Aktivitätsberechnung bezogen auf das Organgewicht geringer ausfiel. Die Abweichungen zwischen den anderen sieben gleichen Fraktionen beider Versuchstiere betrugen dagegen maximal 2,4 \%.

Die 21 weiteren Fraktionen beider Versuchstiere, mit einem relativen Anteil von 14,2 \% bzw. 10,3\% an der gesamten ${ }^{14} \mathrm{C}$-Aktivität, sind in Tabelle 16 aufgeführt. 
Tabelle 16: Absolute $(\mathrm{kBq})$ und relative $(\%)$ Verteilung der ${ }^{14} \mathrm{C}$-Aktivität von 21 weiteren Fraktionen der PC-Cholin- ${ }^{14} \mathrm{C}$ Tiere

\begin{tabular}{|c|c|c|c|c|}
\hline \multirow{3}{*}{$\begin{array}{l}\text { Körperfraktionen } \\
\text { und Atemluft }\end{array}$} & \multicolumn{4}{|c|}{ PC-Cholin- $-{ }^{14} \mathrm{C}$} \\
\hline & \multicolumn{2}{|c|}{ 1. Versuchstier } & \multicolumn{2}{|c|}{ 2. Versuchstier } \\
\hline & $\mathrm{kBq}$ & $\%$ & $\mathrm{kBq}$ & $\%$ \\
\hline Abdominalfett & 4,186 & 1,6 & 0,726 & 0,2 \\
\hline Atemluft & 4,086 & 1,5 & 3,998 & 1,2 \\
\hline Speiseröhre und Kropf & 2,071 & 0,8 & 1,027 & 0,3 \\
\hline Speiseröhren- und Kropfinhalt & 0,033 & 0,0 & 0,018 & 0,0 \\
\hline Drüsenmagen mit Inhalt & 1,083 & 0,4 & 3,340 & 1,0 \\
\hline Muskelmagen & 4,349 & 1,6 & 3,559 & 1,1 \\
\hline Muskelmageninhalt & 0,183 & 0,1 & 0,116 & 0,0 \\
\hline Dünndarminhalt & 2,171 & 0,8 & 1,815 & 0,6 \\
\hline Blinddarm & 1,883 & 0,7 & 3,252 & 1,0 \\
\hline Dickdarm, Kloake mit Inhalt & 4,398 & 1,6 & 2,199 & 0,7 \\
\hline Lunge & 1,810 & 0,7 & 1,871 & 0,6 \\
\hline Herz & 1,041 & 0,4 & 1,910 & 0,6 \\
\hline Nieren & 4,777 & 1,8 & 5,620 & 1,7 \\
\hline Gehirn & 0,310 & 0,1 & 0,091 & 0,0 \\
\hline Luftröhre & 0,373 & 0,1 & 0,507 & 0,1 \\
\hline Blinddarminhalt & - & - & 0,248 & 0,1 \\
\hline Milz & 0,309 & 0,1 & 0,843 & 0,3 \\
\hline Galle & 0,372 & 0,1 & 0,075 & 0,0 \\
\hline feste Blutbestandteile & 0,256 & 0,1 & 0,902 & 0,3 \\
\hline Serum & 1,083 & 0,4 & 0,990 & 0,3 \\
\hline Blut & 3,464 & 1,3 & 0,419 & 0,1 \\
\hline${ }^{14}$ C-Aktivitätsanteil & 38,238 & 14,2 & 33,526 & 10,3 \\
\hline
\end{tabular}

Tabelle 16 verdeutlicht, daß der höchste Anteil an der ${ }^{14} \mathrm{C}$-Aktivität in der Fraktion Nieren des dritten Versuchtieres mit 1,8 \% ermittelt wurde. Bei den Fraktionen Speiseröhren- und Kropfinhalt, Muskelmageninhalt, Gehirn, Blinddarminhalt, Galle beider Versuchstiere sowie feste Blutbestandteile, Luftröhre und Milz des ersten Versuchstieres waren ${ }^{14} \mathrm{C}$-Aktivitäten von unter $0,372 \mathrm{kBq}$ pro Fraktion nachweisbar, die maximal $0,1 \%$ der gesamten ${ }^{14} \mathrm{C}$-Aktivität ausmachten. 
Beim dritten Versuchstier wurde eine ${ }^{14} \mathrm{C}$-Aktivität von $302,057 \mathrm{kBq}$ und bei dem vierten Versuchstier von $239,341 \mathrm{kBq}$ wiedergefunden. Der Hauptteil der ${ }^{14} \mathrm{C}$-Aktivität mit einem relativen Anteil von über $88 \%$ an der gesamten ${ }^{14} \mathrm{C}$-Aktivität fand sich in den in Tabelle 17 aufgeführten acht Fraktionen wieder. In den übrigen 21 Fraktionen (Tabelle 18) konnten nur geringe ${ }^{14} \mathrm{C}$-Aktivitätsanteile gemessen werden.

Tabelle 17: Absolute $(\mathrm{kBq})$ und relative (\%) Verteilung der ${ }^{14} \mathrm{C}$-Aktivität von den Fraktionen mit den höchsten ${ }^{14} \mathrm{C}$-Anteilen der PC-Linolsäure- ${ }^{14} \mathrm{C}$ Tiere

\begin{tabular}{|c|c|c|c|c|}
\hline \multirow{3}{*}{$\begin{array}{l}\text { Körperfraktionen, } \\
\text { Exkremente und Atemluft }\end{array}$} & \multicolumn{4}{|c|}{ PC-Linolsäure $-{ }^{14} \mathrm{C}$} \\
\hline & \multicolumn{2}{|c|}{ 3. Versuchstier } & \multicolumn{2}{|c|}{ 4. Versuchstier } \\
\hline & $\mathrm{kBq}$ & $\%$ & $\mathrm{kBq}$ & $\%$ \\
\hline Exkremente & 81,024 & 26,8 & 44,453 & 18,6 \\
\hline Haut und Federn & 59,006 & 19,5 & 44,743 & 18,7 \\
\hline Knochen & 37,604 & 12,4 & 39,708 & 16,6 \\
\hline Muskel & 32,836 & 10,9 & 39,613 & 16,6 \\
\hline Atemluft & 22,942 & 7,6 & 20,279 & 8,5 \\
\hline Abdominalfett & 13,814 & 4,6 & 0,745 & 0,3 \\
\hline Füße und Kopf & 11,585 & 3,8 & 14,519 & 6,1 \\
\hline Dünndarm & 10,055 & 3,3 & 7,307 & 3,1 \\
\hline${ }^{14} \mathrm{C}$-Aktivitätsanteil & 268,866 & 88,9 & 211,367 & 88,5 \\
\hline
\end{tabular}

Die in Tabelle 17 aufgeführten Fraktionen Exkremente, Haut und Federn beider Tiere wiesen mit jeweils über $18 \%$ die größten relativen Anteile an der gesamten ${ }^{14} \mathrm{C}$-Aktivität auf. Die Fraktionen Knochen und Muskel beider Tiere hatten die dritt- und viertgrößten Anteile an der gesamten ${ }^{14} \mathrm{C}$-Aktivität. Wie aus Tabelle 12 ersichtlich ist, waren die vier Fraktionen mit den größten ${ }^{14} \mathrm{C}$-Aktivitätsanteilen ebenfalls die Fraktionen, mit den höchsten Gewichtsanteilen. Die ermittelte ${ }^{14} \mathrm{C}$-Aktivität bezogen auf die Gewichte der jeweiligen Fraktionen bewirkte, daß der größte Anteil der ${ }^{14} \mathrm{C}$-Aktivität auf sie entfiel. Die Fraktion Atemluft, die bei den PC-Cholin- ${ }^{14} \mathrm{C}$ Versuchstieren einen ${ }^{14} \mathrm{C}$-Aktivitätsanteil von durchschnittlich unter 1,4\% aufwies (Tabelle 16), zeigte bei den Versuchstieren drei und vier ${ }^{14}$ C-Aktivitätsanteile von $7,6 \%$ bzw. 8,5\%. Sie war die Fraktion mit dem fünftgrößten ${ }^{14}$ C-Aktivitätsanteil. 
Bei den Fraktionen Knochen und Muskel wies das vierte Versuchstier über $4 \%$ höhere prozentuale Anteile an der gesamten ${ }^{14} \mathrm{C}$-Aktivität auf als das Dritte. In den Exkrementen des dritten Versuchtieres waren dagegen mit 26,8 \% um 8,2 \% höhere ${ }^{14} \mathrm{C}$-Aktivitätsanteile meßbar als beim Vierten. Ebenso wies die Fraktion Abdominalfett des dritten Tieres deutlich höhere ${ }^{14} \mathrm{C}$-Aktivitätsanteile auf, als die des vierten Tieres. Bei den anderen in Tabelle 17 aufgeführten Fraktionen waren bei beiden Versuchstieren die ${ }^{14} \mathrm{C}$-Aktivitätsanteile der jeweils gleichen Fraktionen geringfügig abweichend.

In den 21 weiteren Fraktionen waren insgesamt beim dritten Versuchstier mit 11,1\% und beim vierten Versuchstier mit $11,5 \%$ geringe Anteile an der gesamten ${ }^{14} \mathrm{C}$-Aktivität enthalten (Tabelle 18).

Tabelle 18: Absolute $(\mathrm{kBq})$ und relative (\%) Verteilung der ${ }^{14} \mathrm{C}$-Aktivität von 21 weiteren Fraktionen der PC-Linolsäure- ${ }^{14} \mathrm{C}$ Tiere

\begin{tabular}{|l|c|c|c|c|}
\hline \multirow{2}{*}{ Körperfraktionen } & \multicolumn{4}{|c|}{ PC-Linolsäure ${ }^{\mathbf{1 4}} \mathbf{C}$} \\
& \multicolumn{3}{|c|}{$\mathbf{3 .}$ Versuchstier } & $\mathbf{4}$. Versuchstier \\
\cline { 2 - 5 } & $\mathrm{kBq}$ & $\mathbf{0}$ & $\mathrm{kBq}$ & $\mathbf{0}$ \\
\hline Speiseröhre und Kropf & 0,994 & 0,3 & 0,573 & 0,2 \\
\hline Speiseröhren- und Kropfinhalt & 0,001 & - & - & - \\
\hline Drüsenmagen mit Inhalt & 1,335 & 0,4 & 1,000 & 0,4 \\
\hline Muskelmagen & 3,491 & 1,1 & 5,234 & 2,2 \\
\hline Muskelmageninhalt & 0,039 & 0,0 & 0,111 & 0,0 \\
\hline Dünndarminhalt & 1,262 & 0,4 & 1,959 & 0,8 \\
\hline Zwölffingerdarm* & 4,345 & 1,4 & 4,377 & 1,8 \\
\hline Blinddarm & 1,510 & 0,5 & 1,017 & 0,4 \\
\hline Dickdarm, Kloake mit Inhalt & 1,211 & 0,4 & 2,766 & 1,2 \\
\hline Leber & 8,960 & 3,0 & 5,898 & 2,5 \\
\hline Lunge & 0,659 & 0,2 & 0,389 & 0,2 \\
\hline Herz & 1,993 & 0,7 & 1,087 & 0,4 \\
\hline Nieren & 2,260 & 0,7 & 0,540 & 0,2 \\
\hline Gehirn & 0,041 & 0,0 & 0,041 & 0,0 \\
\hline Luftröhre & 0,768 & 0,3 & 0,598 & 0,2 \\
\hline Blinddarminhalt & 2,981 & 1,0 & 1,416 & 0,6 \\
\hline Milz & 0,277 & 0,2 & 0,087 & 0,0 \\
\hline Galle & 0,232 & 0,1 & 0,053 & 0,0 \\
\hline Serum & 0,143 & 0,1 & 0,249 & 0,1 \\
\hline feste Blutbestandteile & 0,184 & 0,1 & 0,165 & 0,1 \\
\hline Blut & 0,505 & 0,2 & 0,413 & 0,2 \\
\hline 14C-Aktivitätsanteil & $\mathbf{3 3 , 1 9 1}$ & $\mathbf{1 1 , 1}$ & $\mathbf{2 7 , 9 7 3}$ & $\mathbf{1 1 , 5}$ \\
\hline
\end{tabular}

*mit Inhalt und Pankreas 
Tabelle 18 zeigt, daß lediglich bei der Fraktion Leber, Muskelmagen, Zwölffingerdarm mit Inhalt und Pankreas beider Versuchtiere und bei der Fraktion Dickdarm, Kloake mit Inhalt des vierten Versuchstieres, ${ }^{14} \mathrm{C}$-Aktivitätsanteile von über einem Prozent nachgewiesen werden konnten. Alle anderen Fraktionen hatten einen Anteil an der gesamten ${ }^{14} \mathrm{C}$-Aktivität von einem oder unter einem Prozent.

\subsection{3 ${ }^{14}$ C-Aktivität pro Gramm der jeweiligen Fraktion}

\subsubsection{PC-Cholin $-{ }^{14} \mathrm{C}$ Tiere}

Die ${ }^{14} \mathrm{C}$-Aktivität in den Fraktionen der Versuchstiere eins und zwei wurde gemessen und die ${ }^{14} \mathrm{C}$-Aktivität pro Gramm der jeweiligen Fraktion $(\mathrm{Bq} / \mathrm{g})$ ermittelt. Bei den Versuchstieren, die mit PC-Cholin- ${ }^{14} \mathrm{C}$ markiert wurden, waren bei beiden Tieren jeweils acht Fraktionen mit über $700 \mathrm{~Bq} / \mathrm{g}$ Fraktion nachweisbar (Tabelle 19). In den übrigen 19 Fraktionen der zwei Versuchstiere wurden ${ }^{14} \mathrm{C}$-Aktivitäten von unter $700 \mathrm{~Bq} / \mathrm{g}$ Fraktion gemessen (Tabelle 20).

Tabelle 19: ${ }^{14} \mathrm{C}$-Aktivität pro Gramm Fraktion $(\mathrm{Bq} / \mathrm{g})$ von den Fraktionen mit den höchsten ${ }^{14} \mathrm{C}$-Gehalten der PC-Cholin- ${ }^{14} \mathrm{C}$ Tiere

\begin{tabular}{|l|c|c|}
\hline \multirow{2}{*}{ Körperfraktionen } & \multicolumn{2}{|c|}{ PC-Cholin- ${ }^{\mathbf{1 4}} \mathbf{C}$} \\
\cline { 2 - 3 } & $\mathbf{1 .}$ Versuchstier & $\mathbf{2 . ~ V e r s u c h s t i e r ~}$ \\
\cline { 2 - 3 } & $\mathrm{Bq} / \mathrm{g}$ & $\mathrm{Bq} / \mathrm{g}$ \\
\hline Leber & 1716,2 & 2023,4 \\
\hline Zwölffingerdarm* & 1168,7 & 1288,7 \\
\hline Milz & 1023,7 & 1007,0 \\
\hline Nieren & 937,2 & 926,4 \\
\hline Galle & 868,5 & 863,3 \\
\hline Exkremente & 864,7 & 834,6 \\
\hline Drüsenmagen mit Inhalt & 702,3 & 960,7 \\
\hline
\end{tabular}

*mit Inhalt und Pankreas

Tabelle 19 zeigt, daß die Fraktion Leber beider Tiere mit 1716,2 Bq/g (erstes Tier) bzw. 2023,4 Bq/g (zweites Tier) die höchste ${ }^{14} \mathrm{C}$-Aktivität aufwies. Bei der Fraktion Zwölffin- 
gerdarm mit Inhalt und Pankreas sowie beim Dünndarm wurden ebenfalls noch ${ }^{14} \mathrm{C}$-Aktivitäten von über $1000 \mathrm{~Bq} / \mathrm{g}$ gefunden.

Während bei der Fraktion Milz beider Tiere und der Fraktion Exkremente des zweiten Tieres ${ }^{14} \mathrm{C}$-Aktivitäten von über $900 \mathrm{~Bq} / \mathrm{g}$ gemessen wurden, wiesen die übrigen Fraktionen ${ }^{14} \mathrm{C}$-Aktivitäten zwischen 803,0 Bq/g und 868,5 Bq/g auf. Eine Ausnahme bildete die Fraktion Exkremente des ersten Versuchstieres, bei der mit $702,3 \mathrm{~Bq} / \mathrm{g}$ die geringste ${ }^{14} \mathrm{C}$ Aktivität der acht Fraktionen ermittelt wurde.

Geringere ${ }^{14}$ C-Aktivitäten pro Gramm Fraktion wurden in den 19 weiteren Fraktionen gemessen (Tabelle 20).

Tabelle 20: ${ }^{14}$ C-Aktivität pro Gramm Fraktion $(\mathrm{Bq} / \mathrm{g})$ von 19 weiteren Fraktionen der PC-Cholin- ${ }^{14} \mathrm{C}$ Tiere

\begin{tabular}{|l|c|c|}
\hline \multirow{2}{*}{ Körperfraktionen } & \multicolumn{2}{|c|}{ PC-Cholin- ${ }^{\mathbf{1 4}}$ C } \\
& $\mathbf{1 .}$ Versuchstier & $\mathbf{2 .}$ Versuchstier \\
\cline { 2 - 3 } & $\mathrm{Bq} / \mathrm{g}$ & $\mathrm{Bq} / \mathrm{g}$ \\
\hline Lunge & 496,0 & 521,1 \\
\hline Dickdarm, Kloake mit Inhalt & 489,2 & 368,3 \\
\hline Blinddarm mit Inhalt & 352,6 & 555,9 \\
\hline Knochen & 315,6 & 336,8 \\
\hline Muskel & 249,7 & 240,5 \\
\hline Füße und Kopf & 266,5 & 311,1 \\
\hline Speiseröhre und Kropf & 254,4 & 193,5 \\
\hline Herz & 257,7 & 357,1 \\
\hline Muskelmagen & 249,9 & 206,7 \\
\hline Abdominalfett & 206,8 & 123,1 \\
\hline Gehirn & 189,0 & 217,7 \\
\hline Luftröhre & 222,2 & 198,0 \\
\hline Haut und Federn & 156,2 & 248,6 \\
\hline Blut & 257,6 & 216,0 \\
\hline Serum & 270,7 & 300,6 \\
\hline Dünndarminhalt & 184,6 & 174,3 \\
\hline feste Blutbestandteile & 128,2 & 165,0 \\
\hline Muskelmageninhalt & 25,2 & 20,5 \\
\hline Speiseröhren- und Kropfinhalt & 6,0 & 11,0 \\
\hline
\end{tabular}

Tabelle 20 zeigt, daß in den Fraktionen Lunge, Dickdarm, Kloake mit Inhalt und Blinddarm mit Inhalt beider Versuchstiere sowie der Fraktion Herz des zweiten Versuchtieres ${ }^{14} \mathrm{C}$-Aktivitäten zwischen 352,6 Bq/g und 521,1 Bq/g nachgewiesen wurden. In den Frak- 
tionen Knochen, Muskel, Füße und Kopf, Muskelmagen, Blut und Serum beider Versuchstiere, Speiseröhre und Kropf, Abdominalfett, Herz und Luftröhre des ersten Versuchstieres und Gehirn, Haut und Federn des zweiten Versuchtieres konnten noch ${ }^{14} \mathrm{C}$-Aktivitäten zwischen 206,7 Bq/g und 336,8 Bq/g festgestellt werden. Die ${ }^{14} \mathrm{C}$-Aktivitäten der übrigen Fraktionen lagen unter $200 \mathrm{~Bq} / \mathrm{g}$.

\subsubsection{PC-Linolsäure- ${ }^{14} \mathrm{C}$ Tiere}

Die ${ }^{14} \mathrm{C}$-Aktivität in den Fraktionen der Versuchstiere drei und vier, deren Markierung mit PC-Linolsäure- ${ }^{14} \mathrm{C}$ erfolgte, wurde gemessen und die ${ }^{14} \mathrm{C}$-Aktivität pro Gramm der jeweiligen Fraktion $(\mathrm{Bq} / \mathrm{g})$ ermittelt. Da die Höhe der ${ }^{14} \mathrm{C}$-Aktivitäten der jeweils gleichen Fraktionen beider Tiere zum Teil sehr unterschiedlich war, konnte keine tabellarische Trennung der wichtigsten Fraktionen von den übrigen erfolgen. Tabelle 21 zeigt die ${ }^{14} \mathrm{C}$-Aktivität pro Gramm $(\mathrm{Bq} / \mathrm{g})$ Fraktion aller Fraktionen der Versuchstiere drei und vier. 
Tabelle 21: ${ }^{14} \mathrm{C}$-Aktivität pro Gramm $(\mathrm{Bq} / \mathrm{g})$ Fraktion aller Fraktionen der PC-Linolsäure- ${ }^{14} \mathrm{C}$ Tiere

\begin{tabular}{|c|c|c|}
\hline \multirow{3}{*}{$\begin{array}{l}\text { Körperfraktionen } \\
\text { und Exkremente }\end{array}$} & \multicolumn{2}{|c|}{ PC-Linolsäure- ${ }^{14} \mathrm{C}$} \\
\hline & 3. Versuchstier & 4. Versuchstier \\
\hline & $\mathrm{Bq} / \mathrm{g}$ & $\mathrm{Bq} / \mathrm{g}$ \\
\hline Abdominalfett & 891,8 & 345,3 \\
\hline Exkremente & 813,7 & 502,7 \\
\hline Galle & 566,0 & 525,4 \\
\hline Blinddarm mit Inhalt & 563,4 & 329,8 \\
\hline Haut und Federn & 461,2 & 445,4 \\
\hline Dünndarm & 372,4 & 322,5 \\
\hline Luftröhre & 336,7 & 393,2 \\
\hline Leber & 333,2 & 327,7 \\
\hline Herz & 357,1 & 268,4 \\
\hline Nieren & 334,4 & 281,5 \\
\hline Zwölffingerdarm* & 325,2 & 234,1 \\
\hline Muskelmagen & 220,7 & 358,8 \\
\hline Knochen & 288,2 & 267,6 \\
\hline Drüsenmagen & 274,8 & 295,8 \\
\hline Milz & 216,8 & 185,7 \\
\hline Füße und Kopf & 185,4 & 232,5 \\
\hline Dickdarm, Kloake mit Inhalt & 178,6 & 398,0 \\
\hline Speiseröhre und Kropf & 154,8 & 151,7 \\
\hline Lunge & 119,6 & 114,3 \\
\hline Muskel & 111,1 & 149,1 \\
\hline Dünndarminhalt & 59,7 & 84,3 \\
\hline Blut & 54,6 & 49,2 \\
\hline Serum & 47,5 & 49,7 \\
\hline feste Blutbestandteile & 30,6 & 33,0 \\
\hline Gehirn & 20,2 & 24,0 \\
\hline Muskelmageninhalt & 4,6 & 16,3 \\
\hline Speiseröhren- und Kropfinhalt & 1,8 & 0,0 \\
\hline
\end{tabular}

*mit Inhalt und Pankreas

Beim dritten Versuchstier konnten die höchsten ${ }^{14} \mathrm{C}$-Aktivitäten mit über $800 \mathrm{~Bq} / \mathrm{g}$ in den Fraktionen Abdominalfett und Exkremente ermittelt werden. Die Fraktionen Galle, Haut und Federn beider Versuchstiere, Blinddarm mit Inhalt des dritten Versuchtieres und Exkremente des vierten Versuchtieres wiesen ${ }^{14} \mathrm{C}$-Aktivitäten zwischen $445,4 \mathrm{~Bq} / \mathrm{g}$ und 566,0 Bq/g auf. Bei den Fraktionen Dünndarm, Luftröhre, Leber, Herz, Nieren, Zwölffingerdarm mit Pankreas und Inhalt, Muskelmagen, Knochen und Drüsenmagen beider Versuchstiere, Milz des dritten Versuchstieres und Abdominalfett, Blinddarm mit Inhalt, 
Dickdarm, Kloake mit Inhalt und Füße und Kopf des vierten Versuchtieres wurden noch ${ }^{14} \mathrm{C}$-Aktivitäten zwischen 322,5 Bq/g und 393,3 Bq/g gemessen. Die ${ }^{14} \mathrm{C}$-Aktivitäten der übrigen Fraktionen lagen unter $200 \mathrm{~Bq} / \mathrm{g}$.

\section{5 $\quad{ }^{14}$ C-Aktivitäten in den Lipidextrakten}

Um die tatsächlichen ${ }^{14} \mathrm{C}$-Aktivitäten der Lipidextrakte der jeweiligen Fraktionen aller Versuchstiere vergleichend darzustellen, wurden die in den Lipidextrakten gemessenen ${ }^{14} \mathrm{C}$-Aktivitäten auf die jeweiligen Organgewichte bezogen und die relative Aktivitätsverteilung berechnet (Tabelle 22 und 23). Von den Fraktionen Blinddarminhalt, Galle und Milz standen geringe Mengen zur Verfügung. Sie reichten nur zur Bestimmung der gesamten ${ }^{14} \mathrm{C}$-Aktivität aus, so daß die Herstellung von Lipidextrakten und weitere dünnschichtchromatographische Trennungen nicht möglich waren. Aus dem Blut konnten ebenfalls keine Lipidextrakte hergestellt werden, da es bei der Extraktion klumpte.

Wie bei der Bestimmung der gesamten ${ }^{14} \mathrm{C}$-Aktivität pro Tier (Tabelle 15 und 17) wiesen auch die Lipidextrakte der Fraktionen Muskel, Exkremente, Knochen, Dünndarm, Haut und Federn, Füße und Kopf aller Versuchstiere, Leber, Zwölffingerdarm mit Inhalt und Pankreas der PC-Cholin- ${ }^{14} \mathrm{C}$ Versuchstiere und Abdominalfett der PC-Linolsäure- ${ }^{14} \mathrm{C}$ Tiere, bezogen auf das jeweilige Organgewicht, die höchsten ${ }^{14} \mathrm{C}$-Aktivitätsanteile auf.

\subsubsection{PC-Cholin- ${ }^{14} \mathrm{C}$ Tiere}

Tabelle 22 zeigt, die ${ }^{14} \mathrm{C}$-Aktivität in den Lipidextrakten der einzelnen Fraktionen, bezogen auf das jeweilige Organgewicht, der PC-Cholin- ${ }^{14} \mathrm{C}$ Tiere. Aufgeführt sind die absoluten Werte und ihre relative Verteilung innerhalb eines Tieres.

Die höchsten ${ }^{14} \mathrm{C}$-Aktivitäten in den Lipidextrakten wurden in den Fraktionen Muskel, Exkremente, Knochen, Leber, Dünndarm, Haut und Federn, Füße und Kopf, Zwölffingerdarm mit Inhalt und Pankreas gemessen, wobei die ${ }^{14} \mathrm{C}$-Aktivität in den Lipidextrakten der Exkremente und des Dünndarms des ersten Versuchtieres sowie Leber, Haut und Federn des 
zweiten Versuchstieres deutlich größere ${ }^{14} \mathrm{C}$-Aktivitätsanteile aufwiesen als die Lipidextrakte der gleichen Fraktionen des jeweiligen anderen Tieres. Alle übrigen Lipidextrakte zeigten in etwa übereinstimmende ${ }^{14} \mathrm{C}$-Aktivitätsanteile in den jeweils gleichen Fraktionen beider Tiere.

Tabelle 22: Absolute $(\mathrm{kBq})$ und relative (\%) Verteilung der ${ }^{14} \mathrm{C}$-Aktivität von den Lipidextrakten aller Fraktionen der PC-Cholin- ${ }^{14} \mathrm{C}$ Tiere

\begin{tabular}{|c|c|c|c|c|}
\hline \multirow{3}{*}{$\begin{array}{l}\text { Lipidextrakte der Körper- } \\
\text { fraktionen und Exkremente }\end{array}$} & \multicolumn{4}{|c|}{ PC-Cholin- $-{ }^{14} \mathrm{C}$} \\
\hline & \multicolumn{2}{|c|}{ 1. Versuchstier } & \multicolumn{2}{|c|}{ 2. Versuchstier } \\
\hline & $\mathrm{kBq}$ & $\%$ & $\mathrm{kBq}$ & $\%$ \\
\hline Muskel & 16,172 & 15,9 & 15,178 & 13,8 \\
\hline Abdominalfett & 2,125 & 2,1 & 0,359 & 0,3 \\
\hline Speiseröhre und Kropf & 1,782 & 1,8 & 0,206 & 0,2 \\
\hline Speiseröhren- und Kropfinhalt & - & - & 0,002 & 0,0 \\
\hline Drüsenmagen mit Inhalt & 1,235 & 1,2 & 0,905 & 0,8 \\
\hline Muskelmagen & - & - & 1,242 & 1,1 \\
\hline Muskelmageninhalt & 0,032 & 0,0 & 0,041 & 0,0 \\
\hline Dünndarm & 10,918 & 10,7 & 5,637 & 5,1 \\
\hline Dünndarminhalt & 1,089 & 1,1 & 0,808 & 0,7 \\
\hline Zwölffingerdarm* & 5,109 & 5,0 & 6,754 & 6,1 \\
\hline Blinddarm & 0,799 & 0,8 & 1,217 & 1,1 \\
\hline Dickdarm, Kloake mit Inhalt & 1,965 & 1,9 & 0,845 & 0,8 \\
\hline Leber & 9,744 & 9,6 & 25,679 & 23,3 \\
\hline Lunge & 0,870 & 0,9 & 0,555 & 0,5 \\
\hline Herz & 0,333 & 0,3 & 0,638 & 0,6 \\
\hline Nieren & 2,456 & 2,4 & 1,820 & 1,7 \\
\hline Gehirn & 0,375 & 0,4 & 0,121 & 0,1 \\
\hline Luftröhre & 0,081 & 0,1 & 0,137 & 0,1 \\
\hline Exkremente & 20,203 & 19,8 & 13,214 & 12,0 \\
\hline Haut und Federn & 4,721 & 4,6 & 10,130 & 9,2 \\
\hline Knochen & 13,171 & 12,9 & 15,492 & 14,1 \\
\hline Füße und Kopf & 7,777 & 7,6 & 8,476 & 7,7 \\
\hline Serum & 0,758 & 0,7 & 0,654 & 0,6 \\
\hline feste Blutbestandteile & 0,156 & 0,2 & 0,062 & 0,1 \\
\hline Aktivität aller Lipidextrakte & 101,871 & 100,0 & 110,172 & 100,0 \\
\hline
\end{tabular}

*mit Inhalt und Pankreas 


\subsubsection{PC-Linolsäure- ${ }^{14} \mathrm{C}$ Tiere}

Bei den Versuchstieren, die mit PC-Linolsäure- ${ }^{14} \mathrm{C}$ markiert wurden, verteilte sich die ${ }^{14} \mathrm{C}$ Aktivität der Lipidextrakte, bezogen auf das jeweilige Organgewicht, wie in Tabelle 23 dargestellt.

Tabelle 23: Absolute $(\mathrm{kBq})$ und relative (\%) Verteilung der ${ }^{14} \mathrm{C}$-Aktivität von den Lipidextrakten aller Fraktionen der PC-Linolsäure- ${ }^{14} \mathrm{C}$ Tiere

\begin{tabular}{|c|c|c|c|c|}
\hline \multirow{3}{*}{$\begin{array}{l}\text { Lipidextrakte der Körper- } \\
\text { fraktionen und Exkremente }\end{array}$} & \multicolumn{4}{|c|}{ PC-Linolsäure- ${ }^{14} \mathrm{C}$} \\
\hline & \multicolumn{2}{|c|}{ 3. Versuchstier } & \multicolumn{2}{|c|}{ 4. Versuchstier } \\
\hline & $\mathrm{kBq}$ & $\%$ & $\mathrm{kBq}$ & $\%$ \\
\hline Muskel & 16,169 & 11,5 & 16,680 & 13,9 \\
\hline Abdominalfett & 11,817 & 8,4 & 0,575 & 0,5 \\
\hline Speiseröhre und Kropf & 0,550 & 0,4 & 0,337 & 0,3 \\
\hline Drüsenmagen mit Inhalt & 0,958 & 0,7 & 0,656 & 0,5 \\
\hline Muskelmagen & 2,134 & 1,5 & 4,009 & 3,3 \\
\hline Muskelmageninhalt & 0,026 & 0,0 & 0,039 & 0,0 \\
\hline Dünndarm & 5,672 & 4,0 & 3,717 & 3,1 \\
\hline Dünndarminhalt & 0,674 & 0,5 & 1,050 & 0,9 \\
\hline Zwölffingerdarm* & 3,269 & 2,3 & 2,022 & 1,7 \\
\hline Blinddarm & 0,751 & 0,5 & 0,471 & 0,4 \\
\hline Dickdarm, Kloake mit Inhalt & 0,634 & 0,4 & 1,705 & 1,4 \\
\hline Leber & 4,345 & 3,1 & 2,707 & 2,2 \\
\hline Lunge & 0,364 & 0,3 & 0,133 & 0,1 \\
\hline Herz & 1,124 & 0,8 & 0,599 & 0,5 \\
\hline Nieren & 1,066 & 0,8 & 0,351 & 0,3 \\
\hline Gehirn & 0,041 & 0,0 & 0,020 & 0,0 \\
\hline Luftröhre & 0,466 & 0,3 & 0,274 & 0,2 \\
\hline Exkremente & 22,016 & 15,6 & 15,346 & 12,8 \\
\hline Haut und Federn & 44,841 & 31,8 & 32,302 & 26,9 \\
\hline Knochen & 18,047 & 12,8 & 27,344 & 22,7 \\
\hline Füße und Kopf & 5,700 & 4,0 & 8,871 & 7,4 \\
\hline Blinddarminhalt & 0,405 & 0,3 & 0,236 & 0,2 \\
\hline Serum & - & - & 0,820 & 0,7 \\
\hline Aktivität aller Lipidextrakte & 141,069 & 100,0 & 120,264 & 100,0 \\
\hline
\end{tabular}

*mit Inhalt und Pankreas

Mit 31,8\% (drittes Versuchstier) und 26,9\% (viertes Versuchstier) wiesen die Lipidextrakte der Fraktionen Haut und Federn die höchsten ${ }^{14} \mathrm{C}$-Aktivitätsanteile auf. Der Lipid- 
extrakt der Fraktion Knochen des vierten Tieres beinhaltete mit 22,7 \% einen circa 10 \% höheren ${ }^{14} \mathrm{C}$-Aktivitätsanteil als beim dritten Tier. Da das vierte Tier nur wenig Abdominalfett besaß, konnte bei der ${ }^{14} \mathrm{C}$-Aktivitätsmenge im Lipidextrakt, bezogen auf das Organgewicht, nur ein relativer Anteil von 0,5 \% gemessen werden, während beim dritten Versuchstier der ${ }^{14} \mathrm{C}$-Aktivitätsanteil 8,4\% ausmachte. Die übrigen Lipidextrakte der jeweils gleichen Fraktionen beider Tiere enthielten in etwa übereinstimmende ${ }^{14} \mathrm{C}$-Aktivitätsanteile.

4.6

\section{Ergebnisse der Trennung der Lipidextrakte mittels Dünnschichtchro- matographie}

Die Trennung der Lipidextrakte aller Körperfraktionen und der Exkremente wurde nach zwei dünnschichtchromatographischen Methoden durchgeführt. Die Lipidfraktionen, die ${ }^{14} \mathrm{C}$-Aktivität enthielten, konnten festgestellt und ihr prozentualer Anteil an der gesamten ${ }^{14} \mathrm{C}$-Aktivität ermittelt und aufgeführt werden. Die durchschnittlichen Ergebnisse der PCCholin- ${ }^{14} \mathrm{C}$ Versuchstiere (Mittelwerte der Tiere eins und zwei) und der PC-Linolsäure- ${ }^{14} \mathrm{C}$ Versuchstiere (Mittelwerte Tiere drei und vier) wurden aufgeführt.

Folgende Fraktionen werden zusammen in Tabellen dargestellt:

- die Körperfraktionen des Gastrointestinaltraktes und der Luftröhre,

- die Körperfraktionen der verschiedenen Organe und Blutbestandteile

- und die übrigen sechs Körperfraktionen und die Exkremente.

\subsubsection{Gemessene ${ }^{14} \mathrm{C}$-Aktivität in den getrennten Lipidfraktionen}

Mit dem Verfahren von FOLCH et al. (1957) erfolgte die Trennung der Lipidextrakte in die Lipidfraktionen Phospholipide (PL), Polymere (PM), freie Fettsäuren (fFS), Triacylglyceride (TG) und Cholesterinester (Chol). 


\subsubsection{PC-Cholin- $-{ }^{14} \mathrm{C}$ Tiere}

Bei den PC-Cholin- ${ }^{14} \mathrm{C}$ Tieren wurde in den Lipidextrakten aller Körperfraktionen und der Exkremente ${ }^{14} \mathrm{C}$-Aktivität ausschließlich in der Lipidfraktion Phospholipide wiedergefunden. In den übrigen Lipidfraktionen Polymere, freie Fettsäuren, Triacylglyceride und Cholesterinester wurden keine ${ }^{14} \mathrm{C}$-Aktivitäten gemessen.

\subsubsection{PC-Linolsäure- ${ }^{14} \mathrm{C}$ Tiere}

Bei den PC-Linolsäure- ${ }^{14} \mathrm{C}$ Tieren verteilte sich die ${ }^{14} \mathrm{C}$-Aktivität über alle Lipidfraktionen der Körperfraktionen und Exkremente. Die ${ }^{14} \mathrm{C}$-Aktivitätsverteilung auf die Lipidfraktionen der Lipidextrakte von fünf Körperfraktionen und der Exkremente wird in Tabelle 24 dargestellt.

Tabelle 24: Relative Verteilung der ${ }^{14} \mathrm{C}$-Aktivität der Lipidextrakte von fünf Körperfraktionen und der Exkremente der PC-Linolsäure- ${ }^{14} \mathrm{C}$ Tiere auf die Lipidfraktionen

\begin{tabular}{|l|r|r|r|r|r|}
\hline \multirow{2}{*}{$\begin{array}{l}\text { Lipidextrakte der Körper- } \\
\text { fraktionen und der Exkremente }\end{array}$} & \multicolumn{5}{|c|}{ PC-Linolsäure- ${ }^{14}$ C } \\
\cline { 2 - 6 } & PL & PM & fFS & TG & Chol \\
\cline { 2 - 6 } & \multicolumn{5}{|c|}{ \%-Aktvität in der Lipidfraktion } \\
\hline Muskel & 22,2 & 0,5 & 0,4 & 76,9 & - \\
\hline Abdominalfett & 5,9 & 1,1 & 1,7 & 91,3 & - \\
\hline Knochen & 17,4 & 3,7 & 1,0 & 77,9 & - \\
\hline Haut und Federn & 9,6 & 1,7 & 0,8 & 87,9 & - \\
\hline Füße und Kopf & 21,7 & 1,9 & 0,7 & 75,7 & - \\
\hline Exkremente & 72,9 & 7,7 & 17,4 & 1,1 & 0,9 \\
\hline
\end{tabular}

Tabelle 24 zeigt, daß im Lipidextrakt der Exkremente der größte relative ${ }^{14} \mathrm{C}$-Aktivitätsanteil in der Lipidfraktion Phospholipide und der zweitgrößte ${ }^{14} \mathrm{C}$-Anteil in der Lipidfraktion freie Fettsäuren gemessen wurde. In den Lipidfraktionen Polymere, Triacylglyceride und 
Cholesterinester waren noch ${ }^{14} \mathrm{C}$-Aktivitätsanteile von 7,7 \%, 1,1\% und 0,9 \% nachweisbar.

Bei den Lipidextrakten der Körperfraktionen konnten dagegen mindestens $75 \%$ der ${ }^{14} \mathrm{C}$ Aktivitätsanteile in der Lipidfraktion Triacylglyceride nachgewiesen werden. Die zweitgrößten ${ }^{14} \mathrm{C}$-Aktivitätsanteile wurden in der Lipidfraktion Phospholipide gemessen. In der Lipidfraktion Polymere wurden maximale ${ }^{14} \mathrm{C}$-Aktivitätsanteile von $3,7 \%$, in der Lipidfraktion freie Fettsäuren von 1,7 \%, gemesssen.

Die Ergebnisse der Untersuchungen zur relativen ${ }^{14} \mathrm{C}$-Aktivitätsverteilung auf die Lipidfraktionen der Lipidextrakte der Körperfraktionen verschiedener Organe und der Blutbestandteile sind in Tabelle 25 dargestellt.

Tabelle 25: Relative Verteilung der ${ }^{14} \mathrm{C}$-Aktivität von Lipidextrakten der Körperfraktionen verschiedener Organe und der Blutbestandteile der PC-Linolsäure- ${ }^{14} \mathrm{C}$ Tiere auf die Lipidfraktionen

\begin{tabular}{|l|c|c|c|c|c|}
\hline \multirow{2}{*}{$\begin{array}{l}\text { Lipidextrakte der } \\
\text { Körperfraktionen }\end{array}$} & \multicolumn{5}{|c|}{ PC-Linolsäure- ${ }^{\mathbf{1 4}} \mathbf{C}$} \\
\cline { 2 - 6 } & PL & PM & fFS & TG & Chol \\
\cline { 2 - 6 } & \multicolumn{5}{|c|}{ \%-Aktvität in der Lipidfraktion } \\
\hline Lunge & 53,8 & 10,4 & 1,4 & 29,4 & 5,0 \\
\hline Leber & 73,1 & 8,3 & - & 16,1 & 2,5 \\
\hline Herz & 32,3 & 1,7 & 0,5 & - & 65,5 \\
\hline Nieren & 79,7 & 5,1 & - & 15,2 & - \\
\hline Gehirn & 82,1 & 10,2 & 1,3 & 1,5 & 4,9 \\
\hline Serum & 57,8 & 4,1 & - & 2,7 & 35,4 \\
\hline feste Blutbestandteile & 65,9 & 17,7 & - & 5,8 & 10,6 \\
\hline
\end{tabular}

Tabelle 25 zeigt, daß die Lipidextrakte der Körperfraktionen verschiedener Organe und die der Blutbestandteile die größten ${ }^{14} \mathrm{C}$-Aktivitätsanteile in der Lipidfraktion Phospholipide aufwiesen. Eine Ausnahme bildete die Körperfraktion Herz, bei der der höchste ${ }^{14} \mathrm{C}$-Aktivitätsanteil des Lipidextraktes in der Lipidfraktion Cholesterinester wiederzufinden war. Die zweitgrößten ${ }^{14} \mathrm{C}$-Aktivitätsanteile waren bei den Lipidextrakten von Lunge, Leber und 
Nieren in der Lipidfraktion Triacylglyceride, bei den Lipidextrakten von Gehirn und feste Blutbestandteile in der Lipidfraktion Polymere, beim Lipidextrakt des Herzens in der Lipidfraktion Phospholipide und beim Lipidextrakt des Serums in der Lipidfraktion Cholesterinester meßbar. Die ${ }^{14} \mathrm{C}$-Aktivitätsanteile der restlichen Lipidfraktionen lagen unter $11 \%$.

Die relative Verteilung der ${ }^{14} \mathrm{C}$-Aktivität auf die Lipidfraktionen der Lipidextrakte der Körperfraktionen des Gastrointestinaltraktes und der Luftröhre zeigt Tabelle 26.

Tabelle 26: Relative Verteilung der ${ }^{14} \mathrm{C}$-Aktivität von Lipidextrakten der Körperfraktionen des Gastrointestinaltraktes und der Luftröhre der PC-Linolsäure- ${ }^{14} \mathrm{C}$ Tiere auf die Lipidfraktionen

\begin{tabular}{|c|c|c|c|c|c|}
\hline \multirow{3}{*}{$\begin{array}{l}\text { Lipidextrakte der } \\
\text { Körperfraktionen }\end{array}$} & \multicolumn{5}{|c|}{ PC-Linolsäure- ${ }^{14} \mathrm{C}$} \\
\hline & PL & PM & fFS & TG & Chol \\
\hline & \multicolumn{5}{|c|}{$\%$-Aktvität in der Lipidfraktion } \\
\hline Luftröhre & 9,0 & 1,5 & 1,3 & 88,2 & - \\
\hline Speiseröhre und Kropf & 20,5 & 2,9 & - & 76,6 & - \\
\hline Drüsenmagen mit Inhalt & 38,6 & 2,6 & 2,1 & 56,7 & - \\
\hline Muskelmagen & 13,6 & 1,8 & 1,8 & 82,8 & - \\
\hline Muskelmageninhalt & 60,3 & 12,2 & 6,1 & 21,4 & - \\
\hline Zwölffingerdarm* & 45,9 & 17,3 & 19,9 & 16,9 & - \\
\hline Dünndarm & 38,6 & 11,2 & 22,2 & 27,4 & 0,6 \\
\hline Dünndarminhalt & 62,3 & 18,4 & 14,2 & 4,5 & 0,6 \\
\hline Blinddarm & 55,3 & 4,4 & - & 4,9 & 35,4 \\
\hline Dickdarm, Kloake mit Inhalt & 23,9 & 3,9 & 2,7 & 69,5 & - \\
\hline
\end{tabular}

*mit Inhalt und Pankreas

Aus Tabelle 26 ist ersichtlich, daß in den Lipidfraktionen der Lipidextrakte aus den Körperfraktionen des oberen Gastrointestinaltraktes, von Speiseröhre und Kropf bis Muskelmagen einschließlich Luftröhre, die größten Anteile an der gesamten ${ }^{14} \mathrm{C}$-Aktivität in der Lipidfraktion Triacylglyceride zu finden waren. Die zweithöchsten Anteile wurden in der Lipidfraktion Phospholipide gemessen. Die ${ }^{14} \mathrm{C}$-Aktivitätsanteile in den Lipidfraktionen 
Polymere und freie Fettsäuren betrugen maximal 2,9\%. ${ }^{14} \mathrm{C}$-Aktivitäten in der Lipidfraktion Cholesterinester wurden nicht nachgewiesen.

In den Körperfraktionen vom unteren Teil des Gastrointestinaltraktes, daß heißt vom Muskelmageninhalt bis zu den Blinddärmen, befand sich der höchste ${ }^{14} \mathrm{C}$-Aktivitätsanteil in der Lipidfraktion Phospholipide. In den Lipidextrakten der Körperfraktionen Muskelmageninhalt und Dünndarm wurde der zweithöchste Anteil an ${ }^{14} \mathrm{C}$-Aktivität in der Lipidfraktion Triacylglyceride wiedergefunden. Im Lipidextrakt der Körperfraktion Muskelmageninhalt war der zweitgrößte Anteil in der Lipidfraktion freie Fettsäuren, bei der Körperfraktion Dünndarminhalt in der Lipidfraktion Polymere und bei der Körperfraktion Blinddarm in der Lipidfraktion Cholesterinester gemessen worden. Auch die Lipidfraktion Polymere wies in den Lipidextrakten der Körperfraktionen ${ }^{14} \mathrm{C}$-Aktivitätsanteile bis zu 18,4 \% auf. Ebenso wurden in den freien Fettsäuren ${ }^{14} \mathrm{C}$-Aktivitätsanteile über $22 \%$ in den jeweiligen Lipidextrakten gemessen.

Erst im letzten Abschnitt des Gastrointestinaltraktes, im Lipidextrakt von Dickdarm, Kloake mit Inhalt, war der höchste ${ }^{14} \mathrm{C}$-Aktivitätsanteil wieder in der Lipidfraktion Triacylglyceride und der zweitgrößte ${ }^{14} \mathrm{C}$-Anteil in der Lipidfraktion Phospholipide zu finden.

\subsubsection{Gemessene ${ }^{14} \mathrm{C}$-Aktivität in den getrennten Phospholipidfraktionen}

Die Lipidextrakte der Körperfraktionen und Exkremente wurden dünnschichtchromatographisch in die Lipidfraktionen Lysophosphatidylcholin und Lysophosphatidylethanolamin (Lyso-PC+PE), Phosphatidylcholin (PC), Phosphatidylinosit (PI), Phosphatidylethanolamin (PE), Cardiolipin (CL) und freie Fettsäuren / Triacylglyceride (fFS / TG) getrennt. 


\subsubsection{PC-Cholin- $-{ }^{14} \mathrm{C}$ Tiere}

Die in den Lipidextrakten der Körperfraktionen und Exkremente der PC-Cholin- ${ }^{14} \mathrm{C}$ Tiere wiedergefundene ${ }^{14} \mathrm{C}$-Aktivität verteilte sich über die Lysophosphatidylfraktionen (Lyso$\mathrm{PC}+\mathrm{PE})$ und die Lipidfraktion Phosphatidylcholin (PC). In allen anderen Lipidfraktionen konnte keine ${ }^{14} \mathrm{C}$-Aktivität festgestellt werden.

Die Verteilung der ${ }^{14} \mathrm{C}$-Aktivität auf die Lipidfraktionen der Lipidextrakte von fünf Körperfraktionen und der Exkremente wird in Tabelle 27 aufgeführt.

Tabelle 27: Relative Verteilung der ${ }^{14} \mathrm{C}$-Aktivität der Lipidextrakte von fünf Körperfraktionen und der Exkremente der PC-Cholin- ${ }^{14} \mathrm{C}$ Tiere auf die Lipidfraktionen

\begin{tabular}{|c|c|c|}
\hline \multirow{3}{*}{$\begin{array}{l}\text { Lipidextrakte der Körper- } \\
\text { fraktionen und Exkremente }\end{array}$} & \multicolumn{2}{|c|}{ PC-Cholin- ${ }^{14} \mathrm{C}$} \\
\hline & Lyso-PC+PE & PC \\
\hline & \multicolumn{2}{|c|}{ \%-Aktivität in der Lipidfraktion } \\
\hline Muskel & 18,3 & 81,7 \\
\hline Abdominalfett & 10,2 & 89,8 \\
\hline Knochen & 18,9 & 81,1 \\
\hline Haut und Federn & 21,0 & 79,0 \\
\hline Füße und Kopf & 22,7 & 77,3 \\
\hline Exkremente & 46,6 & 53,4 \\
\hline
\end{tabular}

Wie Tabelle 27 zeigt, wurden die höchsten ${ }^{14} \mathrm{C}$-Aktivitätsanteile in der Lipidfraktion Phosphatidylcholin festgestellt. Im Lipidextrakt der Exkremente verteilte sich die ${ }^{14} \mathrm{C}$-Aktivität zu etwa gleichen Anteilen auf die Lysophosphatidyl- und Phosphatidylcholinfraktionen.

Mit ${ }^{14}$ C-Aktivitätsanteilen zwischen 18,3\% - 22,7 \% in den Lysophosphatidylfraktionen der Körperfraktionen Muskel, Knochen, Haut und Federn sowie Füße und Kopf wurden fast übereinstimmende Anteile an der gesamten ${ }^{14} \mathrm{C}$-Aktivität gemessen. Der Lipidextrakt der Körperfraktion Abdominalfett zeigte dagegen nur ${ }^{14} \mathrm{C}$-Aktivitätsanteile von 10,2 \%. 
Die relative Verteilung der ${ }^{14} \mathrm{C}$-Aktivität auf die Lipidfraktionen der jeweiligen Lipidextrakte der Körperfraktionen verschiedener Organe und der Blutbestandteile wird in Tabelle 28 aufgeführt.

Tabelle 28: Relative Verteilung der ${ }^{14} \mathrm{C}$-Aktivität von Lipidextrakten verschiedener Organe und der Blutbestandteile der PC-Cholin- ${ }^{14} \mathrm{C}$ Tiere auf die Lipidfraktionen

\begin{tabular}{|c|c|c|}
\hline \multirow{3}{*}{$\begin{array}{l}\text { Lipidextrakte der } \\
\text { Körperfraktionen }\end{array}$} & \multicolumn{2}{|c|}{ PC-Cholin- $-{ }^{14} \mathrm{C}$} \\
\hline & Lyso-PC+PE & PC \\
\hline & \multicolumn{2}{|c|}{ \%-Aktivität in der Lipidfraktion } \\
\hline Lunge & 14,1 & 85,9 \\
\hline Leber & 13,3 & 86,2 \\
\hline Herz & 12,7 & 87,3 \\
\hline Nieren & 18,7 & 81,3 \\
\hline Gehirn & 32,9 & 67,1 \\
\hline Serum & 11,2 & 88,8 \\
\hline feste Blutbestandteile & 15,7 & 84,3 \\
\hline
\end{tabular}

Tabelle 28 verdeutlicht, daß die höchsten ${ }^{14} \mathrm{C}$-Aktivitätsanteile der Lipidextrakte der aufgeführten Körperfraktionen in der Lipidfraktion Phosphatidylcholin wiedergefunden wurden. Mit Ausnahme des Gehirns konnten ${ }^{14} \mathrm{C}$-Aktivitätsanteile von über 81,3\% festgestellt werden. Der Lipidextrakt der Körperfraktion Gehirn hatte in der Phosphatidylcholinfraktion einen ${ }^{14} \mathrm{C}$-Aktivitätsanteil von nur 67,1 \%. Dafür wies er in den Lysophosphatidylfraktionen mit 32,9\% einen deutlich höheren ${ }^{14} \mathrm{C}$-Aktivitätsanteil auf als die anderen Lipidextrakte mit ${ }^{14} \mathrm{C}$-Aktivitätsanteilen von maximal $18,7 \%$.

In Tabelle 29 wird die relative Verteilung der ${ }^{14} \mathrm{C}$-Aktivität auf die Lipidfraktionen der Lipidextrakte der Fraktionen des Gastrointestinaltraktes und der Luftröhre aufgeführt. 
Tabelle 29: Relative Verteilung der ${ }^{14} \mathrm{C}$-Aktivität von Lipidextrakten der Körperfraktionen des Gastrointestinaltraktes und der Luftröhre der PC-Cholin- ${ }^{14} \mathrm{C}$ Tiere auf die Lipidfraktionen

\begin{tabular}{|l|c|c|}
\hline \multirow{2}{*}{$\begin{array}{l}\text { Lipidextrakte der } \\
\text { Körperfraktionen }\end{array}$} & \multicolumn{2}{|c|}{ PC-Cholin- ${ }^{14}$ C } \\
\cline { 2 - 3 } & Lyso-PC+PE & PC \\
\hline Luftröhre & 20,9 & 79,1 \\
\hline Speiseröhre und Kropf & 25,3 & 74,7 \\
\hline Drüsenmagen mit Inhalt & 15,1 & 84,9 \\
\hline Muskelmagen & 27,4 & 72,6 \\
\hline Muskelmageninhalt & 57,2 & 42,8 \\
\hline Zwölffingerdarm* & 58,0 & 42,0 \\
\hline Dünndarm & 23,8 & 76,2 \\
\hline Dünndarminhalt & 73,2 & 26,8 \\
\hline Blinddarm & 27,4 & 72,6 \\
\hline Dickdarm, Kloake mit Inhalt & 30,0 & 70,0 \\
\hline
\end{tabular}

*mit Inhalt und Pankreas

Tabelle 29 zeigt, daß die Lipidextrakte der Körperfraktionen Luftröhre, Speiseröhre und Kropf, Muskelmagen, Drüsenmagen mit Inhalt die größten ${ }^{14} \mathrm{C}$-Aktivitätsanteile, von $72,6 \%$ bis 84,9 \%, jeweils in der Lipidfraktion Phosphatidylcholin aufwiesen. In den Lysophosphatidylfraktionen dieser Lipidextrakte wurden ${ }^{14} \mathrm{C}$-Aktivitätsanteile zwischen $15,1 \%-27,4 \%$ gemessen. In den Lipidextrakten der Körperfraktionen Muskelmageninhalt, Zwölffingerdarm mit Inhalt und Pankreas waren $30 \%$ bis $40 \%$ geringere ${ }^{14} \mathrm{C}$-Aktivitätsanteile in den jeweiligen Phosphatidylcholinfraktionen und dafür $30 \%$ bis $40 \%$ höhere ${ }^{14} \mathrm{C}$-Aktivitätsanteile in den jeweiligen Lysophosphatidylfraktionen erkennbar.

In den Lipidextrakten der Körperfraktionen Dünndarm, Blinddarm, Dickdarm, Kloake mit Inhalt waren vergleichbare ${ }^{14} \mathrm{C}$-Aktivitätsverteilungen wie bei den oberen drei Körperfraktionen des Gastointestinaltraktes und der Luftröhre nachweisbar. Nur die Körperfraktion Dünndarminhalt wich davon ab, da die Lysophosphatidylfraktionen mit 73,2 \% die höch- 
sten Anteile an der gesamten ${ }^{14} \mathrm{C}$-Aktivität des Lipidextraktes aufwiesen, und die Lipidfraktion Phosphatidylcholin nur 26,8 \% ausmachte.

\subsubsection{PC-Linolsäure- ${ }^{14} \mathrm{C}$ Tiere}

Bei den PC-Linolsäure- ${ }^{14} \mathrm{C}$ Tieren verteilte sich die ${ }^{14} \mathrm{C}$-Aktivität zum Teil über alle Lipidfraktionen. Tabelle 30 zeigt die relative Verteilung der ${ }^{14} \mathrm{C}$-Aktivität auf die Lipidfraktionen der Lipidextrakte von fünf Körperfraktionen und der Exkremente.

Tabelle 30: Relative Verteilung der ${ }^{14} \mathrm{C}$-Aktivität der Lipidextrakte von fünf Körperfraktionen und der Exkremente der PC-Linolsäure- ${ }^{14} \mathrm{C}$ Tiere auf die Lipidfraktionen

\begin{tabular}{|c|c|c|c|c|c|c|c|}
\hline \multirow{3}{*}{$\begin{array}{l}\text { Lipidextrakte der Körper- } \\
\text { fraktionen und Exkremente }\end{array}$} & \multicolumn{7}{|c|}{ PC-Linolsäure- ${ }^{14} \mathrm{C}$} \\
\hline & $\begin{array}{c}\text { Lyso- } \\
\text { PC+PE }\end{array}$ & PC & PI & PS & PE & $\mathbf{C L}$ & $\begin{array}{l}\text { fFS } \\
\text { / TG }\end{array}$ \\
\hline & \multicolumn{7}{|c|}{ \%-Aktvität in der Lipidfraktion } \\
\hline Muskel & - & 7,4 & - & - & - & - & 92,6 \\
\hline Abdominalfett & - & 1,2 & - & - & - & - & 98,8 \\
\hline Knochen & - & 7,9 & - & - & 0,8 & - & 91,3 \\
\hline Haut und Federn & - & 2,0 & - & - & - & 1,7 & 96,3 \\
\hline Füße und Kopf & - & 5,0 & - & 5,7 & 2,3 & 3,6 & 83,4 \\
\hline Exkremente & - & 27,4 & - & 3,6 & 9,8 & 16,5 & 42,7 \\
\hline
\end{tabular}

Bei den Körperfraktionen und Exkrementen (Tabelle 30) waren die größten ${ }^{14} \mathrm{C}$-Aktivitätsanteile der Lipidextrakte in der Fraktion freie Fettsäuren/Triacylglyceride meßbar. Mit Ausnahme des Lipidextraktes der Körperfraktion Füße und Kopf waren in der Lipidfraktion Phosphatidylcholin die zweitgrößten ${ }^{14} \mathrm{C}$-Aktivitätsanteile zu finden. Die ${ }^{14} \mathrm{C}$-Aktivität der Lipidextrakte der Körperfraktionen Muskel und Abdominalfett fand sich ausschließlich in diesen zwei Lipidfraktionen. In den Lysophosphatidylfraktionen und der Fraktion Phosphatidylinosit wurden keine ${ }^{14} \mathrm{C}$-Aktivitäten nachgewiesen. ${ }^{14} \mathrm{C}$-Aktivität in der Lipidfraktion Phosphatidylethanolamin wurde nur geringfügig in den Lipidextrakten der Körper- 
fraktionen Knochen, Füße und Kopf und zu 9,8 \% im Lipidextrakt der Exkremente nachgewiesen. In der Lipidfraktion Phosphatidylserin wurde nur in den Lipidextrakten der Körperfraktionen Füße und Kopf und in den Exkrementen ${ }^{14} \mathrm{C}$-Aktivität gemessen. In der Fraktion Cardiolipin konnten in den Lipidextrakten der Körperfraktionen Haut und Federn, Füße und Kopf geringe ${ }^{14} \mathrm{C}$-Aktivitätsanteile und im Lipidextrakt der Exkremente ein Anteil von 16,5\% an der gesamten ${ }^{14} \mathrm{C}$-Aktivität des Lipidextraktes festgestellt werden.

Außer bei den fünf Körperfraktionen und den Exkrementen wurde die relative Verteilung der ${ }^{14} \mathrm{C}$-Aktivität auf die Lipidfraktionen der Lipidextrakte der Körperfraktionen bei verschiedenen Organen und den Blutbestandteilen untersucht (Tabelle 31).

Tabelle 31: Relative Verteilung der ${ }^{14} \mathrm{C}$-Aktivität von Lipidextrakten verschiedener Organe und der Blutbestandteile der PC-Linolsäure- ${ }^{14} \mathrm{C}$ Tiere auf die Lipidfraktionen

\begin{tabular}{|l|c|c|c|c|c|c|c|c|}
\hline \multirow{2}{*}{$\begin{array}{l}\text { Lipidextrakte der } \\
\text { Körperfraktionen }\end{array}$} & \multicolumn{7}{|c|}{ PC-Linolsäure- ${ }^{14}$ C } \\
\cline { 2 - 9 } & $\begin{array}{c}\text { Lyso- } \\
\text { PC+PE }\end{array}$ & PC & PI & PS & PE & CL & $\begin{array}{c}\text { fFS } \\
\text { / TG }\end{array}$ \\
\cline { 2 - 9 } & \multicolumn{7}{|c|}{ \%-Aktvität in der Lipidfraktion } \\
\hline Lunge & - & 28,3 & - & - & 10,9 & - & 60,8 \\
\hline Serum & - & 23,7 & 3,8 & - & - & 3,4 & 69,1 \\
\hline feste Blutbestandteile & 1,4 & 32,6 & - & 9,1 & - & - & 56,9 \\
\hline Leber & - & 26,9 & 6,4 & 2,8 & 20,0 & 11,5 & 32,4 \\
\hline Herz & - & 17,1 & - & - & 4,4 & 1,3 & 77,2 \\
\hline Gehirn & 10,7 & 34,4 & 11,5 & - & 25,4 & 4,3 & 13,7 \\
\hline Nieren & 3,6 & 30,6 & 5,0 & 3,4 & 22,4 & - & 35,0 \\
\hline
\end{tabular}

Wie die Lipidextrakte der Körperfraktionen des Gastrointestinaltraktes und der Luftröhre (Tabelle 29) wiesen auch die Lipidextrakte verschiedener Organe und der Blutbestandteile die größten ${ }^{14} \mathrm{C}$-Aktivitätsanteile in der Lipidfraktion freie Fettsäuren/Triacylglyceride und die zweitgrößten ${ }^{14} \mathrm{C}$-Aktivitätsanteile in der Lipidfraktion Phosphatidylcholin auf (Tabelle 31). Eine Ausnahme stellte sich im Lipidextrakt der Körperfraktion Gehirn heraus. Er wies mit 34,4 \% in der Phosphatidylcholinfraktion den höchsten, mit 25,4 \% in der Phosphatidylethanolaminfraktion den zweithöchsten und mit 13,7 \% in der Lipidfraktion freie Fett- 
säuren/Triacylglyceride nur den dritthöchsten Anteil an der ${ }^{14} \mathrm{C}$-Aktivität des Lipidextraktes auf.

Mit 10,9\% in der Lunge, 20,0 \% in der Leber und 22, $4 \%$ in den Nieren konnte in den Lipidextrakten der jeweiligen Körperfraktionen ein relativ hoher ${ }^{14} \mathrm{C}$-Aktivitätsanteil in der Lipidfraktion Phosphatidylethanolamin festgestellt werden. Ansonsten waren nur in den Lipidextrakten die Fraktionen Phosphatidylinosit (Gehirn) und Cardiolipin (Leber) ${ }^{14} \mathrm{C}$ Aktivitätsanteile von über $11 \%$ meßbar. In Tabelle 32 wird die relative Verteilung der ${ }^{14} \mathrm{C}$ Aktivität auf die Lipidfraktionen von Lipidextrakten der Körperfraktionen des Gastrointestinaltraktes und der Luftröhre aufgeführt.

Tabelle 32: Relative Verteilung der ${ }^{14} \mathrm{C}$-Aktivität von Lipidextrakten der Körperfraktionen des Gastrointestinaltraktes und der Luftröhre der PC-Linolsäure- ${ }^{14} \mathrm{C}$ Tiere auf die Lipidfraktionen

\begin{tabular}{|l|c|c|c|c|c|c|c|c|}
\hline \multirow{2}{*}{$\begin{array}{l}\text { Lipidextrakte der } \\
\text { Körperfraktionen }\end{array}$} & \multicolumn{7}{|c|}{ PC-Linolsäure- ${ }^{14}$ C } \\
\cline { 2 - 9 } & $\begin{array}{c}\text { Lyso- } \\
\text { PC+PE }\end{array}$ & PC & PI & PS & PE & CL & $\begin{array}{c}\text { fFS } \\
\text { / TG }\end{array}$ \\
\cline { 2 - 9 } & \multicolumn{7}{|c|}{$\%$-Aktvität in der Lipidfraktion } \\
\hline Luftröhre & - & 3,0 & - & - & 0,7 & - & 96,3 \\
\hline Speiseröhre und Kropf & - & 5,7 & - & - & 2,6 & - & 91,7 \\
\hline Drüsenmagen mit Inhalt & - & 18,8 & - & - & 5,6 & 5,3 & 70,3 \\
\hline Muskelmagen & - & 7,7 & - & - & 1,8 & 1,4 & 89,1 \\
\hline Zwölffingerdarm* & 4,5 & 9,6 & 4,6 & 3,5 & 9,3 & 7,1 & 61,4 \\
\hline Dünndarm & 2,2 & 6,9 & 3,3 & 1,9 & 6,4 & 2,9 & 76,4 \\
\hline Dünndarminhalt & 9,8 & 4,3 & 1,8 & 9,8 & - & 4,1 & 70,2 \\
\hline Blinddarm & 2,3 & 14,9 & 1,6 & 0,6 & 11,3 & 2,7 & 66,6 \\
\hline Dickdarm, Kloake mit Inhalt & - & 4,5 & - & 1,1 & 4,7 & 1,4 & 88,3 \\
\hline
\end{tabular}

*mit Inhalt und Pankreas

Wie aus Tabelle 32 ersichtlich ist, wurden die höchsten ${ }^{14} \mathrm{C}$-Aktivitätsanteile der Lipidextrakte der aufgeführten Körperfraktionen in der Lipidfraktion freie Fettsäuren/Triacylglyceride wiedergefunden. Mit Ausnahme der Lipidextrakte der Körperfraktionen Dünndarminhalt, Dickdarm, Kloake mit Inhalt wiesen alle anderen Körperfraktionen den zweit- 
größten ${ }^{14} \mathrm{C}$-Aktivitätsanteil in der Phosphatidylcholinfraktion auf. Während die Lipidextrakte der Körperfraktionen Luftröhre, Speiseröhre und Kropf nur noch geringe ${ }^{14} \mathrm{C}$-Aktivitätsanteile in der Lipidfraktion Phosphatidylethanolamin aufwiesen, waren bei den Lipidextrakten der Körperfraktionen Muskelmagen, Drüsenmagen mit Inhalt zusätzlich ${ }^{14} \mathrm{C}$ Aktivitätsanteile im Cardiolipin und bei den Lipidextrakten der Körperfraktionen Dickdarm, Kloake mit Inhalt sogar noch in den Phosphatidylserinen nachweisbar.

Mit Ausnahme der Phosphatidylethanolamine bei der Körperfraktion Dünndarminhalt wurde in den übrigen Lipidfraktionen dieser Lipidextrakte ${ }^{14} \mathrm{C}$-Aktivität festgestellt. Der Lipidextrakt der Körperfraktion Blinddarm war der einzige, bei dem in allen Lipidfraktionen ${ }^{14} \mathrm{C}$-Aktivität vorhanden war. 


\section{DISKUSSION}

\section{1}

\section{Zur Methodik und zur Literatur}

Die radioaktive Substanz wurde gelöst in $150 \mu$ Ethanol : Toluol geliefert. Der Versuch davon jeweils $5 \mu \mathrm{lu}$ entnehmen, um exakt feststellen zu können wieviel Aktivität in der Transportkapsel war, scheiterte, da das Phosphatidylcholin aufgrund seiner Dickflüssigkeit in der geringen Menge nicht exakt pipettiert werden konnte.

Wie schon in früheren Arbeiten (MOLNAR, 1968; ABEL, 1971; GERSTÄDT, 1991), wurde sich daher auf die wiedergefundene ${ }^{14} \mathrm{C}$-Aktivität bezogen, indem für jedes Versuchstier die Verteilung der wiedergefundenen ${ }^{14} \mathrm{C}$-Aktivität ermittelt wurde. Diese erfaßte die ${ }^{14} \mathrm{C}$-Aktivität der Atemluft und der Exkremente vom Zeitpunkt der Markierung bis zur Schlachtung sowie die ${ }^{14} \mathrm{C}$-Aktivität aller Körperfraktionen des jeweiligen Tieres. Da alle Fraktionen zur Aktivitätsmessung erfaßt wurden, kann davon ausgegangen werden, daß zwischen wiedergefundener und eingesetzter ${ }^{14} \mathrm{C}$-Aktivität keine großen Differenzen bestanden.

Die Literaturdurchsicht ergab, daß über ${ }^{14} \mathrm{C}$-Aktivitätsmessungen 24 Stunden nach der Applikation von radioaktiv markiertem Phosphatidylcholin in Körperfraktionen und Exkrementen keine vergleichende Literatur auf dem Geflügelsektor und sehr wenig bei anderen Tierarten vorliegt. Diese Tatsache erschwerte die Diskussion, so daß deshalb verstärkt Literatur zum Stoffwechselgeschehen eingesetzt wurde, die wiederum größtenteils aus Tierversuchen mit Ratten stammte. Ähnliche Probleme traten bei der Literatursuche über ${ }^{14} \mathrm{C}$ Aktivitätsmessungen nach dünnschichtchromatographischer Trennung von Lipidextrakten auf. Über dünnschichtchromatographische Trennungen von ${ }^{14} \mathrm{C}$-Aktivitäten der Lipidextrakte von Körperfraktionen und Exkrementen mit Auswertung der relativen Verteilung der ${ }^{14} \mathrm{C}$-Aktivität in einzelnen Lipid- und Phospholipidfraktionen stand keine vergleichende Literatur zur Verfügung. 
$\underline{\text { PC-Cholin- }{ }^{14} \mathrm{C} \text { Tiere }}$

Der Anteil an wiedergefundener ${ }^{14} \mathrm{C}$-Aktivität in der Atemluft betrug beim ersten Versuchstier 1,2\% und beim zweiten Versuchstier 1,5\%. Die Gehalte verdeutlichen, daß Cholin für die Verstoffwechselung in der Atemluft eine sehr geringe Bedeutung hat. LEKIM und BETZING (1976) zeigten in Untersuchungen an Ratten, daß Cholin gegenüber der Metabolisierung in der Atemluft eine hohe Stabilität aufweist. Nach Gabe von Cholin- ${ }^{14} \mathrm{C}$ markiertem Phosphatidylcholin an Ratten konnten sie ebenfalls nur einen Aktivitätsanteil von $1,8 \%$ an der gesamten ${ }^{14} \mathrm{C}$-Aktivität in der Atemluft feststellen.

\section{$\underline{\text { PC-Linolsäure- }{ }^{14} \mathrm{C} \text { Tiere }}$}

Die aus Phospholipiden freigesetzten Fettsäuren unterliegen dem katabolen Stoffwechsel bis zu den Endprodukten Kohlendioxid und Wasser. Daher liefert die hydrolysierte, mit ${ }^{14} \mathrm{C}$-markierte Linolsäure ${ }^{14} \mathrm{CO}_{2}$ (LEKIM und GRAF, 1976). Mit Aktivitätsanteilen von 7,6\% (drittes Versuchstier) und 8,5\% (viertes Versuchstier) an der wiedergefundenen ${ }^{14} \mathrm{C}$ Aktivität beinhaltete die Atemluft den fünftgrößten ${ }^{14} \mathrm{C}$-Aktivitätsanteil aller Fraktionen. Untersuchungen von FOX (1983) ergaben, daß Fettsäuren die in C-2 Position des Phosphatidylcholins markiert wurden deutlich höhere ${ }^{14} \mathrm{C}$-Aktivitätsanteile im Kohlendioxid der Atemluft aufwiesen, als in C-1 Position befindliche Fettsäuren des Phosphatidylcholins und Cholin- ${ }^{14}$ C. Nach Applikation von Phosphatidylcholin an dem die Linolsäure (C-2) mit ${ }^{14} \mathrm{C}$ markiert war, stellten LEKIM und BETZING (1976) nach sechs Versuchsstunden schon eine Abgabe von 7,7 \% der verabreichten Dosis in der Atemluft fest. Bei den eigenen Messungen über einen Zeitraum von 24 Stunden wurden in den ersten fünf Stunden die höchsten ${ }^{14} \mathrm{CO}_{2}$-Aktivitäten in der Atemluft festgestellt. Untersuchungen von EYO (1975) ergaben ähnliche Resultate. Er applizierte ${ }^{14} \mathrm{C}$-markierte Linolsäure an Ratten und stellte höchste ${ }^{14} \mathrm{C}$-Aktivitätsausscheidungen zwischen der ersten und fünften Stunde fest. Im Gegensatz dazu lieferten kurzkettige Fettsäuren direkt in den ersten zwei Stunden maximale Werte. Die Ursache liegt darin, daß kurzkettige Fettsäuren kürzere Absorptionswege haben (EYO, 1975) und schneller oxidiert werden als langkettige Fettsäuren (LOSSOW und CHAIKOFF, 1955). 
$\underline{\text { PC-Cholin- }{ }^{14} \mathrm{C} \text {-Tiere }}$

Trotz geringer prozentualer Unterschiede in den gleichen Fraktionen waren bei beiden Versuchstieren die höchsten ${ }^{14} \mathrm{C}$-Aktivitätsanteile in den Fraktionen Muskel, Exkremente, Knochen und Leber, mit je über 11,5 \%, festzustellen. Da diese Fraktionen die größten Gewichtsanteile aufwiesen, enthielten sie, auf die jeweils gesamte Fraktion bezogen, auch die höchsten ${ }^{14} \mathrm{C}$-Aktivitätsanteile. Ähnlich schien es bei der Fraktion Füße und Kopf mit Aktivitätsanteilen von über $5 \%$ zu sein.

Die Leber stellt das zentrale Organ für die Verstoffwechselung von Phospholipiden dar (KOLB, 1980). Sie beinhaltete 24 Stunden nach der Markierung noch Aktivitätsanteile von 11,7 \% (erstes Tier) bzw. 13,7 \% (zweites Tier). Nach den vorliegenden Ergebnissen können von der Leber aus, folgende Stoffwechselwege des Phosphatidylcholins angenommen werden. FOX (1983) beschrieb nach Untersuchungen an Gallengang-kanülierten Ratten, daß eine beachtliche Menge von ${ }^{14} \mathrm{C}$-markiertem Phosphatidylcholin in die Galle sekretiert wird. ${ }^{14} \mathrm{C}$-Aktivitätsanteile von über $6 \%$ im Dünndarm und über $4 \%$ im Zwölffingerdarm mit Inhalt und Pankreas lassen vermuten, daß aktives Phosphatidylcholin über die Galle in den Darm gelangt. Eine weitere Möglichkeit für solch eine Verteilung wäre, daß ein Teil der ${ }^{14} \mathrm{C}$-Aktivität erst nach 24 Stunden zur Absorption kommt, da sie aufgrund niedrig verdaulicher Futterreste im Darm zurückgehalten wird. Nach SCHOLTYSSEK (1987) kann bei einer normalen Futterration, die Passage unverdaulicher Futterreste bis zu 48 Stunden dauern.

Die Untersuchungen ergaben, daß Cholin- ${ }^{14} \mathrm{C}$ nur an Phosphatidylcholin gebunden in den Lipidextrakten vorliegt. Daher ist anzunehmen, daß nicht das gesamte Phosphatidylcholin im Organismus ungespalten bleibt. Aus der Literatur ist bekannt, daß Cholin z.B. als Acetylcholinbestandteil (BLUSZTAJN und WURTMAN, 1983; ULUS et al., 1988; CANTY und ZEISEL, 1994) oder als Methylgruppendonator fungiert (SCOTT et al., 1969), nachdem das Phosphatidylcholin um- bzw. abgebaut wurde. Ein Methylgruppenakzeptor kann das Homocystein unter Bildung von Methionin sein, welches bei Bedarf weiter zu Cystein umgebaut werden kann (SCHENK und KOLB, 1990). Der Einbau der Aminosäuren in das Federkleid könnte eine Erklärung für die ${ }^{14} \mathrm{C}$-Aktivitätsanteile von über $6 \%$ in der Frak- 
tion Haut und Federn geben, da beide Aminosäuren im Federmehl enthalten sind, welches zu $82 \%$ aus Eiweiß besteht (SCHOLTYSSEK, 1987).

Bei der Klärung der Frage, ob die ${ }^{14} \mathrm{C}$-Aktivitätsanteile der Exkremente nur aus den $\mathrm{Ab}$ bauprodukten des Cholins- ${ }^{14} \mathrm{C}$ bestehen, ist folgendes zu berücksichtigen:

Phospholipide machen den Hauptteil der Gallenlipide aus (BAXTER, 1966). Bei der Emulgierung von Nahrungsbestandteilen bleibt ein Teil der endogenen Phospholipide im Chymus zurück und wird mit den Exkrementen ausgeschieden. Weiter ist aus der Literatur bekannt, daß aufgenommene Nahrungsfette nicht vollständig absorbiert werden (SCHOLTYSSEK, 1987) und somit im geringen Umfang unabsorbiert in den Exkrementen erscheinen. Demnach ist anzunehmen, daß unabsorbierte und mit der Galle sekretierte Phospholipide Einfluß auf den ${ }^{14} \mathrm{C}$-Aktivitätsgehalt der Exkremente haben. Vermutlich wurde das Phosphatidylcholin nicht nur um- bzw. abgebaut mit den Exkrementen ausgeschieden, sondern zum geringen Teil auch intakt.

\section{$\underline{\text { PC-Linolsäure- }{ }^{14} \mathrm{C} \text { Tiere }}$}

Unterschiede der ${ }^{14} \mathrm{C}$-Aktivitätsverteilung zwischen den gleichen Fraktionen beider Tiere lagen hauptsächlich darin begründet, daß das vierte Tier am Tag der Schlachtung mit 825,7 g knapp $60 \mathrm{~g}$ weniger wog als das dritte Tier. Aufgrund dessen wurde angenommen, daß das vierte Tier, bezogen auf das Körpergewicht, mehr Energie für die Aufbauphase von Knochen und Muskeln benötigte. So wies es mit Aktivitätsanteilen von über $16 \%$ in den Fraktionen Knochen und Muskeln um $4 \%$ - $6 \%$ höhere ${ }^{14} \mathrm{C}$-Aktivitätsanteile auf als das dritte Tier. Desweiteren besaß es um 4,3\% geringere ${ }^{14} \mathrm{C}$-Aktivitätsanteile im Abdominalfett als das schwerere Tier. Da der Energieansatz bei wachsenden Broilern sich stofflich aus Protein und Fett zusammensetzt (KIRCHGEBNER, 1997), besteht die Vermutung, daß beim leichteren Tier geringere ${ }^{14} \mathrm{C}$-Aktivitätsanteile mit den Fettsäuren ins Abdominalfett transportiert werden, da es die Fettsäuren vermehrt für den Energiestoffwechsel benötigt.

Das schwerere Tier nahm außerdem höhere Futtermengen auf und hatte somit mehr Energie für Stoffwechselleistungen zur Verfügung. Aus diesem Grund schied es größere Exkrementmengen und somit auch mit 26,8 \% um 8,2 \% höhere ${ }^{14} \mathrm{C}$-Aktivitätsanteile aus, als das leichtere Tier. 
Trotz der Unterschiede bei der ${ }^{14} \mathrm{C}$-Aktivitätsverteilung waren bei beiden Tieren in den Fraktionen Muskel, Exkremente und Knochen die höchsten relativen ${ }^{14} \mathrm{C}$-Aktivitätsanteile, von je über $10 \%$, feststellbar. Da sie zu den Fraktionen mit den größten Gewichtsanteilen zählten, beinhalteten sie, auf die gesamte Fraktion bezogen, die höchsten ${ }^{14} \mathrm{C}$-Aktivitätsanteile. Wie schon in Kapitel 5.2 ausführlich beschrieben, verdeutlicht der ${ }^{14} \mathrm{C}$-Aktivitätsanteil in der Fraktion Atemluft von 7,6 \% bzw. 8,5 \%, daß die ${ }^{14} \mathrm{C}$-markierte Linolsäure des Phosphatidylcholins intermediär energetisch genutzt und somit abgebaut wird, woraus die hohen ${ }^{14} \mathrm{CO}_{2}$-Gehalte resultieren.

Bei der Verdauung werden die Phospholipide im Duodenum hydrolysiert und dann in die Mucosazellen absorbiert (SCOW et al., 1967). Nach der Absorption werden circa $75 \%$ der Fettsäuren nicht mit den Phospholipiden reverestert, sondern als Triacylglyceride in den Lipoproteinen gebunden und so zur Leber transportiert (LEKIM und GRAF, 1976). Von der Leber aus gelangen Triacylglyceride mittels Lipoproteinen ins Fettgewebe (HERMIER, 1997). ${ }^{14} \mathrm{C}$-Aktivitätsanteile von 18,7 \% bzw. 19,5\% im Unterhautfettgewebe von Haut und Federn und von 4,6 \% im Abdominalfett des dritten Tieres lassen auf den aufgeführten Stoffwechselweg schließen.

\subsection{1}

\section{${ }^{14}$ C-Aktivität pro Gramm der Fraktionen mit den höchsten Aktivitäten}

\section{$\underline{\text { PC-Cholin- }{ }^{14} \mathrm{C} \text { Tiere }}$}

Die wiedergefundene ${ }^{14} \mathrm{C}$-Aktivität war beim ersten Versuchstier mit 269,847 kBq geringer als beim zweiten Versuchstier mit $327,378 \mathrm{kBq}$. Die ${ }^{14} \mathrm{C}$-Aktivitäten pro Gramm der Fraktionen mit den höchsten ${ }^{14} \mathrm{C}$-Gehalten wurden in Tabelle 33 aufgeführt. Bei beiden Tieren stimmten die Fraktionen mit den jeweils höchsten ${ }^{14} \mathrm{C}$-Gehalten überein.

Die höchsten Aktivitätsgehalte waren in der Fraktion Leber meßbar, was die Annahme verstärkt, daß die Leber das zentrale Organ im Phospholipidstoffwechsel darstellt (KOLB, 1980). 
Tabelle 33: $\quad{ }^{14} \mathrm{C}$-Aktivität pro Gramm (Bq/g) Fraktion der Fraktionen mit den höchsten ${ }^{14} \mathrm{C}-$ Gehalten der PC-Cholin- $-{ }^{14} \mathrm{C}$ Tiere

\begin{tabular}{|l|c|c|}
\hline \multirow{2}{*}{$\begin{array}{l}\text { Körperfraktionen } \\
\text { und Exkremente }\end{array}$} & \multicolumn{2}{|c|}{ PC-Cholin- ${ }^{\mathbf{1 4}} \mathbf{C}$} \\
\cline { 2 - 3 } & $\mathbf{1 .}$ Versuchstier & $\mathbf{2 .}$ Versuchstier \\
\hline Leber & $\mathrm{Bq} / \mathrm{g}$ & $\mathrm{Bq} / \mathrm{g}$ \\
\hline Zwölffingerdarm* & 1716,2 & 2023,4 \\
\hline Dünndarm & 1168,7 & 1288,7 \\
\hline Milz & 1023,7 & 1007,0 \\
\hline Nieren & 937,2 & 926,4 \\
\hline Galle & 868,5 & 863,3 \\
\hline Exkremente & 864,7 & 834,6 \\
\hline
\end{tabular}

*mit Inhalt und Pankreas

$\underline{\text { Folgende, bei der }{ }^{14} \mathrm{C} \text {-Gesamtaktivitätsverteilung getroffene, Annahmen werden durch die }}$ ${ }^{14} \mathrm{C}$-Aktivitätsbestimmung pro Gramm Fraktion (Tabelle 33) gefestigt:

-Die hohen ${ }^{14} \mathrm{C}$-Aktivitäten pro Gramm in den Frakionen Leber, Darm, Milz und Galle festigen die Annahme, daß das Phosphatidylcholin mit der Galle sekretiert wird, im Darm Funktionen ausübt, zurück in die Leber gelangt und somit im enterohepatischen Kreislauf Einsatz findet.

-Bei den ${ }^{14} \mathrm{C}$-Aktivitäten pro Gramm Fraktion, läßt der hohe ${ }^{14} \mathrm{C}$-Aktivitätsgehalt in den Exkrementen vermuten, daß ein Teil des Phosphatidylcholins unabsorbiert oder endogen mit der Galle in den Darm abgegeben wird, oder daß ein weiterer Teil des Cholins umbzw. abgebaut und so mit den Exkrementen ausgeschieden wird. Dabei scheinen die Nieren eine große Rolle zu spielen, da die Aktivität pro Gramm in ihnen mit zu den Höchsten zählt.

PC-Linolsäure- ${ }^{14} \mathrm{C}$ Tiere

Bei der Auswertung der ${ }^{14} \mathrm{C}$-Aktivität pro Gramm Fraktion erschweren folgende Tatsachen die Diskussion. Zum einen lag die wiedergefundene ${ }^{14} \mathrm{C}$-Aktivität beim dritten Versuchstier mit 302,057 kBq über der des vierten Versuchstieres mit 239,341 kBq. Dann variierten die Gesamtgewichte der Tiere um circa 60 g, d.h. das vierte Versuchstier war mit 825,7g erheblich leichter als das dritte Versuchstier. Da sich die Tiere im Wachstum befanden, kann aufgrund der verschiedenen Wachstumsphasen die energetische Nutzung des Phos- 
phatidylcholins unterschiedlich gewesen sein. Das führt dazu, daß die ${ }^{14} \mathrm{C}$-Aktivitätsanteile pro Gramm der gleichen Fraktionen beider Tiere weder übereinstimmen, noch die gleiche Reihenfolge bei den ${ }^{14} \mathrm{C}$-Aktivitätsanteilen aufweisen. So hatte das dritte Tier im Abdominalfett ${ }^{14} \mathrm{C}$-Aktivitätsanteile von $1,8 \%$ und das vierte Tier von nur $0,3 \%$.

$\underline{\text { Trotzdem werden folgende, bei der }{ }^{14} \mathrm{C} \text {-Gesamtaktivitätsverteilung getroffene, Annahmen }}$ durch die ${ }^{14} \mathrm{C}$-Aktivitätsbestimmung pro Gramm Fraktion erhärtet:

-Die höchsten ${ }^{14} \mathrm{C}$-Aktivitätsgehalte wurden beim dritten Versuchstier im Abdominalfett und die Fünfthöchsten in der Fraktion Haut und Federn festgestellt, was die Annahme bekräfigt, daß ein großer Teil der ${ }^{14} \mathrm{C}$-markierten Fettsäuren in das Fettgewebe transportiert wird.

-Beim vierten Versuchstier dagegen lagen die ${ }^{14} \mathrm{C}$-Aktivitätsanteile des Abdominalfettes nur an sechster Stelle, was den Schluß zuläßt, daß weniger der ${ }^{14} \mathrm{C}$-Aktivität mit den Fettsäuren in das Fettgewebe transportiert, sondern mehr für die direkte energetische Nutzung abgebaut wird. Die Annahme wird dadurch unterstützt, daß beim vierten Tier höhere Aktivitätsanteile in der Atemluft gemessen wurden, als beim dritten Tier.

-Hohe Akivitätsanteile in den Fraktionen Galle, Blinddarm mit Inhalt und Dünndarm lassen vermuten, daß ein Teil der Linolsäure- ${ }^{14} \mathrm{C}$-Aktivität über den Gallenweg in diese Fraktionen gelangt oder erst nach 24 Stunden zur Absorption kommt.

Die Fraktionen Muskel, Knochen bzw. Füße und Kopf zeigen bei der Messung der Aktivität pro Gramm Fraktion keine bedeutenden Aktivitätsanteile. Das festigt die Annahme, daß diese Fraktionen nur aufgrund ihres hohen Gewichtanteiles hohe Anteile an der Gesamtaktivität aufweisen. In den Exkrementen wurden dagegen, auch bei der ${ }^{14} \mathrm{C}$-Aktivitätsbestimmung pro Gramm Fraktion, hohe Aktivitätsanteile festgestellt.

\section{4}

\section{${ }^{14}$ C-Aktivität in den Lipidextrakten und Nichtlipidanteilen}

\section{$\underline{\text { PC-Cholin- }-{ }^{14} \mathrm{C} \text { Tiere }}$}

In fast allen der wichtigsten Körperfraktionen und Exkremente waren ${ }^{14} \mathrm{C}$-Aktivitätsanteile von zum Teil deutlich über $50 \%$ in den Nichtlipidanteilen festzustellen. Demnach werden, in den 24 Stunden von der Markierung bis zur Tötung der Tiere, mindestens $50 \%$ des applizierten Phosphatidylcholins in nichtlipidlösliche Verbindungen um- bzw. abgebaut. 
Die Fraktion Muskel wies mit 25,6 \% - 29,3\% die geringsten ${ }^{14} \mathrm{C}$-Aktivitätsanteile in den Lipidextrakten auf. Nach Angaben von THIELE (1979) beträgt der Phospholipidgehalt von Muskeln nur circa $25 \%$ - 33 \% der Gesamtlipide von z.B. Leber, Gehirn oder Niere, was die geringen ${ }^{14} \mathrm{C}$-Aktivitätsanteile im Lipidextrakt der Fraktion Muskel erklären könnte.

Bei den Fraktionen Leber, Darm und Exkremente wurden ${ }^{14} \mathrm{C}$-Aktivitätsunterschiede von über $20 \%$ in den Lipidextrakten gleicher Fraktionen beider Tiere gemessen. Der ${ }^{14} \mathrm{C}$-Aktivitätsanteil im Leberlipidextrakt des ersten Tieres war mit 30,9\% deutlich geringer als beim zweiten Tier mit 57,3 \%. Mögliche Erklärungsansätze dafür sind, daß beim ersten Tier höhere Stoffwechselaktivitäten zu höheren Um- bzw. Abbauraten des Phosphatidylcholins führen, wodurch entweder das Cholin als Nichtlipidanteil für andere Funktionen, wie z.B. als Acetylcholinbestandteil (BLUSZTAJN und WURTMAN, 1983; ULUS et al., 1988; CANTY und ZEISEL, 1994) oder als Methylgruppendonator (SCHENK und KOLB, 1990) zur Verfügung steht oder abgebaut und ausgeschieden wird. Eine zweite Möglichkeit wäre, daß ein Teil des Phosphatidylcholins unabsorbiert den Darmtrakt passiert. Das würde auch eine Erklärung für die 29,6 \% höheren ${ }^{14} \mathrm{C}$-Anteile in der Lipidfraktion der Exkremente des ersten Tieres mit Aktivitätsanteilen von 48,8 \% geben. Drittens könnte das Phosphatidylcholin des ersten Tieres aufgrund stoffwechselphysiologischer Vorgänge im größerem Umfang als Gallenbestandteil genutzt worden sein, was den 25,8 \% höheren ${ }^{14} \mathrm{C}$-Gehalt im Lipidextrakt vom Dünndarm des ersten Tieres mit 53,1\% erklärte. Möglich wäre außerdem, daß das aktive Phosphatidylcholin teilweise als endogener Gallenbestandteil ausgeschieden wird (JUSTE et al., 1983; JØRGENSEN et al., 1992), was wiederum die ${ }^{14} \mathrm{C}$-Aktivitätsgehalte, besonders beim ersten Tier, in den Lipidextrakten der Exkremente erklären würde.

\section{PC-Linolsäure- ${ }^{14} \mathrm{C}$ Tiere}

Aus der Literatur ist bekannt, daß während der Phospholipidabsorption im Zwölffingerdarm ein großer Teil der am zweiten C-Atom gebundenen Fettsäuren vom Phosphatidylcholin abgespalten wird (LEKIM und BETZING, 1976). Nach der Absorption in die Enterocyten werden diese Fettsäuren in lipidlösliche Verbindungen, wie z.B. Triacylglyceride oder Phospholipide eingebaut und mit Lipoproteinen zur Leber transportiert (PARTHASARATHY et al., 1976; LEKIM und GRAF, 1976). 24 Stunden nach der Markierung waren im Lipidextrakt der Leber aber nur noch ${ }^{14} \mathrm{C}$-Aktivitätsanteile zwischen 
42,1 \% - 49,2 \% feststellbar. Demnach sind schon weitere Umsetzungen im Stoffwechsel erfolgt. Wie HERMIER (1997) bei Untersuchungen an Geflügel bestätigte, werden von der Leber aus die Fettsäuren teilweise in das Fettgewebe transportiert und dort als Triacylglyceride eingelagert. ${ }^{14} \mathrm{C}$-Aktivitätsanteile von $72 \%-86 \%$ in den Lipidextrakten von Abdominalfett und Unterhautfettgewebe von Haut und Federn lassen darauf schließen, daß ein Teil der ${ }^{14} \mathrm{C}$-markierten Linolsäure oder daraus umgebaute Fettsäuren diesen Weg gehen. Auch WENK et al. (1990) beschrieben nach Untersuchungen an Monogastriern, daß ein großer Teil der Futterfettsäuren in das Fettgewebe eingelagert wird.

Die Exkremente zeigten ${ }^{14} \mathrm{C}$-Aktivitätsanteile zwischen $27,3 \%-34,5 \%$ in den jeweiligen Lipidextrakten. Das festigt die in vorherigen Kapiteln getroffene Annahme, daß nicht nur Stoffwechselendprodukte in den Exkrementen vorliegen, sondern daß auch markiertes Phosphatidylcholin zu geringen Anteilen unabsorbiert ausgeschieden wird bzw. endogenen Ursprungs ist. Da endogene Ausscheidungen im Chymus größtenteils aus der Galle stammen (JUSTE et al., 1983; JØRGENSEN et al., 1992) kann angenommen werden, daß Phosphatidylcholin als Gallenbestandteil teilweise endogen exkretiert und somit im Lipidextrakt der Exkremente erfaßt wird.

5.5

${ }^{14}$ C-Aktivitäten in den Lipidextrakten

$\underline{\text { PC-Cholin- }{ }^{14} \mathrm{C} \text { Tiere }}$

Die Lipidextrakte aller Fraktionen wiesen mit ${ }^{14} \mathrm{C}$-Aktivitätsanteilen von $38 \%$ beim ersten Tier und $34 \%$ beim zweiten Tier in etwa übereinstimmende Werte auf. Die Ursache für einen Aktivitätsanteil von unter $40 \%$ in den Lipidextrakten liegt darin, daß Cholin nach der Abspaltung vom Phosphatidylcholin den wasserlöslichen Vitaminen zugeordnet wird (BALTES, 1983) und somit nicht mehr lipidlöslich ist.

Bei der relativen Aktivitätsverteilung in den Lipidextrakten konnte festgestellt werden, daß die acht Fraktionen Muskel, Dünndarm, Zwölffingerdarm mit Inhalt und Pankreas, Leber, Exkremente, Haut und Federn, Knochen sowie Füße und Kopf die höchsten Aktivitätsanteile von insgesamt $86 \%$ (erstes Tier) bzw. $91 \%$ (zweites Tier) enhielten. 
PC-Linolsäure- ${ }^{14} \mathrm{C}$ Tiere

Die Lipidextrakte aller Fraktionen wiesen mit ${ }^{14} \mathrm{C}$-Aktivitätsanteilen von $47 \%$ (drittes Tier) und $50 \%$ (viertes Tier) in etwa übereinstimmende Aktivitätsanteile auf. Die Lipidextrakte enthielten über $10 \%$ höhere ${ }^{14} \mathrm{C}$-Aktivitätsanteile als die der PC-Cholin- ${ }^{14} \mathrm{C}$ Tiere, da die Linolsäure auch ohne Bindung am Phosphatidylcholin oder in Verbindungen, wie z.B. in Mono-, Di- oder Triacylglyceriden, in den Lipidextrakten erfaßt wird (THIELE et al., 1979).

Bei der relativen Aktivitätsverteilung in den Lipidextrakten wiesen die Fraktionen Muskel, Abdominalfett, Dünndarm, Leber, Exkremente, Haut und Federn, Knochen sowie Füße und Kopf die höchsten Aktivitätsanteile von insgesamt $91 \%$ (drittes Tier) bzw. $89 \%$ (viertes Tier) auf.

5.6 Dünnschichtchromatographische Trennung der Lipidextrakte

\subsection{1}

${ }^{14}$ C-Aktivitätsanteile in den Lipidfraktionen

PC-Cholin- ${ }^{14} \mathrm{C}$ Tiere

Bei den PC-Cholin- ${ }^{14} \mathrm{C}$ Tieren wurde, in den Lipidextrakten aller Körperfraktionen und der Exkremente, die gesamte Aktivität in der Lipidfraktion Phospholipide wiedergefunden. Demnach finden keine Um- bzw. Abbauvorgänge des Cholin- ${ }^{14} \mathrm{C}$ in andere lipidlösliche Verbindungen statt. ZIERENBERG und GRUNDY (1982) verabreichten Phosphatidylcholin, an dem Cholin radioaktiv markiert war, an Ratten und fanden nach 24 Stunden ebenfalls über $99 \%$ der Aktivität in der Phospholipidfraktion wieder. Allerdings bezogen sich ihre Angaben lediglich auf Werte im Blut. Vergleichende Angaben anderer Fraktionen wurden bei der Literaturdurchsicht nicht gefunden.

\section{$\underline{\text { PC-Linolsäure- }{ }^{14} \mathrm{C} \text { Tiere }}$}

Im Lipidextrakt der Leber lag die Hauptaktivität von über $73 \%$ in der Phospholipidfraktion und lediglich 16,1\% in der Triacylglyceridfraktion. Untersuchungen von LEKIM und GRAF (1976) zeigten, daß nur $25 \%$ der ${ }^{14} \mathrm{C}$-markierten Fettsäuren an Phosphatidylcholin 
gebunden, in die Leber transportiert werden und $75 \%$ in Triacylglyceriden. LEKIM und BETZING (1976) beschrieben, daß der größte Anteil an ${ }^{14} \mathrm{C}$-Aktivität in den ersten sechs bis acht Stunden absorbiert wird. Demnach war 24 Stunden nach der Applikation schon eine erheblich weitergehende Verstoffwechselung des Phosphatidylcholins erfolgt.

Aus diesen Ergebnissen lassen sich die folgenden Stoffwechselwege ableiten:

In Triacylglyceriden gebundene ${ }^{14} \mathrm{C}$-markierte Fettsäuren werden teilweise mit Lipoproteinen in das Fettgewebe transportiert (HERMIER, 1997). ${ }^{14}$ C-Aktivitäten von 87,9 \% im Lipidextrakt der Fraktion Haut und Federn sowie von über $90 \%$ im Abdominalfett bekräftigen diese Vermutung. Eine weitere Möglichkeit wäre, daß aktives Phosphatidylcholin zum Teil aufgrund relativ unverdaulicher Futterreste im Darm zurück gehalten wird und somit erst nach 24 Stunden zur Absorption kommt. Bei Verwendung normaler Futterrationen liegt die Passagerate für unverdauliche Futterreste bei etwa 24 Stunden und ist nach 48 Stunden vollständig abgeschlossen (SCHOLTYSSEK, 1987). Oder die mit den ${ }^{14} \mathrm{C}-\mathrm{mar}$ kierten Fettsäuren verbundenen Phospholipide finden nach der Absorption als Gallenbestandteil Einsatz und üben 24 Stunden nach der Applikation Funktionen im Darm aus. Lipidextrakte des Zwölffingerdarms mit Pankreas und Inhalt und des Dünndarms enthielten ${ }^{14} \mathrm{C}$-Aktivitätsverteilungen von $39 \%-45 \%$ in der Phospholipidfraktion, $20 \%-22 \%$ in der Fraktion freie Fettsäuren und $17 \%-27 \%$ in der Triacylglyceridfraktion. Vorherige Annahmen bekräftigend, werden die aktiven Phospholipide entweder aus dem Futter absorbiert und liegen somit als freie Fettsäuren, reverestert als Phospholipide und als Triacylglyceride im Darm vor, und/oder haben aufgrund ihres Einsatzes als Gallenbestandteil Funktionen im Darm und liegen deshalb gespalten vor. Da die in den Lipidextrakten vorliegenden ${ }^{14} \mathrm{C}$-Aktivitätsanteile der Exkremente zu 72,9 \% in der Phospholipidfraktion und zu 17,4 \% in der Fraktion freie Fettsäuren gemessen wurden, wird die in den vorherigen Kapiteln getroffene Annahme untermauert, daß ein Teil der Phospholipide und Fettsäuren unabsorbiert oder mit der Galle sekretiert über die Exkremente ausgeschieden wird. 
$\underline{\text { PC-Cholin- }{ }^{14} \mathrm{C} \text { Tiere }}$

Nach Trennung der Lipidextrakte in einzelne Phospholipidfraktionen, konnte bei fast allen Fraktionen die Hauptaktivität der Lipidextrakte in der Phosphatidylcholinfraktion festgestellt werden. Eine Ausnahme bildeten die Lipidextrakte der Fraktionen Zwölffingerdarm mit Inhalt und Pankreas und Exkremente. Der Zwölffingerdarm ist Hauptabsorptionsort für Phospholipide (ANSELL und SPANNER, 1982). In seinem Lipidextrakt wurden $58 \%$ der ${ }^{14} \mathrm{C}$-Aktivität in den Lysophosphatidylfraktionen gemessen, was die Annahme kräftigt, daß ein Teil der Phosphatidylcholine erst nach 24 Stunden zur Absorption kommt und/oder als Gallenbestandteil an Emulgationsprozessen im Darm beteiligt ist. In den Exkrementen lagen 46,6 \% der ${ }^{14} \mathrm{C}$-Aktivitätsanteile in den Lysophosphatidylfraktionen vor. Das zeigt, daß nicht nur ${ }^{14} \mathrm{C}$-Metabolite mit den Exkrementen ausgeschieden werden.

\section{PC-Linolsäure- ${ }^{14} \mathrm{C}$ Tiere}

Bei der Betrachtung der dünnschichtchromatographischen Trennung der Lipidextrakte aus den wichtigsten Fraktionen der PC-Linolsäure- ${ }^{14} \mathrm{C}$ Tiere wird deutlich, daß die Fraktionen Abdominalfett und Haut und Federn $90 \%$ der ${ }^{14} \mathrm{C}$-Aktivitätsanteile in der Lipidfraktion freie Fettsäuren/Triacylglyceride umfaßten. Da Unterhautfettgewebe von Haut und Federn und Abdominalfett als Lipidspeicher dienen (HERMIER, 1997), ist diese Verteilung zu erwarten.

Mit der Trennung der Lipidextrakte in die Phospholipidfraktionen konnten Erkenntnisse über die Stoffwechselwege der ${ }^{14} \mathrm{C}$-Aktivität aus Phosphatidylcholin in andere Phospholipide gewonnen werden. Gemessen wurden ${ }^{14} \mathrm{C}$-Aktivitätsanteile in zuvor nicht markierten Phospholipiden aus den Lipidextrakten von Exkrementen, Leber, Dünndarm und Zwölffingerdarm mit Inhalt und Pankreas. Erwiesen ist, das Phosphatidylcholin durch Basenaustausch in Phosphatidylethanolamin umgewandelt werden kann, aus dem wiederum durch Basenaustausch die Bildung von Phosphatidylserin möglich ist (PARDUN, 1988). In der Leber waren folgende Stoffwechselwege nachvollziehbar. Mit 32,4 \% konnte der höchste Teil der ${ }^{14} \mathrm{C}$-Aktivität in der Fraktion freie Fettsäuren/Triacylglyceride gemessen werden. Die an der zweiten Hydroxylgruppe des Phosphatidylcholins gebundenen Fettsäuren werden bei der Absorption größtenteils abgespalten und dann in Triacylglyceride ge- 
bunden zur Leber transportiert (LEKIM und GRAF, 1976). Anzunehmen ist, daß die vom Phosphatidylcholin getrennten aktiven Fettsäuren teilweise in Phosphatidylinosite und in Cardiolipin eingebaut werden, da beide Fraktionen nicht durch Basenaustausch mit Phosphatidylcholin entstehen können und trotzdem ${ }^{14} \mathrm{C}$-Aktivität enthalten. Der ${ }^{14} \mathrm{C}$-Aktivitätsanteil des Phosphatidylcholins betrug 26,9 \%. Es scheint zuvor zum großen Teil umgebaut worden $\mathrm{zu}$ sein, da das nächstliegende Umwandlungsprodukt Phosphatidylethanolamin ebenfalls einen ${ }^{14} \mathrm{C}$-Aktivitätsanteil von $20 \%$ beinhaltet. Das nach Basenaustausch von Ethanolamin entstehende Phosphatidylserin besaß noch Aktivitätsanteile von 2,8 \%. Die Verteilung spiegelt die in der Literatur angegebene Reihenfolge wieder, daß Phosphatidylcholin das meist vorkommende Phospholipid ist, gefolgt vom Phosphatidylethanolamin (ANSELL und SPANNER, 1982; GETZ et al., 1968).

Im Darm (Dünndarm und Zwölffingerdarm) waren ${ }^{14} \mathrm{C}$-Aktivitätsanteile zwischen 6,9 \% 9,6 \% in der Phosphatidylcholinfraktion meßbar. Da während des Emulgierungsprozesses über $90 \%$ der Fettsäuren (C-2) vom Phosphatidylcholin abgespalten werden (PARTHASARATHY et al., 1974) und nach der Absorption nur ein geringer Anteil der zuvor abgespaltenen Fettsäuren mit Lysophosphatidylcholin reverestert wird (LEKIM und GRAF, 1976), ist der geringe Aktivitätsanteil erklärbar. Der größte Anteil der Fettsäuren wird in Triacylglyceride eingebaut (LEKIM und GRAF, 1976). Das gibt eine Erklärung für die hohen Aktivitätsanteile von 61,4 \% - 76,4 \% in der Fraktion freie Fettsäuren/Triacylglyceride. Auch im Darm wurden ${ }^{14} \mathrm{C}$-Aktivitätsanteile in zuvor nicht markierten Phospholipiden festgestellt. So enthielten die Phosphatidylethanolamine ${ }^{14} \mathrm{C}$-Aktivitätsanteile von 6,4 \% - 9,3 \% und die Phosphatidylserine von 1,9 \% - 3,5 \%. In den Fraktionen Phosphatidylinosit und Cardiolipin waren noch geringe ${ }^{14} \mathrm{C}$-Aktivitätsanteile feststellbar. Die Ergebnisse zeigen, daß in Leber und Darm, die im PARDUN (1988) beschriebenen Umwandlungsprozesse zwischen Phospholipiden, stattfinden.

Im Gegensatz dazu, waren in den Lipidextrakten der Exkremente hauptsächlich ${ }^{14} \mathrm{C}$-Aktivitätsanteile in den Lipidfraktionen freie Fettsäuren/Triacylglyceride und Phosphatidylcholin feststellbar. Demnach werden nicht nur ${ }^{14} \mathrm{C}$-Metabolite ausgeschieden, sondern, wie schon in vorherigen Kapitel angenommen, muß ein Teil der Fettsäuren bzw. des Phosphatidylcholins unabsorbiert oder endogen sekretiert, ausgeschieden worden sein. 

PC-Linolsäure- ${ }^{14} \mathrm{C}$ Tiere

\section{${ }^{14}$ C-Gesamtaktivitätsverteilung der wichtigsten Fraktionen unter Ein- bezug der ${ }^{14} \mathrm{C}$-Aktivitätsgehalte pro Gramm Fraktion und der ${ }^{14} \mathrm{C}$-Akti- vitätsverteilung in den Lipidextrakten}

Ein Vergleich der zehn Fraktionen mit den höchsten ${ }^{14} \mathrm{C}$-Anteilen der Versuchstiere eins bis vier verdeutlicht, daß bei acht Fraktionen der höchste ${ }^{14} \mathrm{C}$-Aktivitätsanteil in den gleichen Fraktionen wiederzufinden war (Abbildung 13). Eine Ausnahme bildeten bei den PC-Cholin- ${ }^{14} \mathrm{C}$ Tieren die Fraktionen Leber, Zwölffingerdarm mit Inhalt und Pankreas und bei den PC-Linolsäure- ${ }^{14} \mathrm{C}$ Tieren die Fraktionen Atemluft und Abdominalfett.

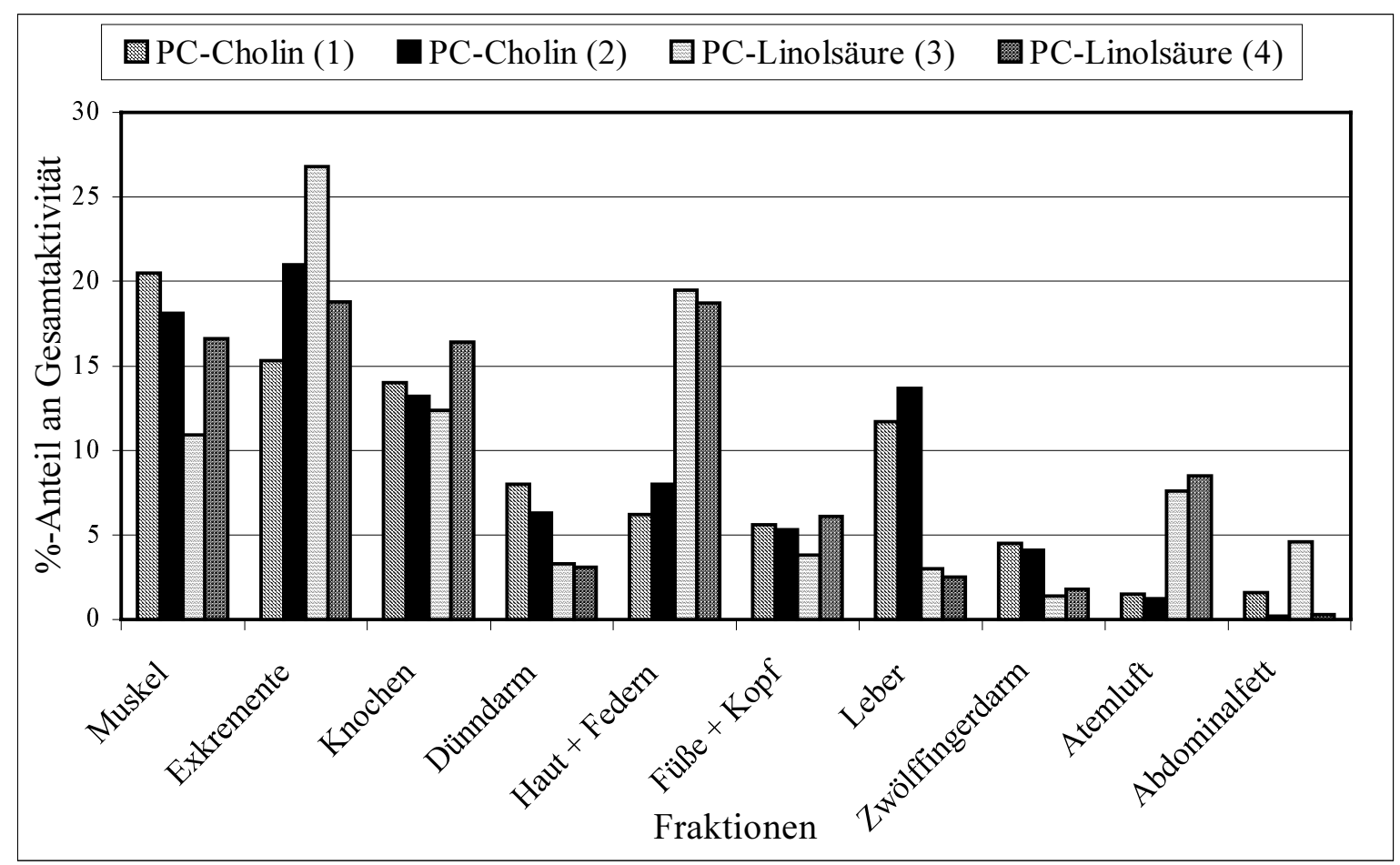

Abbildung 13: Vergleich der jeweils zehn Fraktionen mit den höchsten Aktivitätsanteilen (\%) der vier Versuchstiere 
Abbildung 13 zeigt, daß die Fraktionen Muskel, Exkremente und Knochen beider Markierungsformen Haut und Federn der PC-Linolsäure ${ }^{14} \mathrm{C}$ Tiere und Leber der PC-Cholin- ${ }^{14} \mathrm{C}$ Tiere, mit jeweils über $10,8 \%$, die höchsten ${ }^{14} \mathrm{C}$-Aktivitätsanteile aufwiesen. Wie in vorherigen Kapiteln herausgearbeitet, ist anzunehmen, daß die Fraktionen Muskel und Knochen aufgrund ihrer hohen Gewichte die höchsten ${ }^{14} \mathrm{C}$-Aktivitätsanteile umfassen. Die Exkremente beider Markierungsformen zeigten dagegen auch auf Gramm Fraktion bezogen hohe ${ }^{14} \mathrm{C}$-Aktivitätsgehalte.

Die Leber der PC-Cholin- ${ }^{14} \mathrm{C}$ Tiere wies, 24 Stunden nach der Markierung, deutlich höhere ${ }^{14} \mathrm{C}$-Aktivitätsanteile auf, als die der PC-Linolsäure- ${ }^{14} \mathrm{C}$ - Tiere. Auch bei der Messung der Aktivität pro Gramm Fraktion wurden bei den PC-Cholin- ${ }^{14} \mathrm{C}$ Tieren die höchsten Aktivitätsgehalte in der Leber festgestellt, während die Leber der PC-Linolsäure- ${ }^{14} \mathrm{C}$ Tiere geringere Aktivitäten beinhaltete. Demnach üben beide Markierungsformen unterschiedliche Funktionen im Organismus aus, die sich in einer unterschiedlichen Verteilung der ${ }^{14} \mathrm{C}$-Aktivitätsanteile in den Fraktionen widerspiegelt:

-Die höheren prozentualen ${ }^{14} \mathrm{C}$-Anteile in der Fraktion Atemluft der PC-Linolsäure- ${ }^{14} \mathrm{C}$ Tiere zeigen, daß die ${ }^{14} \mathrm{C}$-markierten Fettsäuren nach der Trennung vom Phosphatidylcholin in den allgemeinen Fettsäurepool eingeschleust werden und teilweise der energetischen Nutzung und somit dem katabolen Stoffwechsel unterliegen, während das Cholin mit höchster Priorität im Phospholipidstoffwechsel Verwendung findet.

-Die deutlich höheren Aktivitätsanteile in der Fraktion Haut und Federn und Abdominalfett der PC-Linolsäure- ${ }^{14} \mathrm{C}$ Tiere bekräftigen die Vermutung, daß die Fettsäuren zur Lagerung in das Unterhautfettgewebe von Haut und Federn und in das Abdominalfett transportiert werden. Die ${ }^{14} \mathrm{C}$-Aktivitätsanteile in der Fraktion Haut und Federn der PC-Cholin- ${ }^{14} \mathrm{C}$ Tiere liegen vermutlich darin begründet, daß ${ }^{14} \mathrm{C}$-aktive Methylgruppen des Cholins in Aminosäuren transferiert und so in die Federn eingebaut werden.

-Der hohe Aktivitätsanteil der PC-Cholin- ${ }^{14} \mathrm{C}$ Tiere in den Fraktionen Leber, Darm und Galle läßt darauf schließen, daß Cholin als Gallenbestandteil im enterohepatischen Kreislauf Einsatz findet, wohingegen die PC-Linolsäure- ${ }^{14} \mathrm{C}$ Tiere geringere Aktivitätsanteile in diesen Fraktionen haben. 


\section{Lipidextrakte}

Ein Vergleich der neun Fraktionen mit den höchsten Aktivitätsanteilen in den Lipidextrakten verdeutlicht, daß diese in den gleichen Fraktionen die höchsten Aktivitätsanteile aufweisen, wie die Fraktionen bei der ${ }^{14} \mathrm{C}$ - Aktivitätsbestimmung. Eine Ausnahme bildet lediglich die Atemluft. Die Lipidextrakte der Fraktionen Muskel, Exkremente und Knochen beider Markierungsformen, Haut und Federn der PC-Linolsäure- ${ }^{14} \mathrm{C}$ Tiere und Leber der PC-Cholin- ${ }^{14} \mathrm{C}$ Tiere enthielten, wie bei der Gesamtaktivitätsbestimmung, die höchsten ${ }^{14} \mathrm{C}$-Aktivitätsanteile je Gewichtseinheit Gewebe. Ebenfalls konnten in den Lipidextrakten des Dünndarms der PC-Cholin- ${ }^{14} \mathrm{C}$ Tiere höhere Aktivitätsanteile festgestellt werden als in den gleichen Lipidextrakten der PC-Linolsäure- ${ }^{14} \mathrm{C}$ Tiere.

\section{7 .2}

\section{${ }^{14}$ C-Aktivitätsverteilung auf die Lipid- und Phospholipidfraktionen nach dünnschichtchromatographischer Trennung der Lipidextrakte}

Bei der Trennung der Lipidextrakte der PC-Cholin- ${ }^{14} \mathrm{C}$ Tiere wurde die gesamte ${ }^{14} \mathrm{C}$-Aktivität in der Lipidfraktion Phospholipide wiedergefunden. Nach Trennung der Phospholipidfraktionen konnte, mit Ausnahme von Exkrementen und Zwölffingerdarm mit Inhalt und Pankreas, die Hauptaktivität in der Phosphatidylcholinfraktion nachgewiesen werden. In den Exkrementen und im Zwölffingerdarm mit Inhalt und Pankreas verteilte sich die ${ }^{14} \mathrm{C}$-Aktivität zusätzlich über die Lysophosphatidylfraktionen. Demnach lag die Aktivität in den Lipidextrakten der PC-Cholin- ${ }^{14} \mathrm{C}$ Tiere nur in Phospholipidfraktionen vor und wurde, nach Abspaltung vom Phosphatidylcholin, nicht in andere lipidlösliche Verbindungen eingebaut.

Die dünnschichtchromatographische Trennung der Lipidextrakte der PC-Linolsäure- ${ }^{14} \mathrm{C}$ Tiere ergab dagegen eine ${ }^{14} \mathrm{C}$-Aktivitätsverteilung über alle Lipid- und Phospholipidfraktionen.

Die Ergebnisse verdeutlichen, daß die Linolsäure ihre Hauptfunktion im Lipidstoffwechsel ausübt, während das Cholin, sobald es vom Phosphatidylcholin abgespalten ist, keine Funktionen mehr im Lipidstoffwechsel hat. 
Mit der vorliegenden Arbeit sollten Grundlagen für die Untersuchung des Stoffwechsels von exogen zugeführten Phospholipiden beim Geflügel geschaffen werden. Als Versuchstiere dienten insgesamt vier 22 bis 25 Tage alte Lohmann Meat Broiler. Zwei Tiere bekamen Phosphatidylcholin-L- $\alpha$-dipalmitoyl, [cholin-methyl- ${ }^{14} \mathrm{C}$ ] appliziert und zwei Tieren wurde Phosphatidylcholin-L- $\alpha-1$-palmitoyl-2-linoleoyl, [linoleoyl-1- $\left.{ }^{14} \mathrm{C}\right]$ verabreicht. Direkt nach der Applikation kam das jeweilige Tier in den Käfig einer Respirationsanlage, die dazu diente, den zeitlichen Verlauf der ${ }^{14} \mathrm{CO}_{2}$-Ausscheidung mit der Atemluft und den Exkrementen zu erfassen. Nach 24 Stunden erfolgte die Tötung der Tiere und die ${ }^{14} \mathrm{C}-\mathrm{Ak}$ tivität in Atemluft, Exkrementen und 26 Körperfraktionen wurde gemessen.

Die Untersuchungen führten zu folgenden Ergebnissen:

- Die relativen ${ }^{14} \mathrm{C}$-Anteile in der Atemluft der PC-Cholin- ${ }^{14} \mathrm{C}$ Tiere betrugen $1,2 \%$ $1,5 \%$ und bei den PC-Linolsäure- ${ }^{14} \mathrm{C}$ Tieren 7,6 \% - 8,5\%. Während bei den PC-Linolsäure- ${ }^{14} \mathrm{C}$ Tieren die höchsten Aktivitätsausscheidungen in den ersten fünf Stunden gemessen wurden, stieg die ${ }^{14} \mathrm{C}$-Aktivität in der Atemluft der PC-Cholin- ${ }^{14} \mathrm{C}$ Tiere über 24 Stunden langsam an.

- Die relativen ${ }^{14} \mathrm{C}$-Anteile in den Exkrementen betrugen bei den PC-Cholin- ${ }^{14} \mathrm{C}$ Tieren $15,3 \%$ - 21,0 \%. Bei den PC-Linolsäure- ${ }^{14} \mathrm{C}$ Tieren lagen sie mit 18,6 \% - 26,8 \% höher.

- Die Fraktionen Muskel, Exkremente, Knochen, Leber, Dünndarm, Haut und Federn, Füße und Kopf der PC-Cholin- ${ }^{14} \mathrm{C}$ Tiere enthielten, mit insgesamt 85,8 \% - 89,7 \%, die höchsten Anteile an der wiedergefundenen Aktivität. Bei den PC-Linolsäure- ${ }^{14} \mathrm{C}$ Tieren umfaßten die Fraktionen Exremente, Haut und Federn, Knochen, Muskel, Atemluft, Abdominalfett, Dünndarm, Füße und Kopf relative ${ }^{14} \mathrm{C}$-Anteile von insgesamt 88,5 \% $88,9 \%$. Die restlichen ${ }^{14} \mathrm{C}$-Anteile verteilten sich über 21 weitere Fraktionen.

- Die Ermittlung der ${ }^{14} \mathrm{C}$-Gehalte pro Gramm Fraktion ergab in den Fraktionen Leber, Dünndarm und Zwölffingerdarm, der PC-Cholin- ${ }^{14} \mathrm{C}$ Tiere, ${ }^{14} \mathrm{C}$-Aktivitäten zwischen 1007,0 - 2023, 4 Bq/g. In den Fraktionen Milz, Nieren, Galle, Exkremente und Drüsenmagen mit Inhalt wurden noch ${ }^{14} \mathrm{C}$-Gehalte zwischen $803,0-937,2 \mathrm{~Bq} / \mathrm{g}$ gemessen. Die übrigen Fraktionen beinhalteten ${ }^{14} \mathrm{C}$-Gehalte zwischen $6,0-555,9 \mathrm{~Bq} / \mathrm{g}$. Bei den 
PC-Linolsäure- ${ }^{14} \mathrm{C}$ Tieren zeigte das dritte Tier in den Fraktionen Abdominalfett, Exkremente, Galle, Blinddarm mit Inhalt, Dünndarm, Herz, Haut und Federn ${ }^{14} \mathrm{C}$-Aktivitäten von 393,2 - 525,4 Bq/g. Beim vierten Tier wurden in den Fraktionen Exkremente, Galle, Haut und Federn, Luftröhre, Muskelmagen, Dickdarm, Kloake mit Inhalt ${ }^{14} \mathrm{C}$-Aktivitäten von 393,2 - 525,4 Bq/g gemessen. Alle übrigen Fraktionen hatten ${ }^{14} \mathrm{C}$ Aktivitäten von unter $350 \mathrm{~Bq} / \mathrm{g}$.

- Die Lipidextrakte der PC-Cholin- ${ }^{14} \mathrm{C}$ Tiere zeigten ${ }^{14} \mathrm{C}$-Anteile von insgesamt $34 \%$ $38 \%$. Die übrigen ${ }^{14} \mathrm{C}$-Aktivitätsanteile befanden sich in den jeweiligen Nichtlipidanteilen. Die Lipidextrakte der PC-Linolsäure- ${ }^{14} \mathrm{C}$ Tiere beinhalteten mit insgesamt $47 \%$ - 50 \% höhere Aktivitätsanteile.

- Die Lipidextrakte der Fraktionen Muskel, Dünndarm, Zwölffingerdarm, Leber, Exkremente, Haut und Federn, Knochen, Füße und Kopf der PC-Cholin- ${ }^{14} \mathrm{C}$ Tiere, wiesen Aktivitätsanteile von insgesamt $86 \%$ - $91 \%$ auf. Die Lipidextrakte der Fraktionen Muskel, Abdominalfett, Dünndarm, Leber, Exkremente, Haut und Federn, Knochen, Füße und Kopf der PC-Linolsäure- ${ }^{14} \mathrm{C}$ Tiere, enthielten ${ }^{14} \mathrm{C}$-Anteile von $89 \%$ - $91 \%$.

- Die dünnschichtchromatographische Trennung der Lipidextrakte in die Lipidfraktionen der PC-Cholin- ${ }^{14} \mathrm{C}$ Tiere ergab, daß die ${ }^{14} \mathrm{C}$-Aktivität ausschließlich in der Phospholipidfraktion feststellbar war. In den Lipidextrakten der PC-Linolsäure- ${ }^{14} \mathrm{C}$ Tiere verteilten sich die ${ }^{14} \mathrm{C}$-Anteile über alle Lipidfraktionen. Bei der dünnschichtchromatographischen Trennung der Lipidextrakte der PC-Cholin- ${ }^{14} \mathrm{C}$ Tiere in die Phospholipidfraktionen, wurde die Hauptaktivität in der Phosphatidylcholinfraktion gemessen. In den Lipidextrakten der Exkremente und des Zwölffingerdarms waren zusätzlich noch hohe Aktivitätsanteile in den Lysophosphatidylfraktionen festzustellen. Die Lipidextrakte der PC-Linolsäure- ${ }^{14} \mathrm{C}$ Tiere wiesen in allen Phospholipidfraktionen ${ }^{14} \mathrm{C}$-Aktivitäten auf.

Aufgrund der Ergebnisse konnten Schlußfolgerungen über mögliche Stoffwechselwege von Cholin- $-{ }^{14} \mathrm{C}$ und Linolsäure- ${ }^{14} \mathrm{C}$ des Phosphatidylcholins im Geflügel getroffen werden. In weiterführenden Versuchen kann die Fraktionierung der Tiere, je nach Fragestellung, vereinfacht werden. 
Mein besonderer Dank gilt Herrn Prof. Dr. S. Molnar für die Überlassung des Themas und die jederzeit gewährte fachliche und persönliche Unterstützung bei der Durchführung dieser Arbeit.

Mein Dank gilt weiterhin Herrn Prof. Dr. G. Flachowsky für die Übernahme des Korreferates.

Den Mitarbeitern des zentralen Isotopenlabors für Medizinische und Biologische Forschung der Universität Göttingen, im besonderen Maße Herrn Klein, Frau Wittig und Frau Hocke, danke ich für die tatkräftige Unterstützung bei der Durchführung der experimentellen und analytischen Arbeit.

Den Mitarbeitern des Institutes für Tierphysiologie und Tierernährung, im Besonderen Frau Pieper, Frau Dr. Rosenow und Herrn Rimbach, danke ich für die hilfreichen Ratschläge, bei Anfertigung der Arbeit.

Meiner Familie, im Besonderen meiner Mutter, möchte ich für die persönliche Unterstützung danken, ebenso wie meinen Freunden, insbesondere Jochen. 


\section{Lebenslauf}

Name:

Petra Melisch

Geburtsdatum:

30.09 .1972

Geburtsort:

Einbeck

Familienstand:

ledig

Eltern:

Jürgen Melisch

verstorben am 04.11.1993

Ingrid Melisch, geb. Helmker

Schulbildung:

1979-1983

Grundschule in Lüthorst

1983-1985

Orientierungsstufe in Dassel

1985-1989

Realschule in Dassel

1989-1992

Fachgymnasium für Ernährung

und Hauswirtschaft in Einbeck

Studium:

1992-1997

Studium der Ernährungswissenschaften an der

Friedrich-Schiller-Universität in Jena

Abschluß: Diplom-Trophologin

Seit 1997

Doktorandin am Institut für Tierphysiologie und Tierernährung der Georg-August-Universität in Göttingen 